\title{
Researching Youth Street Groups in Southern Europe
}

Luca Queirolo Palmas (Coord.), Eduard Ballesté, Paolo Grassi, Juan Camilo Mansilla, María Oliver, Katia Núñez \& Carles Feixa (Dir.)

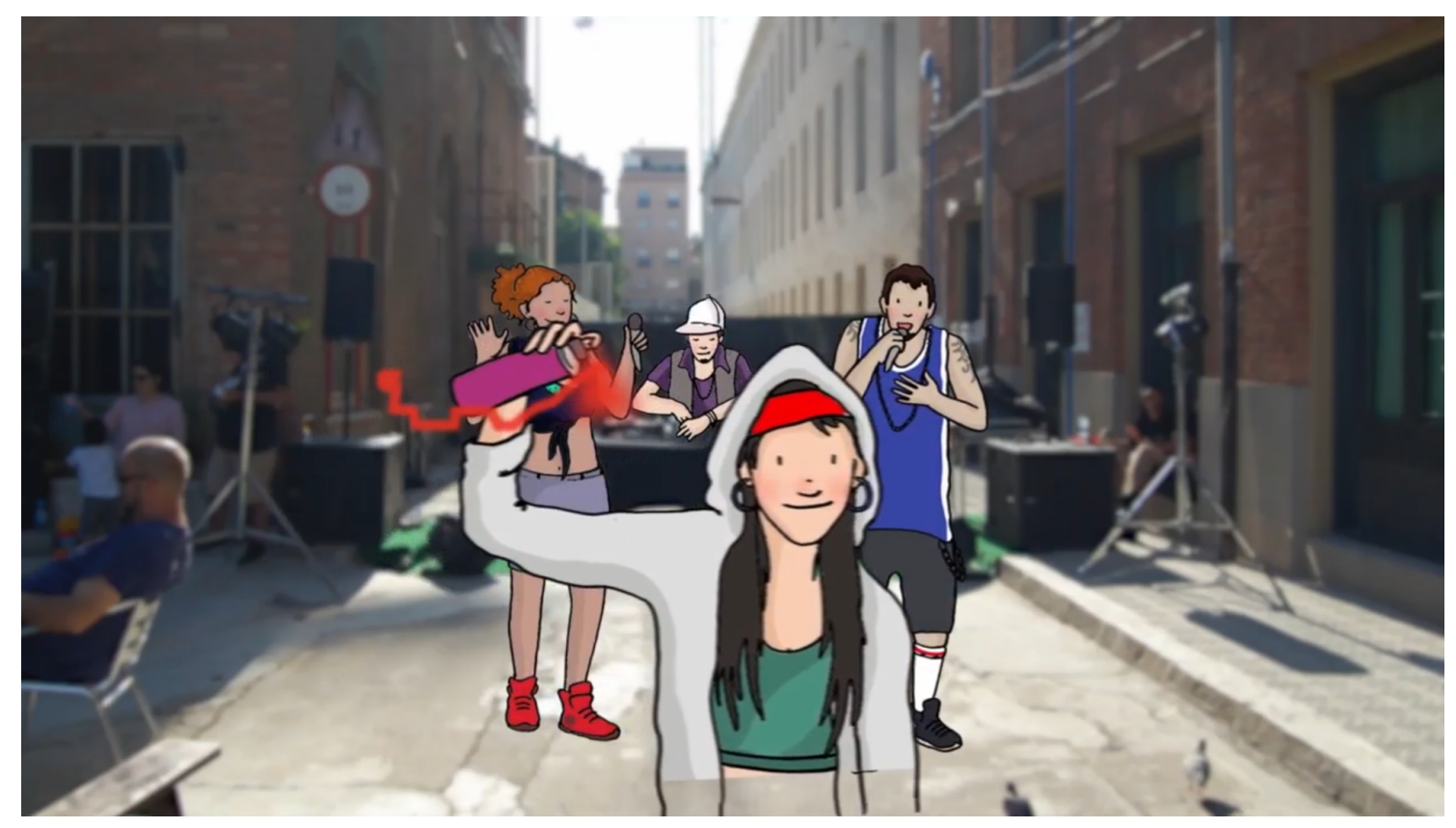


TRANSGANG. Researching Youth Street Groups in Southern Europe

TRANSGANG Working Papers

Number: 6.1

SN: TRANSGANG_WP06.1/2021

Edition: December, 2021

Authors

Luca Queirolo Palmas (Scientific Coordinator), Eduard Ballesté, Paolo Grassi, Juan Camilo Mansilla, María Oliver, Katia Núñez, Carles Feixa (Dir.)

Work distributed under CC licence

\section{cc) (1) $9(-$}

(C) TRANSGANG \& UPF

\section{Recommended format for citation}

Queirolo Palmas, L. (Coord.), Ballesté, E., Grassi, P., Mansilla, J. C., Oliver, M., Núñez, K., Feixa, C. (Dir.) (2021). Researching Youth Street Groups in Southern Europe (TRANSGANG Working Papers 6.1). Barcelona: Universitat Pompeu Fabra \& European Research Council.

DOI: 10.31009/transgang.2021.wp05.2.

ISBN: 978-84-09-21206-4

www.upf.edu/web/transgang

transgang@upf.edu

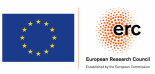

The TRANSGANG project receives funding from the European Research Council (ERC) under the European Union's HORIZON 2020 research and innovation programme under grant agreement $n^{\circ} 742705$ 


\section{Table of Content}

1 Introduction: The persistence and evanescence of gangs. Approaching the emergence of new public enemies and discourses in Marseille, Milan, Madrid and Barcelona

1.1 The weakening of the "Latino gangs" as a media reference for stigma and as an organized and pulsating presence in the streets

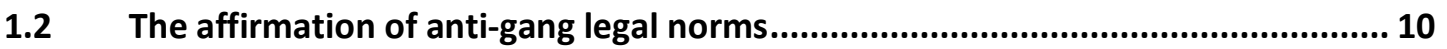

1.3 The fading of the inclusion policies for gangs .......................................................... 10

1.4 The growing media attention towards new young street subjects ...................... 11

1.5 The importance of non-institutional mediations .................................................. 11

1.6 A variable inscription in the urban space ............................................................ 12

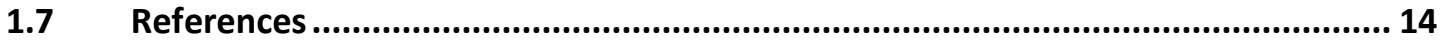

2 Traces of youth street groups in Barcelona (Catalonia)................................................ 16

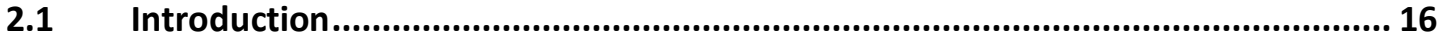

2.2 Researching (Trans)Gangs in Barcelona: from Latin "gangs" to informal groups .. 17

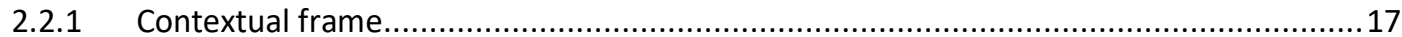

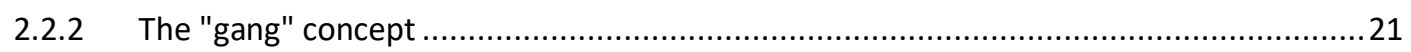

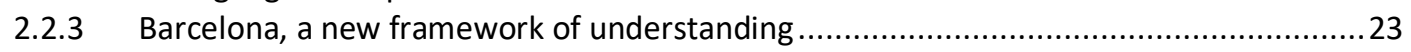

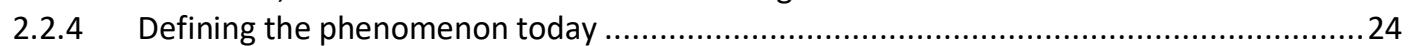

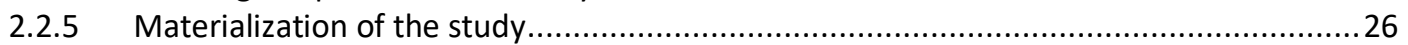

2.3 Visibility and legalization: an unfinished process with lights and shadows........... 27

2.4 The spaces of Barcelona: the gangs' social, political and physical situation........... 31

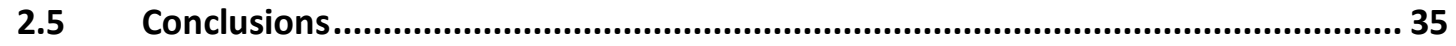

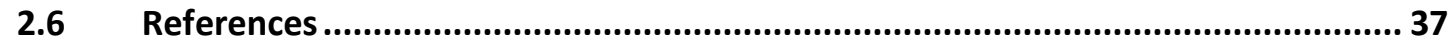

3 (Trans)Gangs in Madrid. Gang policies \& gang practices: experiences of conflict and

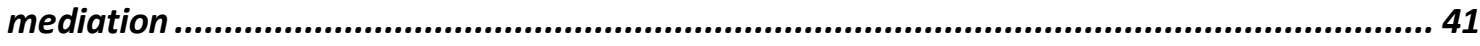

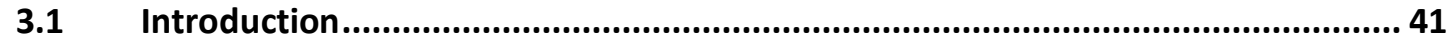

3.2 State of the art: Researching (trans)gangs in Madrid ...............................................48 48

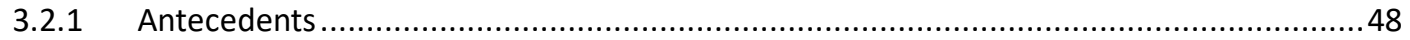

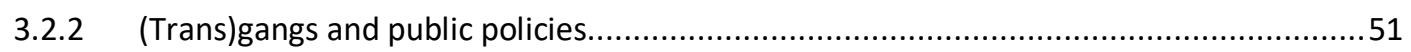

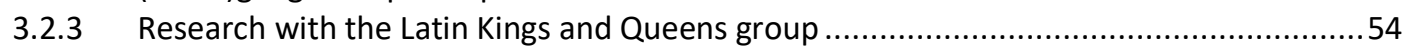

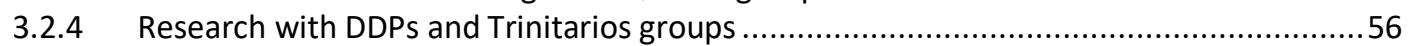

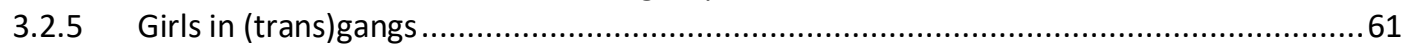

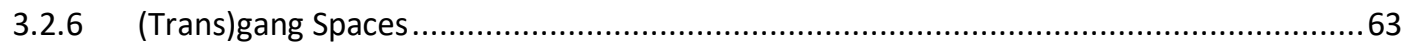

3.3 Empowerment, Conflict and Mediation ................................................................... 64

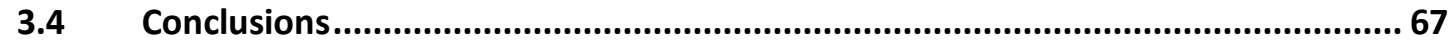

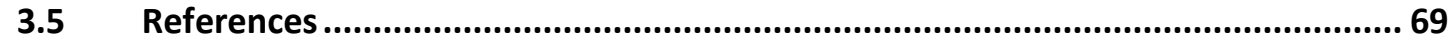

$4 \quad$ Youth street gangs in Marseille: Ethnicity, social mediation and multigenerational

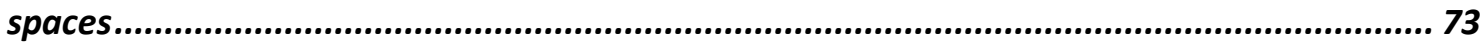

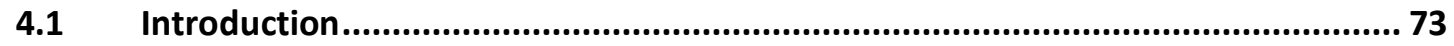

4.2 Terminology of gang studies in France .................................................................... 76 
4.3 The "banlieue" and the "cité" in France and in Marseille ..................................... 77

4.4 Introspection of the act of investigating and shared knowledge ........................... 78

4.5 State of the art: Studying (trans)gangs in Marseille ................................................... 79

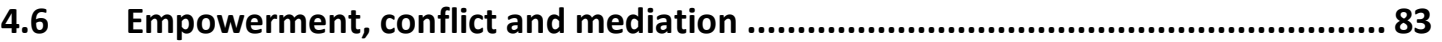

4.6.1 Social mediation in marginalized neighbourhoods in France..........................................8 83

4.6.2 Community integration and social mediation in Marseille ............................................. 85

4.6.3 Football and young people: sport as a tool for social mediation .....................................89

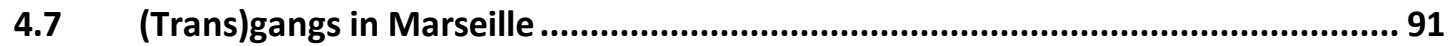

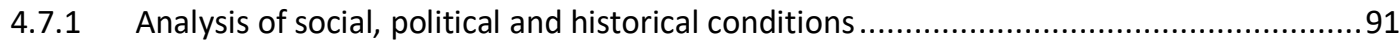

4.7.2 Advanced youth marginality and "ghettoization" ......................................................97

4.7.3 Youth street groups' use of virtual spaces ...................................................................99

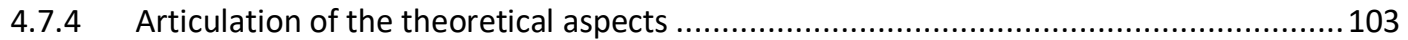

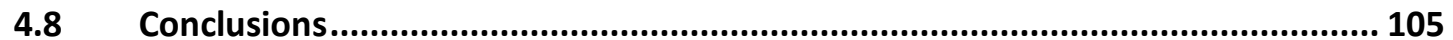

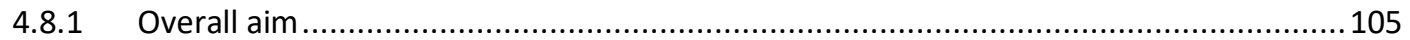

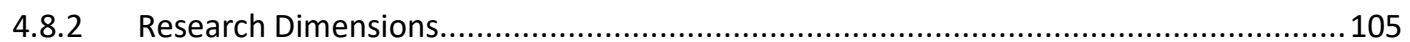

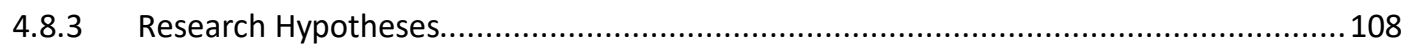

4.8.4 Theories of youth gang formation in France (synthesis).............................................. 111

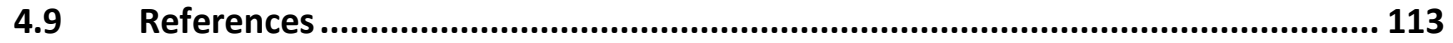

5 (Trans)gangs in Milan: Re-socializing migration experiences in the richest Italian city123

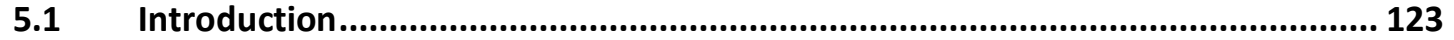

5.2 State of the Art: Researching (trans)gangs in Milan ............................................. 125

5.3 Empowerment, Conflict and Mediation ................................................................. 131

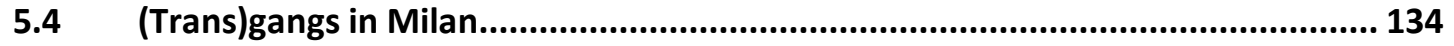

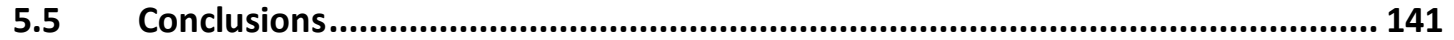

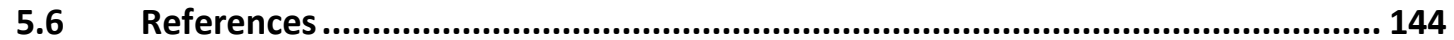

\section{Table of Figures}

Figure 1: Aluche. Work of the Peruvian artist Daniela Ortiz, Matadero Madrid ........................ 8

Figure 2: Foreign population by geographic origin. Barcelona 2000-2018 .............................. 19

Figure 3: Foreign population by age groups. Barcelona (2000-2018) .................................... 20

Figure 4: Foreign population by nationality and age groups. Barcelona (2000-2019).............. 20

Figure 5: Immigrant population in Madrid and Spain. Evolution (2000-2018).......................... 43

Figure 6: Percentage of immigrant population per educational level (2018) ............................ 44

Figure 7: Interdependent theories and local variables (TransGangs in Marseille) ................... 104 


\title{
1 Introduction: The persistence and evanescence of gangs. Approaching the emergence of new public enemies and discourses in Marseille, Milan, Madrid and Barcelona
}

\author{
Luca Queirolo Palmas
}

\author{
Translation into English by Catherine Stonehouse
}

The texts that follow reveal the multiple facets of the European cities Milan, Marseille, Madrid and Barcelona. They show how in the guts of these cities different institutional, associative and informal agents have contributed to forging a space where migration, youth, class, order and social disorder are connected. Tipping our hat to Italo Calvino, we can think of these texts as indispensable supports on which to base an ethnographic approach to the invisible faces of these cities, to their "other" youths in a post-migratory context (Baumann \& Sunier, 1995; Queirolo Palmas, 2012). Not so much because the subjects in question are invisible, on the contrary, they are sometimes part of a spectacle of hypervisibility of which they can be both authors and victims, but rather because their voices are often silenced or represented by the official city based on a set of tropes whose bias is stigma. As Spivak (1988) would say, the subalternity they suffer is also born and accumulates from the fact that they are "spoken" by others. The first way in which these subjects are spoken is by the use of the term "gang". This term is an empty signifier over which there is a continuous struggle on how to fill it with meanings and on the intensity of its appearance and use in public discourse.

The input that distinguishes the Transgang project ${ }^{1}$ is that it seeks another visual angle: to think of these youthful subjects, placed on the fringes of legitimate citizenship, as authors, and not just actors of an already written story, exploring the border places where conflicts are constructed and relationship frictions, mediations and social changes are present. This is both at a horizontal level, among young people, groups and peers, and also at a vertical level, with the world of institutions and their policy interventions, focused to varying degrees on the left or right hand of the State (Bourdieu, 1999; Queirolo Palmas, 2017). In other words, it is about exploring how juvenile "spoken" subjects speak in the first person using another language and other spaces. It is here that the importance of focusing attention on music, sports, digital communication, the production of images, street arts such as graffiti, collective mobilization and social movements can tune our research into the cultural productions of these young invisibilized and inferiorized people, where generational and migratory issues intersect,

\footnotetext{
${ }^{1}$ The TRANSGANG Project won an Advanced Grant by the European Research Council in the 2017 Call. The PI is Carles Feixa Pàmpols, Pompeu Fabra University (Barcelona). The whole project data are: Transnational Gangs as Agents of Mediation: Experiences of conflict resolution in youth street organizations in Southern Europe, North Africa and the Americas (TRANSGANG). European Union: HORIZON-2020, European Research Council - Advanced Grant [H2020-ERC-AdG-742705].
} 
constructing new urban youth cultures. As the researchers who are carrying out field work in the metropolitan area of Barcelona tell us, "in the end, music, hip hop, trap, is the language and space that channels and brings together the young people we want to study".

The ethnographic works presented here on the "other" young people of the city also invite us to think about the issue of comparison. Barcelona, Milan, Marseille and Madrid are not discrete units that can be compared mechanically. Following Burawoy (2000) and Hart (2018), the comparison has to visualize how global processes are developed, implanted, and transformed into the local, without pursuing a universal truth about social events and phenomena, but rather questioning the social construction and the agency capacity of a segment of youth in post-migratory urban contexts. It is this connection between global processes and local fabrications that we want to place at the centre of the comparative analysis. In other words, we propose observing and being aware of how a global pandemic and floating ideoscape (Appadurai, 1996) of gangs, constructed with waves of moral panic, music and fashion, social networks and the spectacle of the film industry, is implanted, accommodated, is used by different agents, in the production of subjectivities and social movements, representations and classifications, conflicts and policies in specific urban contexts.

Marcus (1995), in his proposal for a multi-sited ethnography, invites us to follow the threads, the connections, the frictions, the ruptures, focusing our attention on the circulation of subjects, words, texts, objects and conflicts. Perhaps the four contributions that appear here also restore some resonances between distant and different places where the different temporalities of the encounter between migrations, youth and politics help us to better understand the variable waves of panic, the continuous production of new public enemies, and the generation of conflicts, mediations and interventions. Following this perspective, it is possible to explore not only local accommodations and fabrications, but also connections and symbolic and material resonances between cities, such as those that occur when "Latino gangs" begin to appear in the shadow of the Latin American diaspora in many European cities since the end of the last millennium. This immigration process activated a social reaction and a public discourse of stigma and inferiorization towards the birth of a second migrant generation. Another example of resonances are those that are currently activated in relation to unaccompanied minors, young people from Morocco and refugees who circulate through Spain, France and Italy, seeking opportunities and becoming a potential factor of alarm in many European cities.

In 2020, European societies are in fact, although not always of rights, post-migratory: some due to their colonial inheritances, others due to materiality and the sedimentation/accumulation of flows in the last 30 years within the framework of capitalism and a neoliberal State. Milan, Madrid, and Barcelona speak to us about how young people of Latin-American origin, arrivals, born and raised since the end of the $90 \mathrm{~s}$, are inventing their spaces in the city and in the generational landscape, and are 
being branded as gangs (Feixa, 2006). But Marseille is situated in a much longer time period, which has made it a crucial and historical pole of Mediterranean relations with Algeria and the Arab world and, more recently, a place of transit for refugees and migrants in flight from the Dublin system, following the different routes that cross the Mediterranean and the Balkans. In Marseille, the processes of citizenship (Bastenier and Dassetto, 1993) are rooted in the history of the city and young people from the popular classes reinvent their identifications within a framework that unites the local (being from Marseille), the national (being a citizen), migrant origin (Maghreb, in most cases), morals and beliefs (Muslimness) and are confronted with new migratory flows. In this context, the term "gang" is recurrent, but it fully refers to certain young citizens - the young indigenous people of the Republic - who want to terrorize, quite the opposite of the gang label that falls on the young people of recently arrived migration on the way to insertion. Indeed, in the other cities of the study, when young Latinos stopped embodying the appearance and existence of a migrant youth, new subjects and street groups of Maghreb origin, represented as potential public enemies, began to substitute them as a spectacle and social problem, taking on the role assigned only a few years before to the "Latino gangs."

I reflected on the issue of temporalities and post-migration during my field trip in Madrid in January 2020. The CIE (Centre for Identification and Expulsion) in the neighbourhood of Aluche was revealed as a paradigmatic place for some of these transformations. Here are my field notes:

I walk towards the Centre; it has unusual architecture. From far away it looks like the roof of a coloured tent.... It looks like a circus. But getting closer, other nuances manifest a prison language: there are windows without lights, walls with erased graffiti ("CIE = torture centre"), cameras and loudspeakers, window bars and police cars. There is rubbish everywhere, which I begin to look at and collect, an exercise that is always revealing: advertising material for lawyers especially and internment sheets accompanied by quick medical diagnoses and the consequent supply of psychotropic drugs. It is two in the afternoon and there is a lot of movement of people. At the bus stop, a migrant offers me potato chips and hot coffee; a whole underground economy is structured around the institution. Other migrants are accompanied by people in suits, lawyers I imagine. People who wait, children and families, but also people who enter and leave through a police checkpoint. The place is a symbol: next to it there is a psychiatric hospital; in front is the huge void of the old Francoist prison protected by fences. If this is the environment, the entrance door is also revealing: on one side there is the entrance to the CIE for relatives and lawyers, on the other there is the police station for migrant documentation. As if to remind those who get their papers that they can always lose them, and that deportation is pending there, right before their eyes. 
Figure 1: Aluche. Work of the Peruvian artist Daniela Ortiz, Matadero Madrid

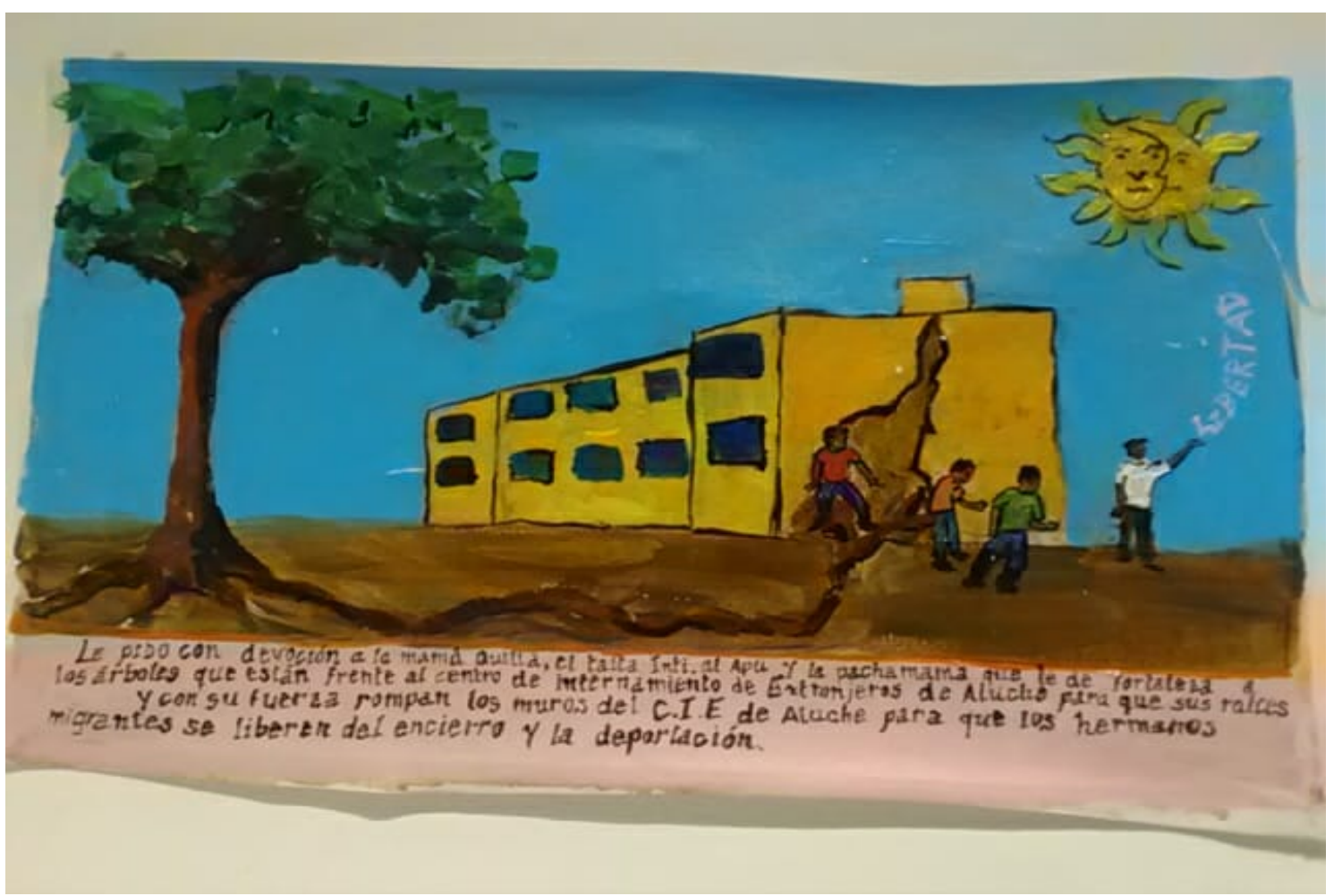

Source: Author's photography

What does this place have to do with the "gangs" and with the theme explored by the texts collected here? Of course many members of street youth groups in the pioneering times of Latino migration passed through here, but perhaps another element should be emphasized. The young people that we intend to study in these four cities increasingly represent that "untimely posterity" of which Sayad (2010) spoke, and which was so in Marseille long before in Milan, Madrid and Barcelona. They live - and they resist - a stigma because they are here to stay. Moreover, many are already in a situation of not being able to be deported, because they have progressively settled here or they were born here, and have earned the ticket of citizenship, although a subaltern citizenship. So the CIE in Madrid tells us in many cases about the past of gangs and youth groups on the street. Currently, the prison would be the corresponding institution for those who overcame the barriers of the first settlement. However, the term "gang" remains as a signifier that can operate both to remind the young citizens of Marseilles of migrant origin of their otherness, and to inferiorize and control the new migrant youth presences.

Approaching the reality of the youth street groups in the four cities then means concentrating on their compositions and variable connections and on the temporalities of the meeting between policies, public discourse, migrations and youth. The issue that guides the comparative process that begins here is not hierarchical and classificatory, but rather aims at denaturing the phenomenon of gangs, and the pathologizing of certain youth groups, looking for variabilities, resonances in conflicts and reactions, places of 
subjectivation and agency. In the logic, and economy, of the project the comparison is between core cases (Barcelona) and contrast cases (Madrid, Milan, Marseille). Barcelona has this role due to the relevance of the "Latin gangs" phenomenon in its first media appearance and also due to the inclusive policies that have been developed at the local level, which aim to generate a non-hostile space of recognition and positive conversion of groups. In particular, the option, and Barcelona's goal was to convert the gangs into legally constituted associations. This type of policy also points out the existence of a space of vertical type mediations between institutions and street youth groups, considered problematic by the urban social order. The question that follows is how this vertical space, which enables a less hostile environment and testifies to a political vision of these youth segments, can favour processes of horizontal mediation and positive transformation of the groups involved. In the opposite direction, the case of Madrid helps us to examine the effects of a clearly hostile institutional space, while the case of Marseille opens the analysis field to the impact of inclusive local policies towards youth groups that are different due to their origins and legal status. Lastly, the case of Milan helps us explore a space where the role of local institutions is minimal neither hostile nor inclusive - and the interventions are managed autonomously by the associative world.

However, the map based on the texts presented here is much more complex and encourages us take a closer look, criticizing the distinction between core and contrast cases. Let's look at some transversal elements to guide us in our reading.

\subsection{The weakening of the "Latino gangs" as a media reference for stigma and as an organized and pulsating presence in the streets}

The Barcelona Background Paper evocatively speaks of "traces of street youth groups" and concludes on the invisibility of the "Latin gangs" even on the occasion of a mediarich event such as the trial against the legal branch of the Latin Kings. The Milan BP wonders about the abysmal distance between the concrete existence of the groups in the street and the floating noise about the danger of the Salvadoran gangs, while the Madrid BP confirms that the Dominican groups continue to exist, although their activities do not promote or bring together a new pandemic and barbaric narrative, a new gang talk (Hallsworth, 2011), capable of generating panic as well as a useful scapegoat. In the words of Maria Oliver, the gang space has been fragmented, pluralized, turned into something rhizomatic and less hierarchical; each corner, a gang, more than groups, chapters, choruses, cliques inserted within large organizations. In the field trips in Milan and Madrid to the urban hotspots of gangs, the Transgang researchers talk to me about the past, showing me the places where group members met, punishments were meted out, and there were dealings and actions. In the words of Paolo Grassi, "Sometimes I think I am doing archaeological work". The phenomenon has withdrawn almost entirely from the public space. Constant legal repression has destroyed and weakened the groups or has progressively pushed them into the shadows. The media had discovered and 
fabricated the "Latino gangs" phenomenon in parallel with the growth of migratory flows and family reunification. From the beginning, these groups were baptized as criminal gangs, associated with criminal news, and there was a clear tendency to stigmatize their aesthetics and cultural practices (Giliberti \& Queirolo, 2014). The term "Latin gang" therefore operated as a metonymic signifier through which to talk about youth violence and the forms of sociability of the children of immigration (Feixa et al., 2008; Giliberti, 2014). The result of this was a direct and naturalized association between violence, crime and youth of Latin American origin. However, the chapters dedicated to Milan, Madrid and Barcelona invite us to reflect on the new connections between the stagnant presence of historical groups of Latin American origin, the fragmentation of the gang space, and the emergence of media discourses that are gearing towards developing new narrative lines and new subjects.

\subsection{The affirmation of anti-gang legal norms}

In all the national contexts of the research, being part of a gang no longer has to do with the illicit, but rather with the criminal, although of course there is a certain discretion of the justice apparatus. Being a member is a crime and is criminally convicted, committing a crime as a member of a group aggravates the sentence. In other words, beyond local policies and the production of hostile or welcoming urban spaces, there is a sedimentation of legal tools that sanction membership intensely, weaken the possibility of a demand for visibility and favour withdrawal and self-marginalization as a protective modality.

\subsection{The fading of the inclusion policies for gangs}

The process of normalization of gangs, through their conversion into associations recognized by public institutions, has been the beacon of a movement that in the first decade of the third millennium has involved different cities, such as Milan and Genoa, and that has resonated in much broader transnational debates on innovative youth policies (Brotherthon, 2011). Barcelona played a paradigmatic role in the development of this type of policy, becoming a global example. My ethnographic research carried out between 2011 and 2013 in Spain (Queirolo Palmas, 2017) already highlighted how almost nothing remained of those policies and how their principles were not applied with the new street groups that were appearing, which were defined as more violent, more criminal, and with less possibilities of integration. The Barcelona chapter, written almost seven years later, confirms a similar diagnosis. While in Milan, the Latin King association that was established in the first decade of 2000 is now totally deactivated, just as street work in youth policies was deactivated. If we look at how young people in the street and of migrant origin have been treated by the public powers in Marseille, we see that the chosen device and the institutional modes of action are not so different from the former Barcelona model for gangs: scattered youth centres in problem urban areas, conversion of groups into semi-subsidized associations, transformation of old leaders 
into promoters of the social and cultural dynamics of the neighbourhoods. In this scenario, as Juan Camilo Mansilla emphasizes, the space of conflict and mediations is structured between local institutions and associations. One of the main limits of these local policies has been their excessive pretence of institutionalizing the groups, of not recognizing the effervescence of the street and youthful sociability.

\subsection{The growing media attention towards new young street subjects}

The chapters in cities where Latino street groups were hegemonic emphasize as an important change the birth of a narrative that projects new public enemies into the debate space: unaccompanied minors and other youth groups of Muslim origin. As the researchers in Barcelona and Madrid point out, under the label "Menas" (unaccompanied minors) there are situations that have nothing to do with unaccompanied minors and include youth of Arab and Muslim origin who circulate on the street. In a way, the "inclusive" character of the label serves to report and point out, once again, the untimely posterity of a broad segment of youth of migrant origin, exactly the same thing that we saw develop through the symbolic function of the term "Latin gang". Regarding unaccompanied minors in the strict sense, unlike policies on gangs, it can be noted that although there is an institutional network that is in charge of protection, there seems to be a lack of policy vision and intervention that is not reduced to containment of some presences labelled as responsible for the disorder in urban life. As Eduard Balleste and Maria Oliver point out, there are conflicts when a juvenile centre wants to send its "menas" to the neighbourhood school; the result is that the young people remain isolated and segregated at the juvenile centre all day without doing anything, imagining and practicing an escape as an affirmation of freedom. These new local appearances are inserted and depend on a global context that has been marked since 2015 by the refugee crisis, the increase in Islamophobia and the emergence of a terrorism that is legitimized through religion and in which a relevant role has been played by young European citizens that are children of migrants. If in Madrid, Barcelona and Milan, young people of Arab and Muslim origin and unaccompanied minors, with different intensities, are at the centre of new forms of sociability and the manufacture of media panic, in Marseille this change takes place and accumulates around a space where Arabness and Muslimness have always been the defining feature of the line of social and urban classification and the prevailing nuance in discourses on migration.

\subsection{The importance of non-institutional mediations}

The texts invite us to focus our attention on more subtle and informal mediation situations, beyond those processes promoted by policy makers and youth policies that have large limitations when applied to street youth. In addition, if the principle of mediation is that the parties participate voluntarily, and that there is a neutral subject between the parties, the space that local policies generates and promotes emphasizes, on 
the contrary, an asymmetric and power dimension. In the chapters, we will see conflictual events and social processes that tell us about attempted or aborted, failed or successful mediations, both formal and informal, recent and long-standing and that are located in a space not governed by institutions. There is, for example, the cultural and social insertion work that the actual street groups do in relation to their members; there are generational relationships between young people on the street and their older brothers and sisters in the neighbourhood who have already experienced similar exclusionary conditions; there is the space of conflicts and mediations that are generated between different youth groups; and there is the space that is created with associations, educators and teachers, social workers, social and neighbourhood movements and that provides border places (Feixa et al., 2019) that become safe places where young people can access material and symbolic resources. Deepening the analysis of these events/processes/situations will help us to better interpret the conditions under which "gangs" and "youth street groups" can be agents of mediation and social transformation in the urban and youth environment.

\subsection{A variable inscription in the urban space}

In Trasher's (1927) classic vision, gangs are the youthful sediments of massive immigration, they grow in urban interstices and are configured as dynamic cultural formations in a context of exclusion and demographic and social change. We could say that these groups re-signify, in terms of the value of use, the spaces outside the control and that are marginal in relation to the interests of the authorities and other economic actors. The urban space, its interstices and areas in the shadow of power thus become places of youthful sociability without a manifest purpose. The gangs occupy the gaps that the growth of the urban fabric has forgotten and not yet commercialized. Almost a century after Trasher's reflections on gangs and interstices, the contemporary use of space by these young actors, and the conflict they raise, is no longer generated in urban voids without surveillance and regulation. On the contrary, they are developed in a full fabric marked by urban plans and local welfare, equipment, furniture, infrastructures, leisure technologies. This full urban space is of course the sedimented result of social conflicts that in the recent past have successfully argued their right to the city (Harvey, 2012) - the value of using space - which is gradually contested by the extractivist logic of capitalism. Gangs, like other actors with low cultural and economic capital, insist on this public space, use it, make commercial conversion problematic, force planners and officials to produce a plethora of laws and regulations in an attempt to contain a infrapolitical resistance that Mike Davis (2001) has defined as magical urbanism. The texts that appear here reflect different insertions of youth groups in the space of the city: more visible/spectacular or more hidden and silenced, more fluid and mobile especially the fabric of urban circulation, or more linked to a sense of neighbourhood belonging as refuge and retreat in relation to urban segregation processes. This spatialization of street youth groups, which often do not renounce occupying the central spaces of the city, passively accepting their marginalization, is a fundamental variable when it comes to 
exploring the conflicts and mediations that are generated.

In what sense, then, does the study of youth street groups in Barcelona continue to be situated today as a core case of comparison work if our objective is to explore and evaluate the capacity of youth street groups as mediation agents? The reflection that reading the chapters involves is that the Barcelona case, contemplated in the present, resonates features of all the variability and heterogeneity that appears in the other three cities. In a way it is situated at the centre of the ethnographic effort, an urban context where the new and old juvenile subjects that we see operating on the streets of the other cities involved in the research materialize contemporaneously in the public scene, in the media discourse, in the experiences of policy makers and other relevant actors, and of course in the attention of researchers. What also emerges from this heterogeneity is the construction of a hybrid and border space in youth and street sociability where the ethnic theme in the strict sense gradually fades, opening the way to a landscape of cultural identifications and subjectivities that are much more open and fluid. Thus, a level of horizontal mediations and cultural production among peers is configured that we find interesting to continue researching and that also refers us to the complexity of a post-migratory society, where the intersectionality (Crenshaw, 2017) of class, gender, origin, age and cultural capital are revealed as the most opportune key for analysis. 


\subsection{References}

Appadurai, A. (1996). Modernity At Large: Cultural Dimensions of Globalization. Minneapolis: University of Minnesota Press.

Bastenier A., Dassetto F. (1993). Immigration et Espace Public: la controverse de l'integration. Paris: L'Harmattan.

Baumann G., Sunier T. (Eds.) (1995). Post-migration ethnicity. De-essentializing cohesion, commitments and comparison. Amsterdam: Het Spinhuis Publishers.

Bourdieu P. (1999). Contrafuegos. Reflexiones para server a la Resistencia contra la invasión neoliberal. Barcelona: Anagrama.

Brotherton, D. (2011). The Latin Kings and the Global Process: An Extended Case Study Analysis, Studi Sulla Questione Criminale (translated into English, Spanish and Italian). 4(1): 7-46.

Burawoy, M. (Ed.) (2000). Global ethnography: forces, connections, and imaginations in a postmodern world. Berkeley: University of California Press.

Crenshaw, K. (2017). On Intersectionality: Essential Writings. New York: The New Press.

Davis, M. (2001). Magical Urbanism: Latinos Reinvent the U.S. Big City. London: Verso.

Feixa C. (Ed.) (2006). Jóvenes latinos en Barcelona. Espacio público y cultura urbana. Barcelona: Anthropos.

Feixa, C. (Dir.), Sánchez García, J. (Coord.), Ballesté, E., Cano-Hila, A. B., Masanet, M.-J., Mecca, M., \& Oliver, M. (2019). The (Trans) Gang: Notes and Queries on Youth Street Group Research (TRANSGANG Working Papers No. 2.1). Barcelona: Universitat Pompeu Fabra \& European Research Council. DOI: http://dx.doi.org/10.31009/transgang.2019.wp02.1

Feixa, C., Canelles, N., Porzio, L., Recio, C., \& Giliberti, L. (2008). Latin Kings in Barcelona. In F. van Gemert, D. Peterson, \& L. Inger-Lise (Eds.), Street Gangs, Migration and Ethnicity (pp. 63-78). Devon: Willan Publishing.

Giliberti, G., Queirolo Palmas, L. (2014). Le bande e la città. Conflitti e spazio pubblico nella Spagna contemporanea. Etnografia e ricerca qualitativa. 3: 423-444.

Giliberti, L. (2014). Bandas Latinas en España? Grupos juveniles de origen migrante, estigmas y síntomas. REIS. 148: 221-238.

Hallsworth, S. (2011). Anatomizing gang talk. In Cerbino, M. (Eds.), Más allá de las pandillas: violencias, juventudes y resistencia en un mundo globalizado. Quito: Flacso.

Hart, G. (2018). Relational Comparison Revisited. Marxist postcolonial geographies in practice. Progress in Human Geography. 3: 371-394.

Harvey, D. (2012). Rebel Cities: From the Right to the City to the Urban Revolution. London: Verso.

Marcus, G. (1995). Ethnography in/of the World System: the Emergence of Multi-sited Ethnography. Annual Review of Anthropology. 24: 95-117. 
Queirolo Palmas, L. (2012). Juventudes y migraciones en Italia. Deconstruyendo la posteridad inoportuna. Revista andaluza de antropología. 3:125-147.

Queirolo Palmas, L. (2017). ¿Cómo se construye un enemigo público? Las 'bandas latinas'. Madrid: Traficantes de Sueños.

Sayad, A. (2010). La doble ausencia: de las ilusiones del emigrado a los padecimientos del inmigrado. Barcelona: Anthropos.

Spivak, G.C. (1988). Can the Subaltern Speak? In Nelson C., Grossberg, L. (Eds.), Marxism and the Interpretation of Culture. Basingstoke: Macmillan.

Trasher F. (1927). The Gang: A study of 1313 gangs in Chicago. Chicago: University of Chicago Press. 


\title{
2 Traces of youth street groups in Barcelona (Catalonia)
}

\author{
Eduard Ballesté Isern
}

\author{
Translation into English by Catherine Stonehouse
}

\subsection{Introduction}

On 3 December, 2018, in the Barcelona National Court a collective trial began of several members of the legal association the Latin Kings \& Queens of Barcelona. The accusation focused on describing them as a criminal organization, although, as the indictment shows, there was not enough evidence and the crimes were not serious enough to warrant this label. The accusations, based on police monitoring, talked about drug trafficking in small quantities and street fighting without clear evidence. These accusations, at the same time, served to construct the group's entire internal structure and define its purpose: to carry out criminal activities. One by one, the various defendants, police and experts talked into the microphone. The defence, through the questions they asked each witness and in their final plea, faced with the prosecution's harsh accusations, tried to demonstrate the lack of evidence that would justify the classification of criminal organization. The trial ended with the release of five of the defendants who remained in pre-trial detention and the requests for penalties were maintained towards the rest, mainly towards King Manaba, who was considered the leader of the organization at that time.

At no time during the 11 days the trial lasted did the media or journalists come to the court entrance looking to cover the case. The trial made only an insignificant appearance in newspapers, television and other media. Thus, 13 and a half years after the trial for the death of Ronny Tapias, we see first-hand the turnaround in media attention concerning Latin gangs: they have gone from filling the media to receiving virtually no media coverage at all. This establishes a good starting point for determining the position that (Latin) gangs occupy at the beginning of this project (2018-2019). It gives us a comparative framework for observing their evolution during the last two decades and comparing it with other youth street groups, such as those formed by young North Africans. Why the change in media focus? Who occupies the place of "public enemy" today? How have youth street groups evolved over these years? What position do these groups currently occupy in the city, in the political structure and in the social space? What mediation and conflict processes exist between groups, with institutions and with other social and political agents? Next, we seek to shed theoretical, methodological and historical light on youth street groups to lay the foundations in order to answer these questions during the study. 
This document outlines the construction and evolution of these groups and the political, social and media journey they have made in Barcelona (and Catalonia). We also look at the different theoretical and analytical contributions, mainly from academia, about (and sometimes with) youth street groups. The document is structured in four points. The first section describes the evolution of youth street groups from a theoretical, academic and, to some extent, historical perspective. Then, entering one of the project's central points, we list and describe the different mediation processes that have been opened with these groups (taking as a central point the process of creating a Latin Kings \& Queens association in Barcelona). In the third part we address the issue of spaces. The methodological construction of spaces must make it possible to define the positions occupied at different times by each group in the social, political and physical space. This can be used to define the gang space and the mediations that occur by locating each agent who plays a role within this space. In the fourth point we present a legal section describing the main laws, regulations and legal situations that affect (or have been affecting) youth groups, "gangs" and other similar groups in Spain and Barcelona. This document dialogues with the Barcelona Research Plan as it allows us to establish a theoretical, historical and methodological context to determine the shape that the research in Barcelona will take during the TRANSGANG project.

\subsection{Researching (Trans)Gangs in Barcelona: from Latin "gangs" to informal groups}

\subsubsection{Contextual frame}

To provide a context it is necessary to begin the theoretical-practical outline of the Background Paper by defining, at a supranational or global level, in what kind of society the research is situated. As described extensively in the Concept Paper (Feixa, Sanchez, et al., 2019), it is necessary to place the study within the model in which we live, that is, a neoliberal model in the economic, political and social (Brenner, Peck, \& Theodore, 2010; Harvey, 2007), which generates specific characteristics of the role and form the State takes on. ${ }^{2}$ These specific characteristics are manifested, for example, in a specific function of certain actors, such as the media, the police, and the judicial system in the classification and "treatment" of certain social groups. This articulation of the "institutional form of society" produces (or lives from), ultimately, a specific classification of the subjects and social groups based on their specific "utility" for the reproduction (or not) of the current distribution of the political, economic and social power. That is, the division between the "normal" and the "abnormal" (Foucault, 1990) makes it possible to understand the social structure based on binomial concepts or categories such as "integration" or "marginalization", or between the positions of those who hold power and those who are dominated (Bourdieu, 2000). From this specific

\footnotetext{
${ }^{2}$ By State, beyond understanding the format of each specific government, we understand all those institutions or organizations that accompany it or that allow its daily penetration into society: judicial power, police, social assistance institutions, among others (Feixa et al., 2019).
} 
perspective, the groups studied here can be located as subjects situated by the different "devices" mentioned above in peripheral spaces of the social, economic, political and cultural (therefore, in the "abnormal", in the "dominated" and the "marginal"). This peripheralization defines the ways of expressing, acting and interrelating between groups, between the groups and the institutions, and between the groups and society itself.

It is also necessary to highlight the importance of the historical moment in which the research is being carried out at a more "local", regional or state level. The current context is that of a crisis not yet overcome that entails the "delegitimization" of the social democratic model of institutional intervention in social issues, mixed with an increase in the neo-liberal economic trend - privatization, temporality and precariousness (Fontana, 2011; Harvey, 2005; Horvat, Zizek, \& Murillo, 2014) - and an increasing delegitimization of the political (Ballesté, 2018; Flesher Fominaya, 2015; Sánchez García, Ballesté Isern, \& Feixa Pàmpols, 2018). A situation that, in our case, results in a specific form of research into "gangs" or youth street groups in different areas. Thus, the cuts in public services, the shift towards an economic model in which the real estate sector, which had accumulated large amounts of proletarian immigrant labour, has lost weight and the unprecedented increase and stagnation of unemployment levels (especially young people) (Queirolo Palmas, 2017) help us to understand the gradual abandonment of the Barcelona intervention model for "gangs" (as a Catalan example of reference) ${ }^{3}$ and the institutional acquisition of a model focused on "concealing" the phenomenon, increasing repression and, at the same time, gradually constructing a "new public enemy": young migrants from North Africa (ibid.).

To all this, we should add the general political context in Catalonia in recent years concerning the project for independence because it allows us to understand the movements that have occurred in recent public, political and media debates. That is, the independence process has meant the appearance of "new public enemies". In the opinion of the Spanish government, public and media the new public enemies are the Catalan government, the independence entities and the civil society related to this movement. The new enemies of Catalan independence are the Spanish government, justice, and the national media. The centrality that this debate has had in the media, political debates and in society itself has meant that other issues, such as Latin gangs, have become concealed or invisible.

At the same time, the migratory processes of people arriving in Spain have changed over the last decade, which also explains the change of focus. Migration from Latin America has decreased with a reduction in family reunification rates (in 2010, the total migrant population from South America in Barcelona was 118,918, decreasing to

\footnotetext{
${ }^{3}$ Although we develop what is understood as the Barcelona Model in a more precise way later, it is necessary to highlight that it refers to a process of dialogue, mediation and construction of a legal space in the treatment of Latin gangs, especially the Latin Kings and Netas. All this is linked to the JOVLAT project (Feixa, Porcio \& Recio, 2006).
} 
94,772 in 2018 - data from IDESCAT from the INE Continuous Register) and the foreign population rates have decreased since the beginning of 2010 (Figure 1). These figures can also be explained by relatively easier access to citizenship by immigrants from Latin America and the Caribbean due to certain administrative facilities consolidated before the economic crisis that began in 2007 or greater maturity of the migration process itself. In the case of Africa, the process is similar. Migration reached a peak around 2010; however, the figures have now dropped to a level similar to that of Latin America and the Caribbean (Figure 2 and 3). Even so, there has been an increase in unaccompanied migrant minors, which has changed the migration characteristics so that we can talk about "a new migration" (although to a lesser extent, this phenomenon already existed in 2010) (Garavito Tarrifa, Sánchez Camacho, \& Carbarcas Bru, 2018).

Figure 2: Foreign population by geographic origin. Barcelona 2000-2018

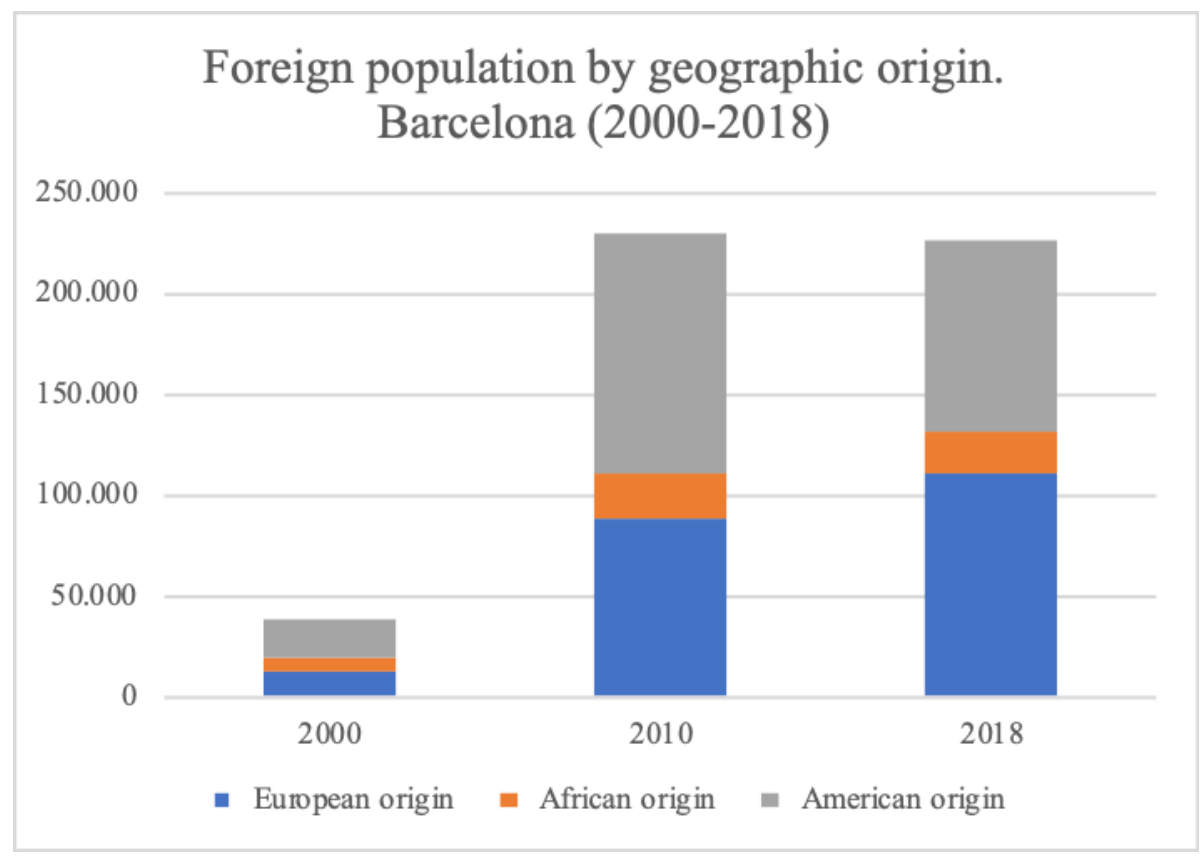

Source: IDESCAT, based on the continuous INE standard (own elaboration). 
Figure 3: Foreign population by age groups. Barcelona (2000-2018).

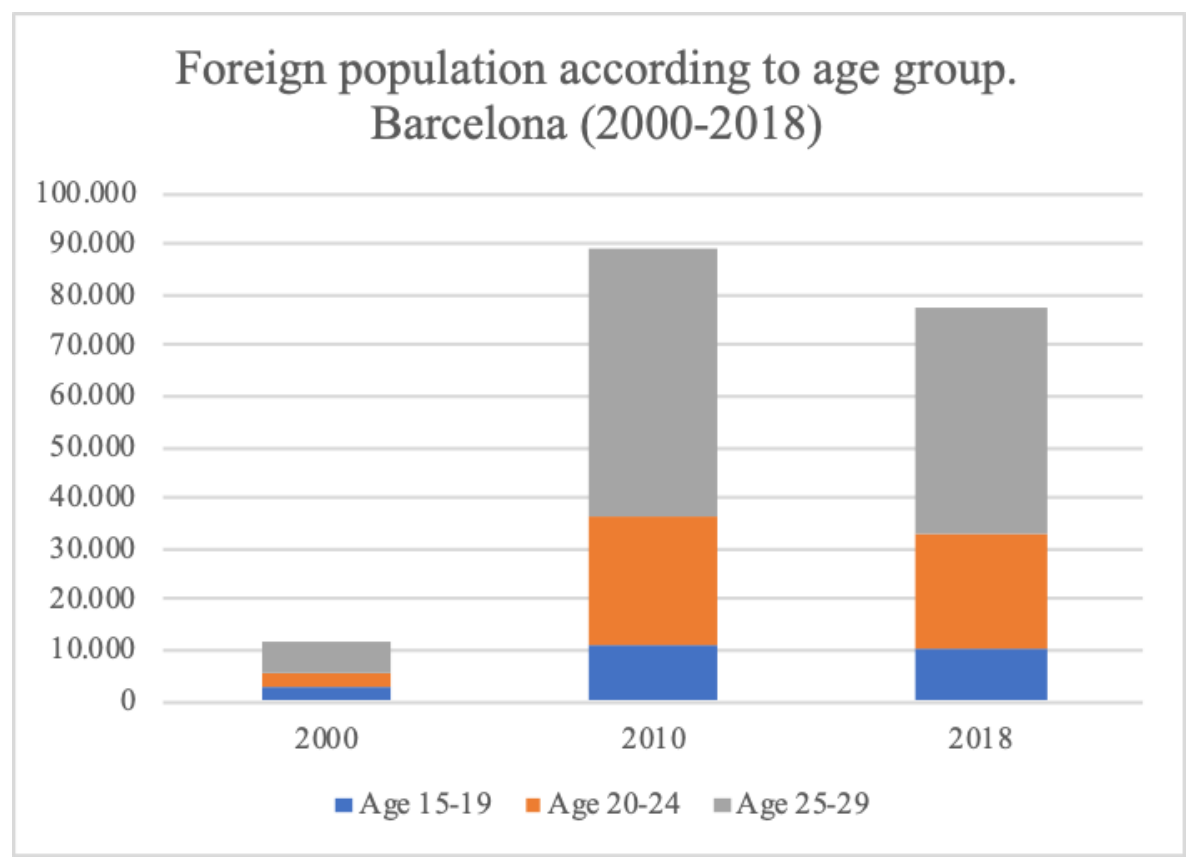

Source: IDESCAT, based on the continuous INE standard (own elaboration).

Figure 4: Foreign population by nationality and age groups. Barcelona (2000-2019).

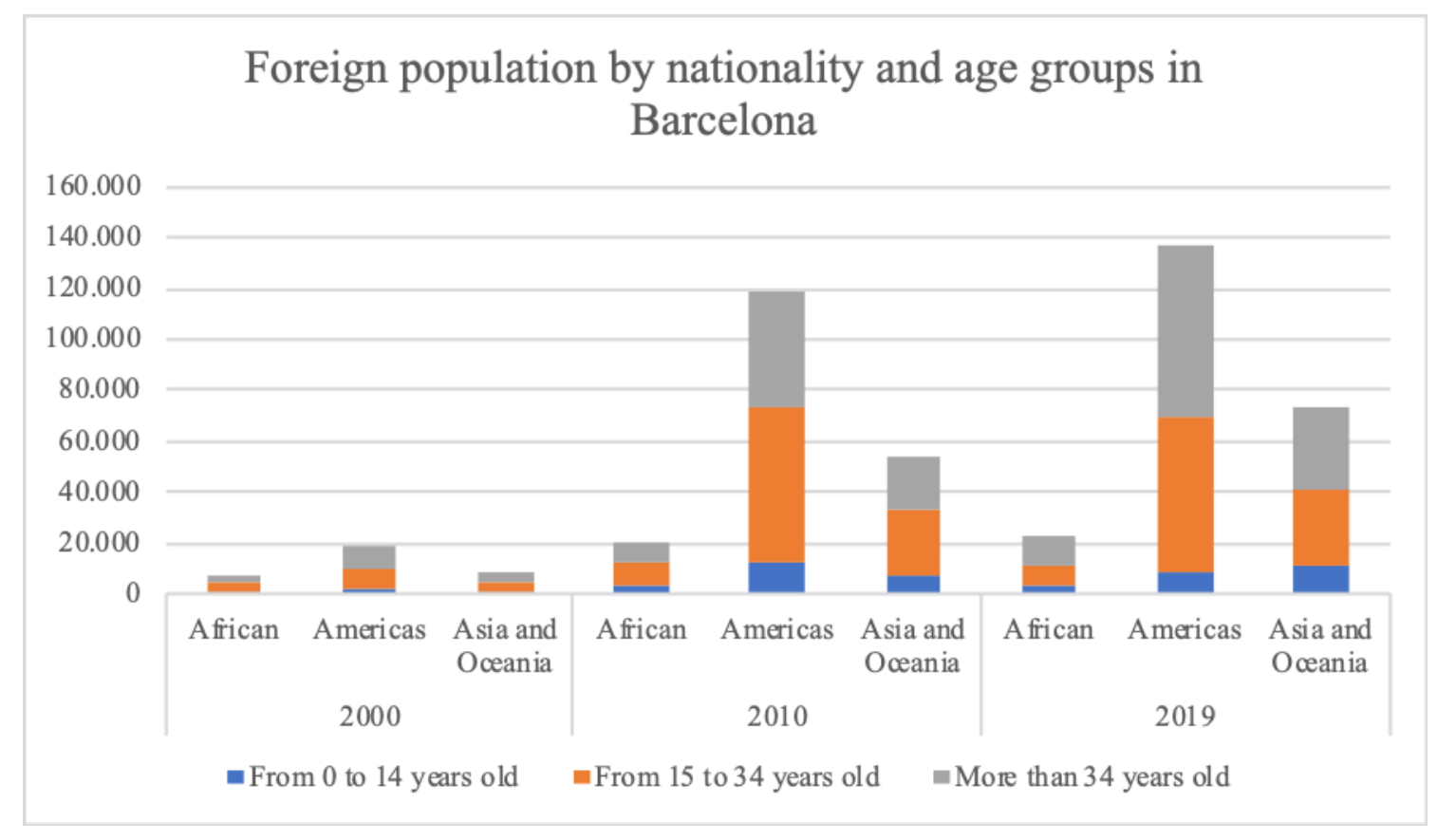

Source: IDESCAT from the INE continuous standard (own elaboration) 
Thus, this "new migration", with very specific characteristics, has led to a change in focus of both public policies and relevance in the media, mainly due to stigma linked to terrorism, drugs, security and crime. We can therefore interpret that during the last two decades the changes in the migratory processes, with a certain decrease or stagnation in immigration from the Americas and Africa, in general, but with a certain increase in young immigrants, have moved the political, media and social attention to these "new" agents. The disappearance of "Latin gangs" from the public sphere has given way to the emergence of new groups that are constructed as "dangerous" through geopolitical or global events, such as the different wars in the Middle East and the increase in jihadist terrorism. However, if we look at the data from the Continuous Population Register, we observe that in general the arrival of migrants has decreased. Although migrant characteristics have changed, the social perception of the increase in migration is mainly determined by a set of media and political narratives that penetrate social imaginary not only at the local level, but also in different ways at the global level.

\subsubsection{The "gang" concept}

It is therefore necessary to specify a new conceptualization of the study object to contextualize these "new" groups that include agents of diverse origins and that are labelled (filled with content) and stigmatized similarly to Latin gangs in the last decade. Thus, both because of the negative connotations of the gang concept, and because of the need to integrate a more plural view of these groups, it is necessary to generate new categorizations. The name "youth street groups" (Brotherton \& Barrios, 2004; Feixa, et al., 2019), used in this project to define the study object, can be seen as a concept that could encompass many formats of different youth groups. In this work this breadth of meanings allows us to analyse different group formats comparatively and establish a relational framework between them. ${ }^{4}$

Historically in Spain "youth gang" has been used to label those subjects who come together in the street and who move away from the norm and have an attitude of challenge towards the socialization processes established within the capitalist neoliberal model (Feixa, 2016; Romani, 1982). That is, from rockers or punks to bandas latinas, and including skinheads, quinquis and okupas (Feixa, 2016), all these youth groups or (sub)cultures have been branded by the public institutions, the media and also in some cases by academia, as spaces of hooliganism, violence and deviation (ibid.). Since the 70s, the phenomenon has been observed from a criminal point of view (Romaní, 1982), first with the appearance of subcultural youth groups and, later at the beginning of the century, with the media appearance of the so-called Latin gangs (Feixa, 2016; Feixa, Porcio \& Recio, 2006; Romaní et al., 2009).

\footnotetext{
${ }^{4}$ Beyond the analytical benefits, it also makes it possible to intentionally escape from the negative connotations that have been associated with the term gang. It is, in short, a sufficiently broad starting point that allows the project, together with the research protagonists themselves, to generate a new definition or meaning for these groups.
} 
To understand the meaning (or meanings) that the word "gang" has had in the urban context of Barcelona (or its Metropolitan Area ${ }^{5}$ ), it is necessary to go back to the beginning of the year 2000 and observe its spectacular arrival with the Latino youth groups. ${ }^{6}$ In 2004, the first project, JOVLAT, was born from the collaboration between the City Council of Barcelona, the Consorci Institut d'Infància $i$ Mon Urbà and Professor Carles Feixa (University of Lleida). It centred on studying and understanding the urban practices of young Latin Americans in the city of Barcelona (Feixa, Porcio \& Recio, 2006). The project focused its attention on the so-called "Latino youth gangs" and the stigma that had been generated to include all young Latin Americans, especially due to the then recent events (the murder of Ronny Tapias in front of a school). The idea of the project was to problematize the image that these "gangs" had acquired through the media, build an image that emerged from the groups themselves and, in parallel, find new ways of working and acting with them (Feixa, Porcio \& Recio, 2006).

It is first necessary to understand who gives the word "Latin gang" its meaning. In this sense, the media and institutional political discourses play a leading role (and still do) in the construction of a specific subject, the "youth street groups" or "gangs", and in the composition of their specific practices, relationships and conflicts. It is the media that, through their influence on public opinion, spread a specific image about "gangs" to the rest of society, often related to processes of violence (internal and external) and criminal activities (Feixa, Porcio \& Recio, 2006; Queirolo Palmas, 2017). This has also penetrated academic and political discourses. This situation has generated various stigmatization processes (Feixa, Cerbino, Recio, Porzio, \& Canelles, 2006) that have led to the construction of a kind of "public enemy" (Queirolo Palmas, 2017), with which an entire population is labelled as a violent or criminal group (Feixa, Cerbino, et al., 2006). ${ }^{7}$ This process of identity construction moves from the media to the public, thereby generating the appearance of stereotypes that focus on physical traits, clothing, activities, occupation of public space, etc. (Feixa, Cerbino, et al., 2006). This starting point is essential for understanding how and who gives the word "gang" its content in Spain and, specifically, in Barcelona.

In the early 2000s, the media discourse on "young people" and "urban tribes" gradually moved from the media to academic productions (Queirolo Palmas, 2017), in the line of

\footnotetext{
${ }^{5}$ The Metropolitan Area of Barcelona (AMB) includes the municipalities of: Badalona, Badia del Vallés, Barberà del Vallés, Barcelona, Begues, Castellbisbal, Castelldefels, Cerdanyola del Vallés, Cervelló, Corbera de Llobregat, Cornellà de Llobregat, El Papiol, El Prat de Llobregat, Esplugues de Francolí, Gavà, l'Hospitalet de Llobregat, La Palma de Cervelló, Molins de Rei, Montcada i Reixat, Montgat, Pallejà, Ripollet, Sant Adrià del Besòs, Sant Andreu de la Barca, Sant Boi de Llobregat, Sant Climent de Llobregat, Sant Cugat del Vallès, Sant Feliu de Llobregat, Sant Joan d'Espí, Sant Just Desvern, Sant Vicenç dels Horts, Santa Coloma de Cervelló, Santa Coloma de Gramenet, Tiana, Torrelles de Llobregat and Viladecans, with a total population of 3,239,337 inhabitants (AMB data).

6 Although, previously in the mid-twentieth century, this denomination had already been used in Catalonia to describe groups of young internal migrants from Spain or gypsies who occupied a subaltern position (Feixa, 1998; Queirolo Palmas, 2014).

${ }^{7}$ As noted by the anthropologist Teresa San Román years ago, a similar process of stigma creation and transfer of values to the whole group occurred with the gypsies in Spain (San Román, 1984, 1997).
} 
"Savagery, primitivism, group narcissism, danger, violence and spectacularizing, pathologizing or hierarchy within the magical" (Feixa et al., 2010; Queirolo Palmas, 2017; Romaní et al., 2009). This movement was also reproduced in the construction of a common imaginary about young migrants and in the composition of the meanings of the term gang: "the gang social object is a device used to designate the forms of sociability that do not conform, from the dangerous classes, specifically from that segment, often ethnic, of young people of proletarian origin" (Queirolo Palmas, 2017, p. 48). With this, a specific non-normalized group is constructed, defined from outside the group, and all kinds of policies are developed based on this definition, both from the right and left hands of the State, to combat it and return it to normal citizenship. ${ }^{8}$ Thus, we see how the criminal construction of the phenomenon (and, sometimes, the very constitution of the forms and actions of these groups - self-fulfilling prophecy) (Queirolo Palmas, 2017 ) is intrinsically related to three groups of actors: police/prosecution, media and academia. Between the three, in a relational way, they build the scope to understand these groups as "bad" and a phenomenon that must be eliminated from society. Even so, it is necessary to point out that within each of the groups of actors there are substantial differences in addressing or understanding these groups, which also leads to the emergence of different internal and inter-group conflicts and visions. In short, the three groups of actors do not act as completely unified agents who always have the same direction.

\subsubsection{Barcelona, a new framework of understanding}

Returning to the JOVLAT project carried out in Barcelona, as Feixa (2016) explains, the communion between academia, youth street groups and public organizations meant the start of a mediation process that would end in the legalization of part of the group of Latin Kings and Netas as a cultural organization. In the case of the Latin Kings, the process began with the drafting of the group's internal statutes (with the collaboration of the Institute of Human Rights of Catalonia) that set out the group's principles in accordance with Catalan laws (ibid.). In 2006, these statutes were presented to the justice department and approved, thus creating the association. This process meant a certain departure from the invisibility and marginalization of young people belonging to these groups and the emergence of joint social projects related to music, sports and culture (Feixa, Scandroglio, López Martínez, \& Ferrándiz, 2011). This process placed the focus on understanding these youth street groups, which usually have roots/expansions that exceed the local and move in a transnational environment (the Latin King Nation, for example), as subjects with their own agency and with more complex dynamics than simply committing criminal activities. This made it possible to start building an image of these groups that was not based exclusively on what the media or the police said, but rather showed how they self-represent themselves as a

\footnotetext{
${ }^{8}$ At this point it is necessary to clarify that the two hands of the State (right and left) in no case act as a monolithic block. The agents that constitute each hand (Feixa, Sanchez, et al., 2019) can enter into conflict or generate alliances and go in the same direction so that the right and left hands of the State overlap.
} 
group. Thus, in Barcelona, unlike in Madrid where a permanent hard hand policy was carried out (Canelles, 2006; Feixa et al., 2011; Scandroglio, 2009), this process, beyond the legalization in 2006 (Cultural Organization of the Latin Kings and Queens in Catalonia and the Netas Association), led to the visibility of a phenomenon that until now had remained hidden (Feixa \& Porzio, 2006; Feixa, Porcio \& Recio, 2006; Queirolo Palmas, 2017). ${ }^{9}$

As Queirolo Palmas (2017) points out, after the second decade of the 2000s the media lost interest in youth street groups, they were "forgotten" and therefore they lost visibility. However, the disappearance of gangs in the media is related, not to the disappearance of these groups, but to the media interest moving to new issues: the economic crisis, youth social movements such as the "indignados", the independence process and the accompanying political and social mobilization, and recently, the growing presence of underage migrants in the streets. In parallel, this disappearance also coincides with the emergence of these new mediation, legalization and visibility policies, which, in short, reveals how media attention is usually focused on spectacular and criminal activities and gives much less attention to the positive processes of the relationship with gangs. Even so, it is necessary to highlight how the whole process of mediation and legalization with the Latin gangs failed to end the hard hand or repressive practices of the State. An example of this is the recent trial that accused several members of the Latin Kings of Barcelona of being a criminal organization and that went back to judge some events that occurred during the period of mediation and legalization.

\subsubsection{Defining the phenomenon today}

We can study the phenomenon of the union of young migrants ${ }^{10}$ in more or less informal specific groups, which has now "gone beyond Latin American groups" and taken on new forms, formats, contents and languages, to include youth groups from other geographical contexts (Feixa et al., 2010; Quiroga, 2003), by understanding the field studied as a common space for generating new border identifications ethnogenesis (between the countries of origin, those of arrival, the interstitial spaces between them and, above all, in the space occupied in the receiving societies) (Feixa $\&$ Porzio, 2006). Thus, "from 2004 and especially after the rise of the French peripheries, gangs and jihadism constitute for the media and for certain academic and intellectual sectors the focus of many discourses on migrant youth, the disturbing articulation of the Latin and the Moor" (Queirolo Palmas, 2017, p. 53).

\footnotetext{
${ }^{9}$ It is not only a matter of invisibility, but rather when they become visible, these groups normally do not have the capacity to speak, which means that others (politicians, the media, social services, etc.) speak in their name (Spivak, 1988).

${ }^{10}$ At this point, it is necessary to reflect on who is considered a migrant and how far the limits of this label reach. Thus, it is possible to observe that the migrant label sometimes includes those groups who were born in Barcelona or Spain to migrant parents, and who have been classified as "second generations" (Queirolo Palmas, 2017). Therefore, certain subjects (although the migration processes always have a large weight in the construction of the agency, even in second generations) are relegated to this label as an oppressive tool according to the proper functioning of the system (Delgado, 2010).
} 
In Catalonia and Spain, over the last decade another phenomenon of high impact has become visible: the appearance of unaccompanied underage migrants (Quiroga, 2003) from North Africa. In cities like Barcelona and Madrid these migrants join other groups of young people, usually the so-called "second generations", evidencing that these second agents although they have been in the new country all their lives are still relegated to a marginalization process. The arrival of unaccompanied minors means (and meant), in turn, an empowerment of child care processes (creation of shelter apartments, the expansion of street educators, intervention programmes, etc.), which shows a two sided treatment of the phenomenon. On one hand, social protection is extended to these groups (left hand of the State), but at the same time these young people suffer almost permanent direct contact with the constituent bodies of the right hand of the State (police, judicial apparatus, etc.).

However, the pragmatic and political focus placed on child care, means that young people who arrive either when they are already 18 or turn 18 once they are here, are forgotten and abandoned. Thus, groups and street support networks are formed between specific groups, such as migrants, minors not integrated into the social system and "second generations" from North Africa, who are often not considered (if not abandoned) by the institutions. This is our second large study group. Although in this case the traditional description of a "gang" is difficult to locate, we understand that these youth groups of the street (physically, as their main meeting place, but also socially, in the construction of identifications and in the political) materialize the processes of groupality in everyday forms of managing conflict and protection and of positive or beneficial socialization spaces (from job opportunities to building common border identities, through networks of solidarity and mutual support).

Different theoretical perspectives (Brotherton \& Barrios, 2004; Hart \& Brotherton, 2003) that have sought to escape the more traditional and criminal definition of gangs, have often highlighted the format of political resistance of these groups (almost, as if it were a social movement). This has produced, in some cases, the idealization of the groups without considering the existing internal contradictions. In the Catalan case, these large contradictions between discourses and practices have already been highlighted, for example in the Latin King Nation (Romaní et al., 2009). Therefore, in this study, we follow the approach proposed by Brotherton and Barrios (2004) for observing the groups as spaces of agency and as places of subaltern socialization, and consider the youth street groups as spaces in dispute, in constant redefinition and adaptation to a changing and precarious social world. We consider them as a place of production of identifications that generate languages and practices that often move in border spaces and, as such, are specifically mobile, contradictory and places of resistance per se (Queirolo Palmas, 2014). Thus, resistance must be understood not so much as a constant and direct tool, but as a counter-hegemonic adaptation to the place to which they are relegated politically, socially and economically; an adaptation or appropriation that allows the generation of common spaces for agents located in the 
peripheral in all areas of our individualized societies. This political or resistance dimension allows us to find common ground between the "historical" Latin gangs and North African youth street groups. Undoubtedly, one of the most important common points of both "groups" is the construction of a "we" that is connected to the effects and situations of migrating. In the case of young people from North Africa, this is evident in the group construction through the entire migration process (the trip, the waiting, the street, etc.), which solidifies on arrival (the youth centres, on the street again, the repression, etc.).

\subsubsection{Materialization of the study}

The research carried out in Barcelona will focus on studying two informal youth street groups (along with other occasional comparatives) with different formats, which bring together these "differentiated visions" of "gangs" that have prevailed over the decades. First, the research focus will centre on the group Latin Kings and Queens of Barcelona. We will analyse the evolution of this group (placing particular emphasis on the process of legalization/institutional mediation opened in 2000 and its consequences in the present), comparing it with other groups with similar characteristics, such as, for example, the Netas. In line with this first research phase, we will also analyse other Latino youth street groups, such as those formed by young Dominicans or young people from the Caribbean and Central America. Secondly, following the migratory processes that have filled the media recently, we will research youth street groups comprised of young North African migrants. Particular attention will be paid to the case of "Unaccompanied Minors (MENAs)" or EXMENAs and the different groups that are being formed by these young people in the "host" cities. We will study the processes of integration or interrelation, the mediation processes with the institution, and finally, the conflicts that have recently been generated around them, especially by the ultra-right and the public stigma produced by their "appearance". ${ }^{11}$ However, first we must make a small theoretical journey to clarify the axes of field work and research in Barcelona and its surroundings. ${ }^{12}$

Although the context in 2018 is completely different, the mediation process described will serve as a basis for understanding the evolution of youth street groups in Barcelona and extrapolating it to "new subjects" such as young people of North African origin or other young people who are part, at some point in their lives, of these studied groups with similar characteristics. We can relate the groups studied here due to this

\footnotetext{
11 As recent examples: "A man enters a juvenile centre armed with a machete" in Canet de Mar (La Vanguardia, 06/03/2019); "Violent attack on a 'menas' centre in Castelldefels by a group of hooded men" (La Vanguardia, 03/10/2019). In both cases, it is a public event (an aggression, a fight, a sexual assault, among others) that generates a citizen reaction against these young people, who without evidence or a deeper explanation are quickly branded as guilty (in the media and also in political discourses), which causes a citizen mobilization against their presence in the population. Sometimes, as in the case of Canet de Mar, as a consequence of this social rejection, there are also platforms and movements of neighbours against racism, stigma and exclusion.

${ }^{12}$ The constituent study groups are outlined in greater depth and detail in the Research Plan.
} 
interrelation between the spectacular visibility of the Latino gangs, inherited from the previous gangs of young people from internal migratory processes, and from the "gypsy" or other subcultures, and linked to the pass from the "Latin to the Moor" (as it seems). This also allows us to understand how intersectional categories are perceived in the relationship at different levels with these youth street groups. That is, how, depending on age, gender, political position and ethnicity, among others, these groups occupy a specific position in the social and political space that should be understood and analysed as a methodological tool for understanding the place they have in our societies, their own internal dynamics, the ways in which they interact and the different mediation processes that open in/with/between them. This specific position in the social and political, in turn, serves as a mirror that allows us to understand, through a social fact (migration, the constitution of these groups or the treatment they receive), how the State works, how it is structured and which mechanisms it activates against actions that reveal the "limits of the nation state" (Sayad, 1996).

Finally, it is necessary to understand how the migrant category acts as a builder of specific individual and group positions in the social, economic and political structure. Although reference is often made to young migrants, it is necessary to emphasize that a large number of young people who were born here (the so-called "second generations") are also included in this group, which reveals the normative values that fall under the "migrant" label (Delgado, 2010). That is, the association of the young migrant (although they were often born here) with youth street groups normally acts as a production of a totalizing image that is extrapolated to the total group (as also happens with other groups like young people of the working classes, squatters, gypsies, etc.). With this, there is an interested reductionism that builds a kind of subject, the "non-normalized young person", related, due to their skin colour, their aesthetics and their practices, to the unwanted, deviated or marginalized subject idea "per se" (Feixa, 2016). This implementation allows us to understand the institutional dynamics of reaction/action in different time spaces with these youth street groups.

\subsection{Visibility and legalization: an unfinished process with lights and shadows}

In a more structural sense, it is necessary to understand the interrelation between youth street groups and other street groups, with the institution and with other agents and bodies present in the social space, to determine their position in the political space and the location granted to them through public policies, legal "approaches", repression and the image that is generated of them by the media, academia and the public. Continuing with the proposal detailed in the Concept Paper (Feixa, et al., 2019), we need to consider in which global and local contextual frameworks the groups are located to understand the different processes they have experienced in recent years. With this, the mediation and legalization process mentioned above can only be understood by analysing the ways in which the State acts at a given time (right hand, left hand and the 
weight each one has) (Bourdieu, 2912; Queirolo Palmas, 2017; Wacquant, 2009; D. Wacquant, 2008). Thus, depending on the political context, but always in interrelation with the socio-political and global economic dynamics, it is possible to understand the space occupied by these groups and the way in which the State and other agents relate/act with/against them at different historical moments. It is important to understand the ways in which the State (and, with it, the city council, social services, the police and the judicial system) considers these street groups to understand not only the spaces of interrelations that open between them, but also the forms of public visibility that the phenomenon receives. The greatest impact of the aforementioned legalization process was the public visibility of Latin "gangs" and, even more important, the ability of these groups to obtain their own spaces for their own voice to express themselves. This, ultimately, allowed the word gang and Latin King, among others, to be filled with meaning from a two-way position in which the young people also had a voice (compared to the previous position, from where they were only described by the media or institutional political discourses) (Spivak, 1988).

In Barcelona, the last two decades have seen different processes for approaching youth street groups. First, there were processes in which the right hand imposed itself and generated a response of criminalization, police and legal persecution, media stigmatization and social marginalization. Second, there were approaches when the left hand gained weight, opening spaces for mediation, legalization or acquisition of a more relational proposal between groups and institutions (Feixa, Porcio \& Recio, 2006). As Queirolo Palmas argues, "the young people of gangs are treated, and therefore known, by the right hand of the State" (Queirolo Palmas, 2017, p. 124), which can only be understood through the imposition over the last 20 years (even more since the 2007 crisis) of a public policy of increasing the criminal state over the social state (Queirolo Palmas, 2017; L. Wacquant, 2011). Thus, in the face of the general dynamics of repression, stigmatization and marginalization, we see how the space in which the left hand of the State is the protagonist is historically short or sporadic.

At the same time, Feixa (2015a), following Carlos Giménez, shows us three forms of interrelation (continuum) between migration and the societies of arrival: living together, coexistence and hostility. These are associated with a specific positioning of the agents involved in the economic, political and social fields. While in living together and coexistence there are important integration or interaction processes leading to interculturalism or multiculturalism processes, in hostility there are symbols of political discrimination and social stigmatization. This makes it possible to understand what processes occur at each specific local historical moment and introduce these processes into broader political, economic and social frameworks. One of them, undoubtedly the generator of recent hostility frameworks, is the interconnection between the economic crisis (and, above all, the austerity measures to cope with it) and the creation of public enemies (related, although not always as in the case of squatters or anarchists, to migratory processes). This establishes social groups that are not considered to be "good 
citizens" and serves to create close "enemies" (horizontal violence) who take the attention away from the political and economic leaders (Solís Solis, 2017).

Ultimately, this interrelation, beyond intersectional issues such as gender or origin, refers us to an issue highlighted by Wacquant (2009) concerning class struggle and the blaming/criminalization of poverty. It is therefore a stratification of poverty that generates violence or stigmatization that descends to those "next to us or slightly below" (Solís Solís, 2017), generating discrimination frameworks that are reproduced within the neighbourhoods or spaces traditionally occupied by the working classes. That is, in the face of the growing inequality produced by an economic and political model that promotes "accumulation by dispossession" (Harvey, 2004) and the precariousness of work together with its integration as a central space in the control of lives and subjects (Gago, 2015), we observe how different power strategies are developed to place the focus on certain social groups as being guilty. Thus, to avoid the emergence of unitary struggles against the hegemonic political and economic positions that condemn a large part of the population to marginal or precarious situations, the State, institutional politicians and the media (among others) build the figure of the "guilty" on which they can offload the responsibilities of the growing subordination. This guilt usually falls to "abnormal" groups or subjects, ranging from migrants, the poor, young people or, in our case, youth street groups. All of this continues to be an example of what Foucault stated a long time ago and which represents the reproduction of the system no longer through the control over people's lives, but through the distinction between normal (acceptable) subjects and those who are on the side-lines of the "way forward". These non-normal subjects are the objective of strategies and devices that either guide them towards the reproductive normality of current power relations or relegate them to discrimination, marginalization and repression (Foucault, 1995, 1998).

The example of the open mediation process with the Latin Kings in Barcelona serves as the main reference for analysing different phases of intervention (public, academic and through the youth groups involved) in mediation processes, empowerment, but also of resolution of or approaches towards conflictive phases. Thus, the last 15 years in Barcelona allow us to observe different moments in the institutional, media and political relationship with these groups. While at the beginning of 2006 a process of legalization of "gangs" and acceptance of these as youth associations (a temporary space where the left hand of the State was the protagonist) was opened, in a few years, due to the change in the municipal and regional political panorama, this position was abandoned to return to criminalization and prosecution. The effects that each phase or approach has had on the "gangs" themselves, in society and at the media level, clarify the consequences of taking on a more dialogued or resolutive version compared to the persecutor or criminalizing version. As a base point, this process of mediation between institutions and gangs, with the appearance of other actors such as academia or the media, provides a temporarily broad comparable study framework and a historical starting point. Even so, we propose in this research work to reach a broader definition of mediation that also 
focuses on the inter-relational processes between the groups studied, between groups and citizens, between the groups and the media, etc. It is therefore necessary to do deeper into complex, daily and smaller forms of mediation to accommodate all the processes that these young people experience in their day to day (Giménez Romero, 1997). A mediation that, in short, can also be seen as between equals and a generator of spaces of emancipation or struggle against the oppressions they experience.

Along these lines, the different processes of daily mediation are closely related to the violence (physical, symbolic, social, economic and political) that surrounds these youth groups or to which they are condemned. Therefore, the youth street group is a central point of three types of violence that places them in different positions (also within the common space of these groups: the gang space). First, there is the violence from above or, what is the same, the structural violence that these groups receive through the State, its organs and institutions, the symbolic violence of the media and political discourses (for example, stigmatizing news, legal proceedings such as the one cited in the introduction, etc.). Second, there is the violence that is situated on the same scale among equals, which is often produced and reproduced as a result of the structural violence to which they are subjected and, even more, to precariousness and the "moral condemnation" of their lives. This violence would mean both the responses to structural violence (against the police or against citizens) and to the violence reproduced within the group itself (power relations, violence between members, hierarchies, etc.). Third, there is the downward violence. This violence is reproduced between the groups themselves (conflicts between gangs or groups, fights, territorial disputes, etc.) as well as in the strategy of "sliding" the stigma towards other subjects or agents who are in a more precarious situation. This is the violence that materializes in the inhabited public space through the reproduction or enhancement of common stigmas or rejection of certain specific social groups. ${ }^{13}$ In parallel, the groups themselves give meaning to the violence experienced, giving it an ordered or coherent meaning that contrasts with the "vital" chaos and that reveals "other violence" that occurs within the group, between groups or outward from the groups. Therefore, it is necessary to analyse more than one dimension of violence and understand it, among other ways, as another profile of resistance, mediation and the search for respect.

Even so, this process is not the only one that will be reflected in this study. The field work that will be carried out in Barcelona seeks to understand those "mediations" that have occurred in recent decades with "Latino" youth street groups and use this as a methodological and theoretical lever for analysing other youth street groups that, due to their situation in the social, physical and political space, interact in various ways with the other agents present.

\footnotetext{
${ }^{13}$ Solís (2017) explains, through fieldwork in a stigmatized neighbourhood of a middle-sized city in Catalonia, how this downward violence is reproduced among, for example, Spanish migrant working classes of the mid-twentieth century and groups of recent transnational migrations.
} 
Finally, it is necessary to understand the youth street groups themselves as their own spaces for specific informal or formal mediation, as valid agents for dialogue with the institutions or actors present in the political or social space, and also as bridges for reducing the cultural shock (mediating with the institution, helping to find work, offering "social" spaces that are beneficial to young people where institutions do not arrive, etc.) (Feixa et al., 2019). To do this, although the bases for understanding the mediation processes of these groups have already been explained, it will be necessary, through the field work, to observe new processes or dimensions of said mediation that allow us to go deeper into the everyday, non-institutional or "complex institutional" ways of relating. That is, we need to understand the actors present in each type of mediation, the positions that each actor adopts depending on the situation or the group itself, and in what way all of this affects or reaches the different citizen groups.

\subsection{The spaces of Barcelona: the gangs' social, political and physical situation}

Understanding the spaces of the current youth street groups, as the name itself indicates, is based on observing the public space of the street corner and the square, from the centrality of the physical notion of occupation and being. In physical terms, these groups make their existence visible through the appropriation or redefinition of urban spaces as places of belonging in the face of permanent privatization of public space and the struggle for its meanings (Delgado, 2011; Lefebvre, 1991). The distribution of individuals or groups in the physical space cannot be detached from the position they occupy (or to which they are relegated) in other spaces such as political, social or cultural spaces. Understanding the space as a methodological tool for making visible the different positions held by social groups in the different fields of the social structure or as making visible the different capitals that are concentrated there (Bourdieu, 1999) will serve as a way of cataloguing the space of the youth street groups, the actors or agents that participate in or influence this space, and the positions of greater or lesser centrality that each group has in each space (Ballesté, 2018; Solís \& Ballesté, 2018). These differentiated positions will allow us to reconstruct the different spaces that youth street groups occupy and thus understand how the "gang" space itself develops and what types of mediation are possible, accepted or promoted at certain specific times (Feixa, et al., 2019).

At the same time, as discussed in the Concept Paper (Feixa, et al., 2019) and in the Kick Off Meeting Minutes, it is necessary to go beyond the physical framework to try to understand what space the different groups studied occupy in the political and social fields to determine the actual gang space. Although one of the aims of the project is to understand and analyse that border space that the gangs occupy in their position in the physical, social, political and "migratory" space, here we will discuss some ideas that allow the reader to understand the spatial starting point. According to Bourdieu's definition for political space (field) (Bourdieu, 2000; Meichsner, 2007), it is possible to 
observe the differentiated positions between those who hold power and those who are situated in a position of domination. The centrality in the political space depends on the capacity of the agents that participate in it to determine the rules of the game or dictate the shape that this game takes on (Bourdieu, 1982). Those who accumulate power, therefore, decide the limits of what is possible, so that, to a greater or lesser extent, all the dominated groups must follow and accept these rules to have a presence. In Barcelona, youth street groups are usually relegated to a peripheral space of the political because of their low capacity to influence the construction of these rules (or, what would be the same, the inability to decide on their own constitution as valid political agents). The discourses that have been poured on them or have been spilled from institutional policies and from the media as well as the forms and formats that have been adopted by the negotiation/institutional policies for their treatment (with a strong predominance of the right hand of the State) are manifestations of this relegation. Thus, the mediation processes that took place in Barcelona in the mid-2000s meant an approach to a less peripheral space for these groups; however, the more or less rapid suppression of this dialogue and the permanence of the "repressive culture" of the State shows a clear marginalization of these groups as agents capable of having a voice in the field of politics and in the construction of a discourse, of laws or of projects in which they are valid agents.

The spaces of relationship and mediation with the "Latin gangs" attest to the position of distance from the normal and the accepted. Thus, their own existence, their own forms or practices and the occupation they have of public space materializes, in the case of Barcelona, in an almost continuous process of relegation to marginality and condemnation. A condemnation and marginality that, ultimately, evidences the null space granted to these groups to propose or shape the rules of the game (expand the possible frameworks). Only in the process of those years of mediation, could it be seen how these young people became minimally active agents within the political field; an "entrance" in the field that, as we have seen, was quickly suppressed so they once again became peripheralized.

This occupation of the political space is closely related to the processes of invisibility that they suffer or, in the opposite case, the processes of over-dimensioning in which they are defined, are "filled with content" and attributed with characteristics elaborated from outside the groups (normally, from spaces of power such as the State or the media). Thus, while youth street groups are invisible as agents without the ability to speak, be or be present (Spivak, 1988), they are normally defined by agents who are external to them as violent, criminal or unwanted groups (Feixa, 2015b; Feixa, Porcio \& Recio, 2006; Feixa et al., 2010). This political positioning is also related to the position occupied in the social space (Bourdieu, 1985; Solís \& Ballesté, 2018). Thus, taking the "Latin gangs" as an example and, specifically, the case of the Latin Kings in Barcelona (although the process can clearly be extrapolated to other groups), it can be seen that the temporary space in which the members of that group were recognized as valid 
interlocutors was extremely reduced and, on the contrary, the phases of invisibility, stigmatization, repression and marginalization are those that define the group as a kind of "public enemy" for which there is no space for recognition, dialogue or intermediation (Queirolo Palmas, 2017). The appearance of spectacular news stories, images in the media of "gang members" arrested by large police raids, the holding of macro-trials and the political construction of discourses about them in which they are situated as authentic local and global mafias, serve to position these groups in a specific place in the social space (also peripheral). This peripheralization of these groups helps us understand the vision that the "citizen" has of them. This vision is branded with the image they are given and that penetrates the image that is generated about them in most of society: that is, far from the idea of the good citizen (Ballesté, 2018; Delgado, 2016). The sensationalism with which these groups are treated by the media plays a fundamental role in this. The media, as we said, generally make them invisible and only show them through criminal activities or criminal proceedings, thereby generating a biased and simplistic image about the meaning, practices and formats of these groups. ${ }^{14}$

Understanding that the social space is the space where the different social relationships and the intersectional dominations that arise from them are present, and also the place where the rest of the spaces or fields interact (Bourdieu, 1985), the peripheral relegations previously described are translated into the vision that the "civil society" has of these groups, generating, as a reaction, an increase in stigmatization. There is thus a social differentiation between what is accepted and what is not, the good and the bad, what is respectable and what must be corrected or, as Foucault would say, the normal and the non-normal (Ballesté, 2018; Ballesté \& Feixa, 2019; Foucault, 2009). At the same time, it is necessary to emphasize that this positioning, already peripheral due to the condition of being a youth street group, is not the same for each of the groups. These differentiated positions are affected by the intersectional conditions (social class, age, gender, ethnicity, but also political positioning, forms of action, etc.) that place each group in different degrees of oppression or marginalization, and it is possible to generate certain internal differentiations between each of the groups studied here.

In short, the three spaces described can be understood to be relational to each other. Thus, the greater the peripheralization in the social space, the greater it is in the political space (and vice versa), which also causes the occupation of peripheral physical spaces (Ballesté, 2018). At the same time, it is necessary to emphasize that this peripheralization of the physical is not a matter exclusively of distance from the urban centre, but of forms of occupation of space that reduce or make the group's presence invisible. For example, when these groups start to occupy central spaces of Barcelona, they normally suffer processes of exclusion or expulsion from different agents: police harassment due to the presence of neighbourhood stigma, or rejection and confrontation (Delgado, 2008).

\footnotetext{
${ }^{14}$ Note the similarity with how other "groups" are treated in their public construction, such as anarchists, young political activists (Ballesté, 2018) or gypsies (San Román, 1984).
} 
Finally, the border space is constructed as a theoretical and analytical tool for bringing together the other spaces mentioned so far. Taking from decolonial theories (Mignolo, 2015), the border space is positioned as an interstitial place that locates the agents studied here in the midst of different social, political and economic processes. That is, the inability to speak, be, be present or construct themselves as valid and existing subjects, leads to the construction of spaces between the places of origin and destination; between modernity and subalternity; between marginalization and physical appearance. In the midst of these dichotomies, the young people studied here are constantly looking for spaces of emancipation in each of the social places to construct a "confrontation" to stigma through the strengthening of respect (Bourgois, 2010). It is therefore a question of spaces in dispute and re-signification in which these contradictions between the "normal" and the "abnormal", between the "accepted" and the "rejected" or, in short, between "modernity" and " subalternity" take shape.

In the case of Barcelona, all the spaces mentioned here (also that of the youth street groups themselves) are dynamic and, depending on the relationship with the other agents that make them up, they cause a movement of these groups from the centre to the periphery (or vice versa). This helps us understand what forms of mediation and treatment they receive from these different agents. ${ }^{15}$ Thus, considering the Latin Kings' legalization process as a point of reference, we can see how it meant a change in the place occupied by the group in each space. The reduction of the criminal version caused a less peripheral positioning in the political space, represented in the ability to be accepted, heard and defined by themselves, which led to an increase in public social policies. All this, transferred to the social space meant, although momentarily, a public appearance of a different version of gangs, defined by themselves, which also affected the vision that the citizens had of them. In the gang space we see how at that time the agents that interacted in it (all those described above, but also other gangs) moved to position the Latin Kings in a different, more central position compared to the other gangs. Finally, in the physical space, this also materialized with the public appearance of the group, in activities that it carried out in the public space (parks, squares, etc.), as in the use of institutional spaces for its meetings and activities.

Currently we find a re-concealment of the phenomenon of Latin gangs. Their disappearance from the media along with a certain reduction in academic attention has occurred in parallel with the return of a repressive and criminalizing policy. In the case of young Latin American people from street groups we find specific physical spaces of appearance that are usually located in peripheral regions of the Metropolitan Area of Barcelona (the L'Hospitalet or Cornellà neighbourhoods, for example) along with a certain inactivity in the physical space. ${ }^{16}$ However, the opposite is true with youth street

15 This peripheralization, although normally imposed by political and economic powers, can also be organized and used by the groups and agents themselves as a form of resistance that, by making them invisible, allows them to move away from media or political centres and, consequently, from possible repressions, stigmatization and/or violence.

16 Going from a large presence in certain urban spaces (squares and subway stops where groups such as 
groups from North Africa. Their recent mass entry into the media, following lines similar to those used in the early 2000s for Latin gangs, has led to an increase in stigma and the peripheralization of these young people both in the social and political spaces. Situations such as those experienced in Calella de Palafrugell or Canet de Mar (previously cited as a footnote) corroborate this idea of public rejection of these groups that, as a direct consequence, also generate supportive responses to combat this rejection. In short, we find ourselves in a situation where the young people of these groups are not the ones who speak or self-represent themselves (they do not make the rules of the game), but rather it is the public together with the media who position these groups in a specific peripheral space of the social and political. In physical terms, although their presence in the city centres is high (in neighbourhoods such as El Born or El Raval, for example), they continue to maintain a kind of concealment or criminalization. Both their presence in specific stigmatized places (Forat de la Vergonya or Plaça Sant Pau del Camp, among others) and the high police persecution or presence place these groups of young North Africans in "places" that are not visible, stigmatized or peripheral inside the city centre.

\subsection{Conclusions}

The purpose of the Background Paper about Barcelona is to establish a theoretical, methodological and historical basis for youth street groups in the city. The document reviews the last two decades to shed light on different dimensions of the phenomenon. As main agents in the cataloguing of these groups and in public action on them, looking at the production of images by the media, academia and the different legal apparatus of the State allows us to understand how these groups have evolved and determine comparative frameworks between "Latin gangs" and youth groups of young North Africans. We can therefore understand what position each group has occupied at a certain time, how that position has evolved based on the other actors and agents, and finally, what position the State and its institutions have occupied in relation to the groups.

Previous projects, such as JOVLAT, among others, make it possible to place the research within a broader framework and collect the sediments from these studies. The main challenges of the study in Barcelona will be to continue this previous research focused on Latin American youth groups as well as open a new research door for applying these studies to groups of young North Africans. The case of Barcelona, because of its centrality in the project itself and because it is the Core Case of the Southern European region, will allow us to establish the link between local studies in North Africa and those in the Americas. As a "meeting" space, in Barcelona, as

the Latin Kings had their chapters), we observe through initial fieldwork how their physical disappearance is palpable. It is not a disappearance of the gangs themselves (following other studies or as the media themselves report), but a certain concealment of their permanence in the physical as a place of articulation. Along these lines, the project itself must observe what its own evolution has been, the impact that the police and judicial persecution has had over the years and the new uses of the space they employ. 
described throughout this work, a comparative and relational study will be carried out between the different groups mentioned. This will make it possible to expand the often closed vision of youth street groups and broaden the idea of differential mediation between groups, with institutions and with other agents.

As a specific case study, in Barcelona it is planned to define the different spaces where street groups are positioned. Understanding these different locations will allow us to construct the gang space itself (the border space) from which to understand how these groups are treated, who interacts/relates with them, how the State acts and what vision citizens have of each group. At the same time, in conjunction with the young people's own subjectivities, we can establish new definitions for these groups, full of practices, symbols and languages that allow us to understand them beyond the external representations that are employed. All this collected material must, ultimately, allow us to open the idea of "youth gangs" to new definitions, integrating other subjects who, present on the street, also form their own networks and groups. This should leave a space for dialogue with the young people themselves and with the agents that interact with them (stakeholders), which will make it possible to define and reconceptualize new dimensions of mediation and conflict. From these dimensions we will learn about the role and forms of the groups themselves, about the positive and negative forms of relationship between groups and with institutions, and also about the stigmatization or marginalization processes suffered by the young migrants currently in Barcelona. Returning to Foucault, it is a question of recognizing the ways in which these subjects are considered "non-normal" and observing the different processes, conflicts and differentiated oppressions that fall on them according to different variables such as social class, gender, origin, but also their practices, symbols, and the occupation of the physical space. Finally, by understanding the social position to which they are relegated and how this relegation implies differentiated agencies, we can shed light on the forms of control, repression, persecution, stigmatization, dialogue, legalization and mediation that appear over time, and, in turn, how the young people resist, construct common spaces, fill them with practices, languages and meanings and face the social positions they occupy through agency processes. 


\subsection{References}

Ballesté, E. (2018). El poder en los movimientos. Jóvenes activistas en el post-15M: estudio de caso sobre la Marea Blanca, la PAH y los Colectivos Anticapitalistas en Lleida. University of Lleida.

Ballesté, E., \& Feixa Pàmpols, C. (2019). El Sur político del Norte global: repensando la participación política juvenil en España. Nómadas, (50), 175-193. https://doi.org/10.30578/nomadas.n50a11

Bourdieu, P. (1982). La représentation politique. Éléments pour une théorie du champ politique. Actes de La Recherche En Sciences Sociales, 36-37, 3-24.

Bourdieu, P. (1985). The Social Space and the Genesis of Groups. Theory and Society, 14(6), 723-744.

Bourdieu, P. (2000). Sobre el Campo Político. Lyon, Presses Universitaires De Con, Conversacion Fritsch, Philippe.

Bourdieu, P. (dir.) (1999). La miseria del mundo. Madrid: Akal Ediciones.

Bourdieu, P. (dir.) (2912). Sur l'État: Cours au Collège de France, 1989-1992. París: Seuil.

Bourgois, P. I. (2010). En busca de respeto: vendiendo crack en Harlem. Buenos Aires: Siglo XXI Editores.

Brenner, N., Peck, J., \& Theodore, N. (2010). After neoliberalization? Globalizations, 7(3), 327-345. https://doi.org/10.1080/14747731003669669

Brotherton, D. C., \& Barrios, L. (2004). The Almighty Latin King and Queen Nation. Street Politics and the Transformation of a New York City Gang. New York: Columbia University Press.

Canelles, N. (2006). La construcción social de las bandas latinas en Cataluña. UAB, Bellaterra.

Delgado, M. (2008). Marca y territorio. Sobre la hipervisibilidad de los inmigrantes en espacios públicos urbanos. In J. García Roca \& J. Lacomba (Eds.), La inmigración en la sociedad española (pp. 351375). Barcelona: Edicions Bellaterra.

Delgado, M. (2010). Gli studi sulle migrazioni in Spagna. Un bilancio e alcune riflessioni. In S. Palidda (Ed.), Il discorso ambiguo sulle migrazioni (pp. 21-38). Messina: Mesogea.

Delgado, M. (2011). El Espacio público como ideología. Madrid: Los Libros de la Catarata.

Delgado, M. (2016). Ciudadanismo: la reforma ética y estética del capitalismo. Madrid : Catarata.

Feixa, C. (1998). De jóvenes, bandas y tribus. Barcelona: Ariel.

Feixa, C. (2015a). Antropología, conflicto y migración en contextos locales. In C. Giménez \& P. Gómez (Eds.), Análisis, prevención y transformación de conflictos en contextos de inmigración (pp. 159179). Madrid: UAM-ediciones.

Feixa, C. (2015b). Bandas latinas en Cataluña (y más allá). In M. Ledesma (Ed.), Justicia, derecho y sociedad. Debates interdisciplinarios para el análisis de la justicia en Perú. Lima: Centro de Estudios Constitucionales, Tribunal Constitucional de Perú. 
Feixa, C. (2016). Antropología Criminal. Delincuentes y marginados. Barcelona: Editorial UOC.

Feixa, C., Cerbino, M., Recio, C., Porzio, L., \& Canelles, N. (2006). De las "bandas" a las “organizaciones juveniles." In C. Feixa, L. Porzio, \& C. Recio (Eds.), Jóvenes latinos en Barcelona. Espacio público y cultura urbana (pp. 89-142). Barcelona: Anthropos Editorial.

Feixa, C., \& Porzio, L. (2006). Jóvenes "latinos" en Barcelona: identidades culturales. In C. Feixa, L. Porzio, \& C. Recio (Eds.), Jóvenes latinos en Barcelona. Espacio público y cultura urbana (pp. 5975). Barcelona: Anthropos Editorial.

Feixa, C., Porzio, L., \& Recio, C. (Eds.). (2006). Jóvenes “latinos” en Barcelona: Espacio público y cultura urbana. Barcelona: Anthropos Editorial.

Feixa, C., Romaní, O., Hakim, N., Latorre, A., Porzio, L., \& Rodríguez, A. (2010). Spain Irregular Lives in the Southern Rim of Europe. In K. Fangen, K. Fossan, \& F. A. Mohn (Eds.), Inclusion and exclusion of young adult migrants in Europe. Barriers and bridges (pp. 17-50). London: Ashgate.

Feixa, C., Sánchez García, J., Ballesté, E., Cano-Hila, A. B., Masanet, M.-J., Mecca, M., \& Oliver, M. (2019). The (Trans) Gang: Notes and Queries on Youth Street Group Research (TRANSGANG Working Papers No. 2-1). Barcelona.

Feixa, C., Scandroglio, B., López Martínez, J. S., \& Ferrándiz, F. (2011). ¿Organización cultural o asociación ilícita? Reyes y reinas latinos entre Madrid y Barcelona. Papers: Revista de Sociología, 96(1), 145-163. https://doi.org/10.5565/rev/papers/v96n1.165

Flesher Fominaya, C. (2015). Redefining the Crisis/Redefining Democracy: Mobilising for the Right to Housing in Spain's PAH Movement. South European Society and Politics, 20(4), 465-485. https://doi.org/10.1080/13608746.2015.1058216

Fontana, J. (2011). Por el bien del imperio : una historia del mundo desde 1945. Barcelona: Pasado \& Presente.

Foucault, M. (1990). The History of Sexuality Volume 1: An Introduction. European Heart Journal. New York: Pantheon Books. https://doi.org/10.1017/CCOL9780521865906.003

Foucault, M. (1995). Discipline \& Punish: The Brith of the Prison. New York: Penguin Books. https://doi.org/10.1017/CBO9781107415324.004

Foucault, M. (1998). The history of sexuality. London: Penguin.

Foucault, M. (2009). Vigilar y castigar. Nacimiento de la prisión. Educació social. Revista d'intervenció sòcioeducativa. México, D.F.: Siglo Veintiuno. https://doi.org/10.1017/CBO9781107415324.004

Gago, V. (2015). La razon neoliberal. Economías barrocas y pragmática popular. Madrid: Traficantes de Sueños.

Garavito Tarrifa, S., Sánchez Camacho, A. M., \& Carbarcas Bru, Y. (2018). Menores inmigrantes no acompañados, las orillas de la vulnerabilidad, estatus de irregulares y su tratamiento al llegar a España. Summa Iuris, 6(2), 285-296. https://doi.org/10.21501/23394536.3178

Giménez Romero, C. (1997). La naturaleza de la Mediación Intercultural. Migraciones. Publicación Del Instituto Universitario de Estudios Sobre Migraciones, (2), 125-159. 
Hart, S., \& Brotherton, D. C. (2003). Snapshots of a Movement: The New York Latin Kings and Queens 1996-99. In L. Kontos, D. C. Brotherton, \& L. Barrios (Eds.), Gangs and Society: Alternative Perspectives (pp. 314-336). New York: Columbia University Press.

Harvey, D. (2004). The "New" imperialism: accumulation by dispossession. Socialist Register, 40.

Harvey, D. (2005). A Brief History of Neoliberalism. New York: Oxford University Press. https://doi.org/10.1177/002234330704400117

Harvey, D. (2007). Breve historia del Neoliberalismo. Madrid: Akal.

Horvat, S., Zizek, S., \& Murillo, E. (2014). El Sur pide la palabra: el futuro de una Europa en crisis. Barcelona: Los Libros del Lince.

Lefebvre, H. (1991). The Production of Space. Cambridge: Blackwell Publishing.

Meichsner, S. (2007). El campo político en la perspectiva teórica de Bourdieu. Critique, 2, 1-22.

Mignolo, W. (2015). Habitar la frontera. Sentir y pensar la descolonialidad (Antología, 1999-2014). Barcelona: CIDOB.

Queirolo Palmas, L. (2014). El problema de las bandas en España como objeto de producción académica y de activismo etnográfico. Papers: Revista de Sociología, 99(2), 261-284. https://doi.org/10.5565/rev/papers.595

Queirolo Palmas, L. (2017). ¿Cómo se construye un enemigo público? Las “bandas latinas.” Madrid: Traficantes de Sueños.

Quiroga, V. (2003). Els petits harraga. Menors immigrants irregulars no acompanyats d'origen marroquí a Catalunya. Universitat Rovira i Virgili. Universitat Rovira i Virgili.

Romaní, O. (1982). Droga i subcultura. Una història cultural del haix a Barcelona. Universitat de Barcelona.

Romaní, O., Porzio, L., Rodríguez, A., Canelles, N., Giliberti, L., \& Maza, G. (2009). De nacions, reialeses i marginacions. L’organització dels "reyes y reinas latinos" de Catalunya, un estudi de cas. Recerca i Immigració 2. Generalitat de Catalunya, (February).

San Román, T. (1984). Gitanos en Madrid y Barcelona: ensayos sobre aculturación y etnicidad. Barcelona: Universitat Autònoma de Barcelona.

San Román, T. (1997). La diferencia inquietante: viejas y nuevas estrategias culturales de los gitanos. Madrid: Siglo XXI.

Sánchez García, José, Ballesté Isern, E., \& Feixa Pàmpols, C. (2018). ¿Qué fue de la primavera indignada? Movimientos sociales, política y juventud en tres continentes. Lleida: Editorial Milenio.

Sayad, A. (1996). Immigration et le pensée d'État. Reflexion sur la “double peine.” In VV.AA. (Ed.), Immigrant Delinquency. Bruselas: Comisión Europea.

Scandroglio, B. (2009). Jóvenes, grupos y violencia. De las tribus urbanas a las bandas latinas. Barcelona: Icaria. 
Solís, J. M., \& Ballesté Isern, E. (2018). Acción y reacción: campo político, espacio social y dinámicas de los grupos reivindicativos. In J. Sanchéz, E. Ballesté, \& C. Feixa (Eds.), ¿Qué fue de la primavera indignada? Movimientos sociales, politica y juventud en tres continentes. Lleida: Milenio.

Solís Solís, J. M. (2017). La Mariola desde dentro y desde fuera: efectos internos del estigma territorial (Espai temps). Lleida: Universitat de Lleida.

Spivak, G. Ch. (1988). Can the subaltern speak.pdf. Chakravorty, G. (1988). Can the Subaltern Speak. Marxism and the Interpretation of Culture. https://doi.org/10.4135/9781446212233.n7

Wacquant, L. (2009). Punishing the Poor: The Neoliberal Government of Social Insecurity. Duke: Duke University Press.

Wacquant, L. (2011). Forjando el Estado Neoliberal. Workfare, Prisonfare e Inseguridad Social. Prohistoria, 16. https://doi.org/10.1007/978-3-658-18201-4 4

Wacquant, L. J. D. (2008). Urban outcasts: a comparative sociology of advanced marginality. New York: Polity Press. 


\title{
3 (Trans)Gangs in Madrid. Gang policies \& gang practices: experiences of conflict and mediation
}

\author{
María Oliver and Katia Núñez
}

\subsection{Introduction}

This Background Paper has been created with the intention of providing the guidelines for the research with youth street groups that the TRANSGANG project is carrying out in three interconnected scenarios: North of Africa, Europe and the Americas. Unlike previous projects regarding youth street groups or gangs, the TRANSGANG project is interested in researching experiences of conflict and mediation in which these groups are active agents of those experiences of mediation with other groups, within the groups themselves, with social stakeholders and/ or administrations, etc.

First of all, it is necessary to define the object of research, youth street groups, or gangs, as they majority of them are usually referred to by media and society in general. From the academic point of view these groups have mainly been studied using the North American street gang as an archetype exported to other parts of the world, not only through the migratory movements (whether voluntary or forceful) but also through the representation of them that the cinema and TV industries made during the second half of the last century. This view, apart from the limitations it may have regarding diversity of groups and models, has tended to be quite sensationalistic, focusing on external aspects such as the outfits, symbolism and rituals and paying less attention to the subjacent reasons for them to exist, such as inequality, lack of opportunities, discrimination and, in general, absence of social justice.

Following the guidelines of the project, we understand the term gang to imply, in general terms, a negative connotation, and so we prefer the use of a more neutral one, youth street groups, that will be the one used to refer to the groups we are working with. We also understand, however, that the first term is the most commonly used, even among members of these groups themselves, so its use will also be accepted. However, it is necessary to point out once again that the term is recovered from the North American tradition, and that in the TRANSGANG areas we can find at least as many different terms as cities: pandilla, in Spain and Cuba, for example, having a negative connotation in Cuba, but not in Spain before the arrival of Latino youth street groups; mara in El Salvador; tcharmils in Morocco or baltagyya in Eygipt, for example (Feixa et al., 2019). In order to have a functional and updated definition that can be applied to all the areas and groups implicated in the research, the TRANSGANG research team has updated Thrasher's (1927) classical definition of gang (the additions are in bold):

A (transnational) gang is an interstitial group originally formed spontaneously and later integrated through conflict. It is characterized by the following type of behavior: face-toface (and online) encounters, fights (and fun), movements through space as if it was a unit 
(and search for intimate spaces), conflicts (and alliances) with similar groups and planning. The result of this collective behavior is the development of a tradition, a nonreflexive internal structure (and the establishment of rules to regulate exchanges with other gangs and institutions), esprit-de-corps, moral solidarity, group consciousness and an identity link territorial (already in their homeland, in their new land or in cyberspace) (Feixa et al., 2019).

This redefinition takes into account all previous studies on gangs, from the Birmingham and Chicago Schools and their focus on illegal activities and the most negative social aspects of these groups, to critical perspectives such as the Latin American gang studies, with more emphasis on the social and agency features of youth street groups.

With this in mind, it is important to outline the position of Madrid within the investigation: Madrid, Spain, is one of the European cities that have been chosen as "contrast" cases in the TRANSGANG framework. This framework has split the cities of study in two groups: Core Cases (cities in which there have been policies of good practices to deal with youth street groups) and Contrast Cases (cities in which other kind of policies have been applied) (ibid.).

As we will develop in the section devoted to the legal framework, up to the day the policies of the Autonomous Community of Madrid have been those of Mano dura, and even Supermano dura inspired in the gang policies exported from the USA, first to Latin America (Wolf, 2017) and then to Europe. Although during the last four years there has been a slight tendency to open more spaces for mediation with youth street groups in the city due to the fact that the city council opted for integration and left hand policies, this tendency could easily be reverted by the change in government that the last elections of May 2019 has brought about, and which has implied the entrance of a far-right party into the government of the city of Madrid. The party is known for its discourse against migration and its open criminalization of migrants, and therefore it's expected that they will demand Mano dura policies towards gang members.

Madrid is, together with Barcelona, one of the cities in which (trans)gangs first appeared in Spain, and, with almost all probability, in Europe. Since the last third of the $21^{\text {st }}$ century and until the beginning of the global crisis in 2008 , the city has been recipient of migrations from both South America and North Africa. It's estimated that in the Community of Madrid there are around 825.000 persons from migrant origins, that is about $12 \%$ of the total population, but taking into account that this figure is based on the people registered in the census; the total amount with people both with nationalized status and in irregular situation is higher ${ }^{17}$. Madrid has always registered higher immigration levels than the media of Spain:

\footnotetext{
${ }^{17}$ Source: http://www.madrid.org/es/transparencia/informacion-institucional/planes-programas/planinmigracion-comunidad-madrid-2019-2021
} 
Figure 5: Immigrant population in Madrid and Spain. Evolution (2000-2018).

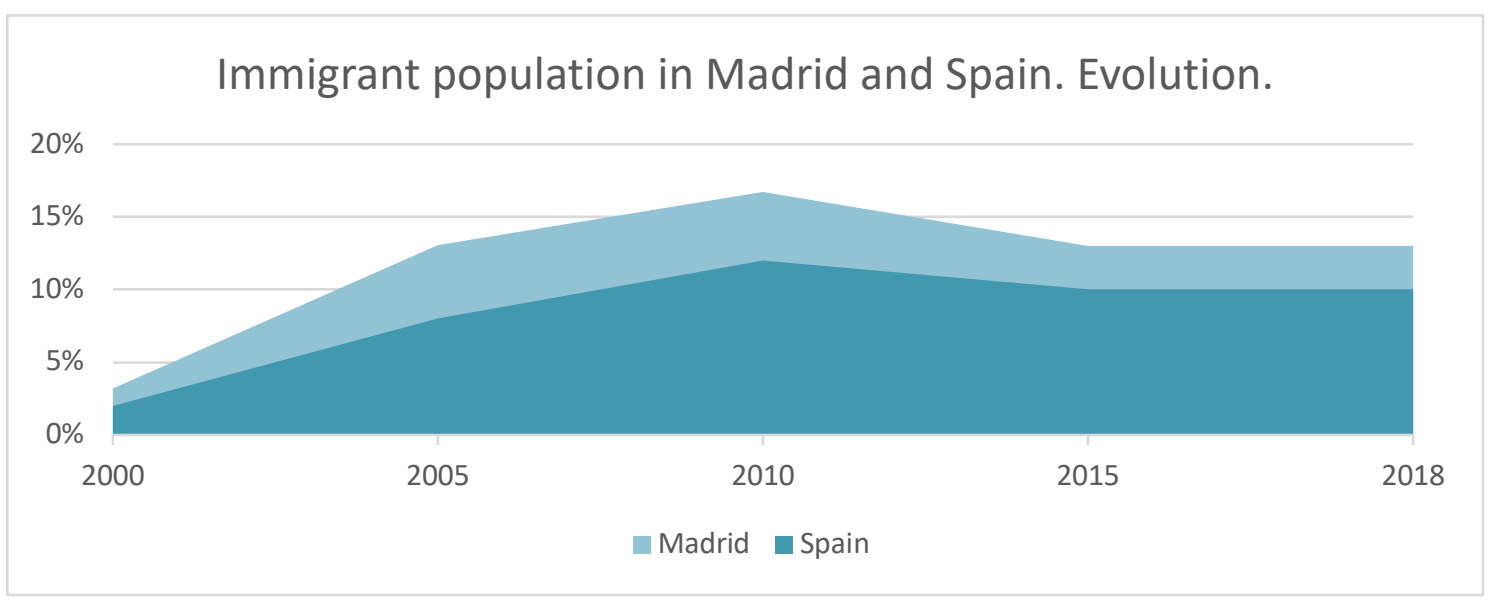

Source:http://www.madrid.org/es/transparencia/informacion-institucional/planes-programas/plan-inmigracioncomunidad-madrid-2019-2021

Migratory processes in the $20^{\text {th }}$ and beginning of the $21^{\text {st }}$ century are a direct consequence of the neoliberal processes that have been implemented since the second half of the $20^{\text {th }}$ century. With the decentralization of production and the expansion of the global market, differences between "developed" and "developing" countries grew, and the second group became progressively more dependent on the first; the mobilization of people in search of a dignified future is a direct cause of this change in global conditions (Castells, 1997). The issue of migration is key in TRANSGANG project, because almost all the members of youth street groups we will be researching have a relation with it, whether it is by personal experience or by way of a close relationship; either they have migrated themselves (or their families) or they share an important part of their lives with someone who belong to the first group.

There is an approximation offered by the government of the Community of Madrid, in its Migration Plan 2019-2021, of the percentage of migrant population for economic reasons based on the origin, differentiating migration from developing countries from that of developed ones; thus, the economic migrant population is considered to be the $61 \%$ of total migration, with origin in Latin America (23,75\%), Romania and Bulgaria $(16,88 \%)$, Morocco $(16,30 \%)$ and China (4,75\%). The rest of migration, broadly speaking, comes from United Kingdom (5,11\%), Italy (4,37\%), Germany (2,35\%) and France $(2,09 \%)$. Regarding age, the average age of the migrant population in Madrid is 34,5 years old. Young migrant population, between 15 and 24, represents $14,83 \%$ of the total (Community of Madrid, 2018). Of these, and in behalf of our research, it's an important question to know the educational level and/or current status of this young migrant population, because, as quoted by Queirolo Palmas, "the ones who are now in the streets have been excluded from everything (school, job...)" (Queirolo Palmas, 2017, p. 179) and "for the subjects expelled from the educational system, the book and 
written text are the code of a control machine" that "classifies them as cultural handicaps" (ibid. p. 106).

Figure 6: Percentage of immigrant population per educational level (2018)

\section{Percentage of immigrant population per educational level}
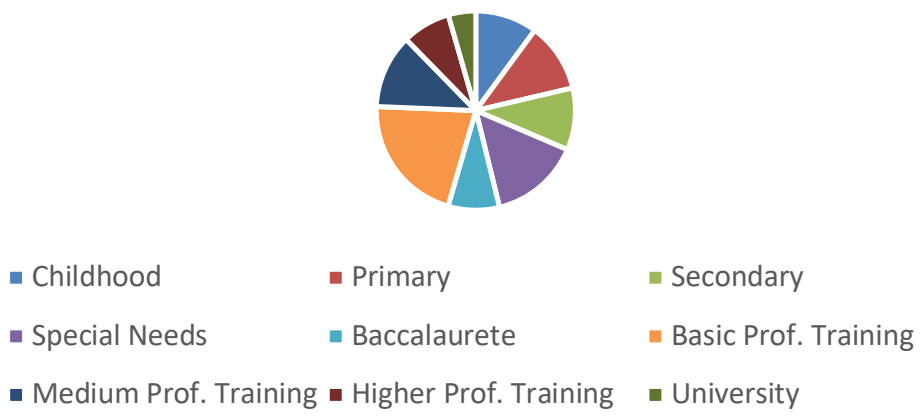

Source: http://www.madrid.org/es/transparencia/informacion-institucional/planes-programas/plan-inmigracioncomunidad-madrid-2019-2021

The focus of attention of this Background Paper, when referring to migrants or young people from migrant descend, will be on persons who have migrated in search of better economic and social conditions for themselves and/or their families. With these figures in mind, it's easy to understand that the city of Madrid is a multicultural one. In the last four years some shy attempts have been made from the city council to achieve a higher level of interculturalism, but public policies implemented are still on course and it will take some time to assess the results, which in turn will need certain perseverance and continuity to settle. There is also the possibility that with the change of government both in the city and in the Community of Madrid these policies are ceased or even reverted, so this research will closely observe and analyse this factor.

As it happens in other cities of Europe, migrant population in Madrid settled on its arrival in working class neighbourhoods, where, in general terms, the last global crisis has impacted the most. It is in those neighbourhoods, therefore, where we find some of the most economically depressed population, both "natives" and migrants; we need to bear in mind that said migrant population arrived in Spain in a moment of economic growth, to take over unqualified jobs, such as those on the construction sector for men and house-keeping and cares for women. When the crisis broke, in 2008, this migrant population was among the one who first lost its job, "during the crisis period, foreign people are registering a highest probability of losing their job" (Medina et al., 2010, p. 47), and, while before the crisis nothing seemed to indicate that there were race bias in dismissals, "once the economic crisis started, a greatest impact on foreigners is observed" (ibid. p. 47); "their unemployment rate rose from the $17 \%$ registered in 2008 until $29 \%$ registered in the third trimester of 2009 , and this even though in that trimester 
a reduction in the non-native actives was registered" (Mahía \& Arce, 2010). It became common to see more people in the streets as unemployment grew, and among that people, an important number of migrants, with male predominance, gathered in streets, parks and squares, which, for a society used to spending leisure time in private places like cafés or malls, was, at the very least, striking, and, in occasions, even suspicious. They came to share that space with its "natural" users, youngsters, both from native and migrant origins. That "appropriation" of the public space contributed to its consideration as a disputed space, even though it had not been occupied in the same way by natives before. Young migrant people had the same labour aspirations as their older generation:

\footnotetext{
The project of young immigrant subjects has as a priority the insertion in the labour market, as a matter of necessity. The availability for this transition is also linked to the family migratory project: the adults migrated in search of work, and the young subjects share and carry out the same wattempt (Marin-Bevilaqua et al., 2013, p. 512).
}

However, to the crisis factor another must be added in young migrants' quest for integration in the labour market: as they arrived in Spain by means of family reunification, they obtained the legal document that allowed them to live and study in Spain until they come off age, but once they turned 18, if they had not obtain full citizenship through their parents' legal situation, they needed to obtain a new permission that also grants them the permission to work, as only a small percentage of young migrants considered continuing their studies further than the compulsory stage. The combination of being migrant, not specialized, and being in an irregular legal situation hindered their possibilities of accessing the labour market with any guaranty of success: "The young immigrant, in their condition of undocumented and non-citizen, becomes a vulnerable worker, both due to the deficient professional qualification and the incorporation into a labour market marked by high rates of unemployment, precarization and informality" (ibid., p. 511).

It's in that situation of crisis, dispute of public spaces and sharing neighbourhoods, where we can find traces of horizontal violence, defined by Butler (2009) as stigmatization, exerted "by peripheral groups towards other peripheral groups that, normally, find themselves in an equal or worse situation (Auyero, Bourgeois, \& Scheper-Hughes, 2015; Wacquant, 2008). This is clearly shown in those migrationreceiving societies." (Feixa et al., 2019, p. 16) This strategy allows for a "reorganization" of the social structure in which the "native" working class can feel as if it isn't the last link of the chain: "the working class, as a strategy for getting rid of stigma and repositioning itself in society, reproduces marginal roles towards those who are a little worse off" (Bourdieu, 1977; Goffman, 1986, quoted in Feixa et al., 2019, p.16).

The oldest youth street groups members around the years 2008-2010 suffered the consequences of the crisis themselves, as they were part of that active migrant population more susceptible to lose their jobs; as for the youngest, many found 
themselves in the situation of having very recently arrived in a new country almost at the same time as the crisis broke, with the consequent familiar stress that situation of uncertainty about the future provoked, on top of all the issues implied by migration caused by familiar reunification in teenagers "a need for renegotiation in family, gender and generation relationships. The clash of reunion involves factors such as the time of separation, the experiences of both the mother and the children during the separation, and the expectations created" (Canelles, 2006, p. 78).

We find our subjects of study thus particularly vulnerable, occupying the margins of a society in which, after the crisis, fragmentation and inequalities have grown exponentially. As a consequence of all these circumstances, - lack of formal occupation, use of public spaces, different types of grouping - the idea that immigration and poverty are triggers for the access of young people to these youth street groups considered as dangerous promoted, and still does, the stigmatization of migrants and/or of those who are in a situation of poverty and social exclusion. If this unilateral vision of the problem is fostered, the rejection and exclusion of young migrants who have settled in these neighbourhoods will continue to be reproduced and, at the same time, access to crime circles will be enhanced, circles which do not have to do with the idea of belonging to the youth street groups that occupy our research.

Both issues referred above, migration and stigmatization, are key in the construction of identities of young people, both inside or outside a youth street group, and in many cases it's in this construction of their identities where we find the answer for the membership to the groups. In the TRANSGANG project we understand identities as a fluid and changing concept, rather than a fixed one; social conditions, as the two mentioned above (but not exclusively), shape identities, together with other factors as age, gender or ethnicity, that need always to be taken into account in our analysis of the data collected (Feixa et al., 2019).

Spaces, as mentioned before, are also carefully considered in this research, not only physical spaces, but also social and political ones are given special consideration. It's clear that members of youth street groups inhabit in the borders of these spaces (Mignolo, 2003): the neighbourhoods they live in, even when occupying a near-thecentre physical space in the geography of the city, can be considered as border spaces from the socioeconomic point of view. Socially, members of youth street groups are, in most of the occasions, in peripheral situations, and when they are put on the spotlight is usually by the media and because of a negative event. In Cómo se Construye un Enemigo Público. Las Bandas Latinas, by Luca Queirolo Palmas (2017), the author reflects about how youth streets groups are put in or out the media spotlight depending on "stages, political coalitions, the characteristics of each media and their editorial line" (p. 79). Politically, they are situated in the margins of the political space, seldom having any active role in the political life of their city, and often used as a scapegoat by political parties depending on the interest or yield they can obtain by applying, or promising, left or right hand (Bourdieu interviewed by Droit \& Ferenczi, 1992) 
measures regarding gangs. These border spaces, consequently, also have the consideration of disputed spaces (Delgado, 2010): in border physical spaces is where youth street groups spend most of their leisure time, where they can make themselves more visible and have a kind of presence and agency. The dispute of these spaces can be held with other groups, but also with social agents, as neighbours, associations, administrations, or the police.

Inhabiting the borders leads to a kind of thinking labelled as "border thinking", a way of understanding the world, knowledge and dynamics from a decolonial point of view, deconstructing the idea that the only valid knowledge about the world is the one produced by Western societies. The idea of "otherness", as Mignolo (2012) explains,

\begin{abstract}
doesn't exist ontologically. It is a discursive invention. Who invented "the other" if not the same in the process of constructing the same? Such an invention is the outcome of an enunciation. The enunciation doesn't name an existing entity, but invents it. The enunciation needs an enunciator (agent), an institution (not everyone can invent the anthropos), but to impose the anthropos as "the other" in the collective imaginary, it is necessary to be in a position of managing the discourse (verbal, visual, audial) by which you name and describe an entity (the anthropos or "the other") and succeed in making believe that it exists (p. 4).
\end{abstract}

Thinking from the borders and acknowledging the voice and agency of those who actually live on the borders, is a cornerstone of this project.

This Background Paper is divided in seven sections: after the introduction follows a State of the Art in gangs research in Madrid, both in order to show the progression of the research in the area and to set up the current research; then we will focus on Empowerment, conflict and mediation, the main elements of interest in our research, and in which different experiences of success are analysed, as well as the barriers that have impeded those experiences; then, in the fourth section, devoted to (trans)gangs in Madrid, we refer to the specific contexts, spaces and situations of youth street groups in the city; the next section, as its name indicates, analyses the legal framework of youth street groups, taking into account laws, sentences and current processes; the final section of this Background Paper is devoted to the conclusions, where general objectives are provided and hypothesis to investigate proposed.

According to the TRANSGANG methodological approach, the way to carry out this research is a multi-sited and multileveled ethnography in all the cities chosen for the project. Contrast cases' research, starting in January 2020, will consist on three focus groups, two life stories and six narrative interviews, together with participant observation. The focus of the research will be on mediation, conflict, gang policies and experiences (Feixa et al., 2019) ${ }^{18}$.

\footnotetext{
${ }^{18}$ For a full account of TRANSGANG project methodological framework, refer to TRANSGANG project Concept Paper (Feixa et al., 2019).
} 


\subsection{State of the art: Researching (trans)gangs in Madrid}

\subsubsection{Antecedents}

(Trans)gangs in Madrid have been researched up to the date from several perspectives and with different goals; from the academy and social entities (usually in collaboration) to police forces (with special units dedicated to these groups) and the Attorney General's office. The TRANSGANG view of gangs as agents of mediation, however, has been less explored, and that is the main objective of our research.

Even though youth street groups from Latin America arrived first in Madrid, research with them started in Barcelona with Carles Feixa's work with Latin Kings and Netas (Feixa 2006, 2008, 2011, 2015). Public visibility of youth street groups, or Latino gangs, as they were immediately called by the media, came with the murder of a young Colombian boy, Ronny Tapias, on October 2003. Back then it was considered as an unknown phenomenon in Spain because of the fact that the groups were composed by young people from South America, but the truth is that they were not (and still are not) that different from the kind of street groups that had been so common in the 80 's, however, and soon both had the same negative connotation, that of fights, crime, and marginalization, with the added possibility of mobilizing a dangerous speech against migration based on anti-gangs politics. This: "The media soon dedicated a great deal of attention to the phenomenon: moral panic campaigns (as the one that followed the death of a young mod by a rocker)" (Feixa \& Porcio, 2004, p. 13), could have been written last week regarding Latino groups. The phenomenon attracted the attention not only of the media, however, but also of the academy and the authorities, although in the case of the authorities the interest and response to the onset of those new youth street groups was very different in Madrid and Catalonia. While in the second there seemed to be an interest in dealing with the groups from a social, anthropological perspective, in Madrid repressive policies and measures were sought. Although the academy's view didn't necessarily match that of the authorities, this last view was key in the development of those firsts investigations, because in many cases it affected the trust between researchers and subjects, but also because right hand policies made almost impossible to develop social measures with the groups.

It needs to be said that the first research in Barcelona was prompted and promoted by the City Council after the group of Latin Kings \& Queens of the city had asked for a space in a Youth House of the city under the name of STAE. As the narrative of the moment goes "the first reaction was to expel them [...] but people from the Youth Council, after an intense debate, decided they could not prejudge them and that they should be given an opportunity" (Feixa 2006, p. 40).

In 2005 Carles Feixa, together with an interdisciplinary team, launched said research project on the members of the Almighty Latin King and Queen Nation in Barcelona, which also included the Neta Association. Its main objective was to highlight the "real 
life" of these young migrants, their daily life, myths, legends and the way in which they built their "social identity marginalized, clandestine or simply unknown" (Feixa and Canelles, 2006: 43). During the years 2005 and 2006 the young people who participated in the project decided to create social entities such as the "Cultural Association of the Kings and Queens of Latinos" and the "Sociocultural Sports and Cultural Association of Netas", as part of the integration process promoted by the project of the team led by Carles Feixa (Queirolo Palmas, 2013).

The analysis of the situation in Barcelona 15 years after that process is one of the objectives of TRANSGANG, being the city a Core Case of the project. As expressed by Queirolo Palmas (2013), on the one hand, the Catalan institutions did not fully shed their prejudices, so young members of the new associations continued to be burdened with gang-related stigma and did not find themselves supported. On the other hand, politicians and academics did not reach agreements regarding the treatment that the situation should be given: while academics bet on the consolidation of these groups and their transformation into cultural groups, politicians rather bet for "the complete assimilation and disappearance of the groups", and therefore they ended up collaborating with the academics in order to implement restrictive policies on the groups. (Queirolo Palmas, 2013, 2014).

Following the path drawn by action/research in Barcelona, research started also in Madrid: the original focus of research with these groups to the academy was to understand why they were here, "so far from home", so as to say, and what drew young people to them. From a politic and police point of view the main interest was to find ways to "avoid" youngsters joining a "gang" as much as avoiding their growth in the cities they had already been detected to be:

\footnotetext{
The chief meet with all the schools' headmasters [of the area] and told them not to wait for a fight to happen, but if they suspected a kid was into a gang issue or was being coerced, they must tell us. Then we could go straight to take and act straight away and even if we had to tell the kid: look, we know what you are up to and we see you. 60 or $70 \%$ of the times it works. And then it's cut from the beginning, and what you do is to tackle it radically. Because if you start to let it be that's when the group grows and then it is worse. (Police agent quoted in Aparicio, Tornos and Cabala, 2009, p. 50)
}

From our perspective of more than 10 years later, this statement seems, at least, naive, because from then on youth street groups went through a phase of fast growth even under some of their members were under close police surveillance. The previous quote is extracted from one of the firsts reports of actual research about Latino youth street groups in Madrid, that of Aparicio \& Tornos (2009), a results report on a research called "Diagnosis of youth groups of Latin American migrants' children", subsidized by the General Direction of Immigrants Integration, belonging to the Secretary of the State for Immigration and Emigration of the Labour and Immigration Ministry of Spain. As the introduction to the report goes, it is focused on understanding the causes and background of Latino groups in Spain, from a psychological and anthropological 
perspective, with some fieldwork done in specific neighbourhoods in the city of Madrid, selected under the criteria of their appearance in the news in relation with Latino gangs, as they were called. As in the case of Barcelona, the starting point of the investigation (or of the setting of the investigation) is a murder. Opposite to what happened in Barcelona, in this case the victim is actually a member of a "gang", specifically a member of the Latin Kings, Rafael Amaya, known as Maestro, killed by the Netas in November $14^{\text {th }} 2004$ in the neighbourhood of Opañel.

This episode is key to understand the whole development and evolution in the relationship and conflict of both groups in Spain, but especially in Madrid, for the years to come. The report contains an explanation of both the urban and social contexts of the research and of the social, police and political actors who were active part in the everyday lives of those contexts, including the families of groups' members. It also contains some interviews to ex-members, families and stakeholders, but the view of the groups is mainly external. Regarding direct observation, that first attempt to research groups turned out quite unsatisfactory, as it was not possible for researchers to develop participant observation or to gain the trust of any of the groups observed.

In the period that goes from the year 2003 to 2010 there were several press and academic articles that dealt with the phenomenon of youth street groups in Madrid, but they tended to be an analysis more or less throughout of what was being published in the news, police reports and USA street-gangs reports (Castro et al., 2012; Corral, 2008; Botello \& Moya, 2005). An interesting one, however, is the results report published by Martín, Martínez and Rosa (2009), who research violent behaviour in 40 youngsters and young adults belonging to urban tribes (Latino youth street groups, football-fans groups and leftist and rightist political groups), through semi-open interviews compared:

\footnotetext{
The results obtained are coherent with the "theory of primary socialization" (26) and with the theory of "differential" socialization (27). It is possible to postulate an oversocialization of the violent group and an infrasocialization of the other socializing agents. This imbalance is clearly observed when analyzing the interaction between personal, group and social identities. Thus, when the group (violent) identity is dominant and emergent in different environments, young people present more extreme behaviors and their relationship with the violent group is greater (Martín, Martínez \& Rosa, 2009, p. 134).
}

Although the main focus here is the violent behaviour of the groups, the results and conclusions put the focus of the problem not only in the groups per se, but on the lacks of the rest of social agents' support and opportunities, and suggest that one of the best counterparts to spending so much time in the streets is to have a stable, satisfying occupation, ideally a job, as it: "favors the normalization of their behavior and reduces the chances of falling into violent behavior. A job with sufficient economic rewards and a good working environment that includes alternative social support is considered satisfactory" (ibid., p. 132). 


\subsection{2 (Trans)gangs and public policies}

With the information we have now, researchers agree that the first major (trans)gang to arrive in Madrid were the Latin Kings. According to their own internal documents, they "officially" constituted as a group in February of the year 2000, but this fact has been dismissed by some members of the group who participated in its creation (Feixa, Scandroglio, López \& Ferrándiz, 2011). The specific date, however, is not essential. The group was created in Madrid that year, and others followed: Netas, Dominican Don't Play (DDPs) Trinitarios (3nis), are the four major groups that up to the date have a bigger presence in the city of Madrid. Brought by the migrant flows of the beginning of the century that made that not only adults or young adults migrated for economic reasons, but also that families were temporally separated, these groups acted in many occasions as natural mediators for their newly arrived members, often barely teenagers that, while one or both of the parents migrated with the intention of getting an stability that would allow them to start a process of family reunification in Europe, had remained in their countries of origin with some member of their family, typically a grandmother.

Here we have the two prototypical categories that would originally conform the youth street groups from migrant origins that we can still find today in Madrid: young adults and reunited teenagers. Nowadays, however, the groups are much more diverse and homogeneous, teenagers from different origins share public spaces, get mixed at schools, high schools, parks, malls... and this is multiculturality is also reflected in youth street groups; although in a lesser number, we can find members not only from Latin America, but also "natives", from Eastern Europe and from the North of Africa, integrated within them. What doesn't seem to have changed substantially is the rap, trap, reggaeton culture, their aesthetics and even ways of communication are still their main cultural influence and reference, although it will be interesting to verify how much of that influence comes from members and how much from mainstream music culture, and also to note if the members whose cultural heritage is different from that of the majority of the group also contribute some features of their traditions to the group and if there is any kind of transfer from one culture to other.

Of the characteristics of these groups we also need to highlight others that are more related to the way in which they are organized and managed. We can find different forms and levels of domination and subordination, but also a reproduction of power structures such as those of the nation-states: patriarchal structures of superiority (invisibilization and/or separation of spaces of women); existence of regulations and norms (that come from the creation of the groupings and are modified and adapted to the new environments); punishments carried out for breaching of rules; payment of fees (usually invested afterwards in the groups' own needs)... but we also find, in general terms heterogeneous groups in which a sense of great cohesion, the idea of group identity, support and protection prevail.

Back to the policies developed in the Community of Madrid, mano dura seems to have 
been increased during the last year, but it has been main line of action since the arrival of the gangs, Queirolo Palmas, who investigated gangs in Madrid and Barcelona from 2011 to 2013, wrote "speeches of barbaric and illegalization were protagonist for a lot of time in Madrid" (Queirolo Palmas, 2017, p. 23). According to police forces' reports, in the summer of 2018, during the months of July and August, the number of young people arrested under charges of belonging to a gang was already double of the previous year: 30 (2018) vs. 15 (2017), and the balance of the two years is overwhelming: "So far this year, 216 gang members have been arrested compared to 160 in the same period of 2017, which represents an increase of 35\%." (Durán, 2018b). The police forces of Madrid have, however, a special corps dedicated to vigilance, tutoring and guidance of the youngest citizens, the Tutor Agents; Although they were not created to work with gangs in particular, they have learnt about them in the streets and accompanied many of their members since their appearance in the public scene, as the majority of the places where they enforce their influence can be considered "ganglands" - parks, corners, the outside of high schools, etc. Their main objectives are to prevent school absenteeism, follow up youngsters with minor sentences, and prevent small drug dealing and other illegal activities among minors and young people. However, since their creation in 2002 its numbers have varied: from the more than 200 agents in 2011 to a little less than 170 in 2018 (FEMP, 2019).

The city council of Madrid was asked by the opposition about the measures being developed to tackle the increase in the activity of Latino groups in Madrid and asked for an agreement in the council's policies focused on prevention, intervention and mediation with the groups. (C's Madrid, 2018) Although said agreement was approved unanimously, the council pointed out that there were already measures focused on prevention of radicalization and accompaniment of minors in the city of Madrid, although they are not specifically directed to young members of Latino youth street groups but to young people in general with a high risk of school dropping, social exclusion and/or radicalization. The measures consist mainly on afternoon school reinforcement and opening of spaces for children and teenagers - there are 43 of these centres in Madrid city -; the ASPA project, directed to the prevention and re-education of violent behaviours; the action of social educators in the streets who mediate and work to avoid conflicts. The measures are, however, not enough to counter course the shortness of resources caused by the cutbacks in social spent at both regional and national levels that have been taking place from the year 2011, especially in the social field, that provoked that many entities working with young people in Madrid were left without financial support and most of the intervention projects with street educators were paralyzed. This situation left young people from the most deprived neighbourhoods with practically no resources and no street intervention professionals.

The situation of helplessness suffered by young people in many neighbourhoods especially in Madrid-, impelled them to seek support in their peer groups, whether or not they were "Latino gangs". It is important to visualize the structural violence 
suffered by people who have settled in those more depressed neighbourhoods of the cities, because there is where we find the combination of shortage of personal resources and State ones. In the case of Madrid, above all, this structural violence is manifested in the lack of leisure and free time resources for young people, or, in any case, a problem of understanding from the administration of the actual needs and interests of these young people, who don't find the current offer one that meet their expectations; also a shortage of offer of non-regulated education programs to access employment, of professionals on the street, of access to affordable housing and in general terms of real and viable measures of access to youth employment, among other shortcomings.

This situation of (diminished resources in Madrid, together with persecution and restrictive policies, has become a breeding ground for some factions of the youth street groups to strengthen and react even more violently, which only proves that restrictive measures from a punitive perspective, where young people who have been members (or are active members) are stigmatized and delegitimized, or simply part of the environment of these groups, have not obtained the desired effect, but the opposite. These groups are currently active and in recent years, the media has echoed some unfortunate events of fights, deaths or serious injuries, encouraging a greater sense of rejection towards these youth groups and their young members, their environment, and, by extension, migrant youngsters of similar characteristics, who are stigmatized while also find difficult access to resources and activities away from violence. It is important that the administrations and public institutions are aware of the reality of the young people who make up these groups, so that, instead of continuing to promote a stigmatized profile of these young people, they are participants in the possible solutions to avoid the reproduction of stigmatization among groups of equals. It is true that in each city there are specific conditions, which will facilitate or hinder intervention with street groups, and there is no single successful formula in this regard, but there are good practice models to follow, which could be adapted to the conditions of each context.

Regarding the situation of the specific youth street groups that are active in Madrid as of current date, the TRANSGANG Local Research Team is familiar with the mayor Latino groups: Latin Kings \& Queens (ALKQN), the Dominican Don't Play (DDP's) and the Trinitarios (3nis), although we also have knowledge of Netas. There are also other smaller -or diminished- Latino groups, but they will be taken into account mainly in their relationship with the ones mentioned before, as the situation of Madrid within the project as a contrast case city implies a more reduced time of research.

The transnational path followed by these youth street groups from the streets and penitentiaries of the USA to Spain is similar in all the cases, although of course each of them keep their own history, stories and particularities. Among the common characteristics we may highlight the foundational premise of fighting racism and oppression suffered by Latino people in the USA. They also share a close relationship with prison environments, either because they were actually born inside a prison or because they grew in numbers once some of their leaders were jailed. By means of 
migrations back to the countries of origin -sometimes voluntary, but mainly forced as deportations- gang members spread the groups in Central and South America, and just like that, economic migrants who travelled from those countries at the end of the XX and beginning of the XXI centuries brought the spirit of the groups with them, to a new society and environment so far as possible from their countries of origin but in which they found, in many occasions, the same reasons to organize themselves in these groups as their predecessors have found in the first place: racism, stigmatization and lack of social support.

\subsubsection{Research with the Latin Kings and Queens group}

The Latin Kings are an example of both developments: born in the streets of Chicago in the 1960's, they jumped to a New York correctional in the 1980's, and from there, Chicago and New York, with similar names but different literatures and some particularities in symbology and traditions, jumped to South America. That dichotomy, denominated as the Chicago and New York "schools" inside the group, also travelled to Europe when the groups did, and is an important point to take into account when dealing with the differences and internal struggles we might find during the research.

Almost simultaneously with that first mentioned attempt of research with Latino youth street groups in Madrid (Aparicio \& Tornos, 2009), action-research also started in Madrid with better success regarding the connections with group members and the possibility for researchers to develop participant observation with a group of Latin Kings and Queens in Madrid, though the situation there was more difficult than in Barcelona, as what the police and the media called "the leadership of the Latin Kings" in Madrid had been jailed and was waiting for a trial in 2006. This investigation started connected with the one developed in Barcelona the previous years and the network of academics who would develop it came "recommended", and even accompanied, by the ones who have already been working with the groups in Catalonia, so it was somehow easier to establish those first contacts and trust that the researchers in the investigation mentioned before were not able to make. Thus, Scandroglio and López (2010), worked closely with the Latin Kings and Queens group in Madrid. That experience, from 2007 to 2009, unlike the one in Barcelona, developed "independently or, rather, in clear opposition to the social and institutional context in which it has been carried out" (ibid. p. 251), and the reason of such research circumstances was the negative of the government of the Community of Madrid and the City Council to work together with the academy and other stakeholders into alternative proposals to deal with the situation.

In the conclusions of the report the researchers explained how the lack of institutional support was the most important obstacle to achieve some of the expected results, both by the group and the research team. The institutional response in Madrid was not unique, however, and the national one was diffuse, not conclusive, which added to the difficulty of following a homogeneous path of working with, and offering solutions to youth street groups, which, it may not be forgotten, were composed in no small part by 
underage members. One example is the Ruling on Urban Spaces and Youth Violence of July $15^{\text {th }} 2009$, referred by the Madrid Juvenile Court Judge Concepción Rodríguez González del Real in her paper "Youth Groups of Violent Character. Intervention Strategies: Institutions Facing the Social Conflict of Violent Youth Groups" (Rodríguez, 2010). Regarding “gangs" it
emphasizes that they do not necessarily have to have a negative connotation when affirming that far from being violent by definition, the gangs are constituted as a substitute for the family and the close environment of the young person, contributing a feeling of belonging to a group and, in a certain way, a concrete answer to the doubts of adolescence (ibid. p. 8).

The mentioned paper was composed on demand by the Community of Madrid, and in its conclusions it is stated that more prevention and left hand measures are needed in order to deal with the phenomenon, naming as examples of good practices some integration programmes developed in the USA, as the G.R.E.A.T. ${ }^{19}$ program or the Operation Ceasefire ${ }^{20}$, as "hardening policies followed in the USA and the Mano Dura and Supermano Dura programs [...] have failed. Birkbek already showed the reactive nature of gangs, the hardening not only does not end them, but gives them cohesion" (ibid. p. 14).

Some of the drawbacks of this research are still remembered by the members of the group ten years after, and alleged as a reason not to participate in public life or in the activities that other associations of social purposes propose them. The most meaningful was the impossibility of reaching any kind of agreement with police forces for them to reconsider their directions of "hunting" group members on the streets just to identify them as so; that situation prevented some members to attend activities, and discouraged the ones who actually attended to do it again. The hardest consequence on the group was that some of the participants on the investigation, after being identified by National Police Agents when they were attending a conference, were, a year after, arrested and charged with illicit association, being the identifications made in that conference used as part of the burden of proof. One of the key objectives of the research, "to transform the group into a recognized, legitimate social agent, connected with the social and institutional networks of its environment" (Scandroglio \& López, 2010, p. 251), couldn't, therefore, be reached, and is still ballasting action-research in Madrid, at least with the group of Latin Kings and Queens.

The situation of the ALKQN group today in Spain, and in particular in Madrid, is the example of what has happened with the group in many of the other cities and countries where the group exists: from the initial arrival and growth (2000-2005) it has experienced many changes in both numbers and directions. After the year 2005, with the detention of 14 members considered as the leaders at national and regional levels,

\footnotetext{
${ }^{19} \mathrm{https}$ //www.great-online.org/GREAT-Home

${ }^{20} \mathrm{https}$ //operationceasefire.com/
} 
the group lost an important amount of its members, due not only to the menace of being imprisoned themselves, but also to the lack of leadership that have, in part, kept the group together in the past. With the path led by the regularization process in Barcelona, however, a hope window opened for the group in Madrid, both for the members who were in prison waiting for a trial and for the ones in the streets who, in a more discrete way, still kept the group alive.

The implication of the research team, led at first from Barcelona with Carles Feixa's intervention, and then by Bárbara Scandroglio and Jorge López from Madrid threw some hope on the group, and its numbers grew again, though it was still meagre than it had been before the detentions. The negative of the regional government of Madrid, together with the modification and hardening of the law that refers to "criminal organizations" in 2010 (which will be analysed in depth in the next section), threw the group back into clandestinity, a situation that has continued until lately, even though a small part of the group is now devoted to creating a legal association that can run in parallel with the group and that can provide non formal education and labour opportunities to the members of the group, and that they count with the support of some civil associations, like RUMIÑAHUI, and NGO's, like SUYAE, which provide safe spaces for them to participate in forums, conferences and formative activities. Still, the situation of the group is delicate, and its members show much reticence to participating in projects and activities proposed by external agents, as it was the case of the Mediation Seminar in which TRANSGANG participated in 2018. There are also other factors to take into consideration in the case of this particular group: internal issues have always been present regarding leadership and origins, but also regarding the suitability of becoming a legal association. The internal conflict is strong, and the group is not at all homogeneous in their search of public recognition, which makes it even more complex to take steps in one or other direction. This situation will be taken into account when working in the research with the group.

As of today's date, regarding this group, it is possible to refer to several different intervention programs to which some research is associated, that are being developed by some civil associations and NGO's in the region of Madrid, some of them addressing directly the youth street groups as a whole while others are addressed to young people in risk of social exclusion, a description in which group members usually fit, but that are not exclusively designed to focus on their particular needs and capacities. It is necessary to point out, for the sake of the research, that not all the agents implied in the field in the case of youth street groups in Madrid seem to feel comfortable collaborating and sharing information and contacts, a situation that could imply a handicap for research in specific situations.

\subsubsection{Research with DDPs and Trinitarios groups}

The fieldwork with the groups of the Dominican Don't Play (DDP) and the Trinitarios (3nis or Trinis), by Katia Núñez, TRANSGANG's local researcher in Madrid, began in 
January 2015 in a working-class neighbourhood of Madrid, with a large population of Dominican origin, together with a variety of origins and other collectives. The initial stage of the ethnographic work was rather a first immersion in the field. The fieldwork consisted of semi-structured interviews with 6 former members of the DDP environment and a former member of the Trinis. There were many issues that we began to observe in the field, issues in which we then decided to continue deepening in the second stage that was carried out from October 2015 to September 2016. We continued with the field work in the same neighbourhood that we had started, but this time the girls from the DDP environment (and who had been part of girls' groups) were also included in the research, something that had not been possible during the initial fieldwork. From the moment the girls were contacted, the relationship became more solid and the presence of the researcher in the neighbourhood became a work routine that greatly facilitated fieldwork.

At the beginning of the fieldwork (in 2014) when we accessed the neighbourhood where the DDPs were supposed to have settled, we learned that both groups coexisted in the same district, separated by a street: the DDP belonged to the lower side of the neighbourhood and the Trinis belonged to the upper side. At the beginning the confrontations happened frequently, because whoever dared to cross to the "land" of the other group was attacked, which then caused the "vendetta" of the aggrieved member. But as we observed the situation and with the passage of time, we realized that the clashes not only occurred in the neighbourhood, but that they could explode anywhere there was "a chapter" of any of the groups or anywhere they were summoned for a fight.

While the fieldwork was developing with the groups of DDPs and Trinis in Madrid, the media were sending alarming news about them, either because they were fighting each other, or with other rival groups such as Netas or Latin King. The novelty in this case is that Katia Núñez was already in the field and was able to contrast some of the pieces of news as they were being published, observe the reactions of the members of the groups, their environment and stakeholders. From her fieldwork notes it is possible to get a glimpse of the bigger picture of what has been happening in Madrid regarding her research groups and their transnational connections.

The main problem when dealing with research on Dominican Don't Play (DDP) and Trinitarios (3nis-Trinis), has been the little previous information on these two groups, since most of the research done on "Latino gangs" in Madrid, has been performed on Latin Kings or Netas. The little information that has circulated is that provided by the media, over which we have discovered that most of the time lack any basis. On the other hand, the entities that performed (and still perform) some intervention with these groups in Madrid do not easily share information about them. On the one hand, there is the secrecy of the members of the groups, who prefer not to give information to anyone outside the group, in addition to the distrust that would suppose, if those who intervene shared any kind of information with outsiders. This speech was the main basis for 
denying access to a researcher outside the environment of the entities that performed the intervention.

With the modification of LO $5 / 2000$, which gave way to LO $8 / 2006$, in which "the criminal responsibility of minors is regulated", the hardening of the measures to be applied to young people is encouraged, this also affects underage people who commit a crime and whose membership to a gang can be proved. The penalties for juvenile offenders, who are also gang members, go from 2 to 5 years, with the possibility of entering closed detention regimes and probation for up to 5 years. For Feixa and Canelles (2007) this hardening of the penalties for minors has been done thinking, above all, on members of Latino gangs, leaving aside other types of groupings. (Feixa and Canelles, 2007, p. 24).

With the implementation of LO 5/2010, youth street organizations are now considered criminal organizations, thus increasing the secrecy and distrust of the young people who belong to these groups, thus making it difficult to access them and performing a quality intervention. In this way, the application of restrictive measures throughout Spain is increased, however, their application does not reduce violence and neither do the socalled "Latino gangs" disappear.

Despite this, we decided to begin an investigation of these two groups in Madrid. The field work with the DDP and the Trinis began in January 2015, in a working-class neighbourhood of Madrid with a large population of Dominican origin and other groups. Although both groups were created in the US, the speeches of members of both groups vary on the process of creating the chapters in Madrid. In one of the stories, one of the informants of the DDP indicated that there were only Trinis in one of the districts of Madrid, along with other groups such as the Forty Two, the Latin King, Netas, (among others), but a fight between two leaders caused the division and that a side "opened a separate store" and created the chapter of the Trinis. We do not know to what extent this is true, but that version is not far from the one indicated by the Trinis in the US. According to versions of an informant, the Madrid DDP's group began their activities on December 22, 2004.

As expressed by Durán (2019), the group of Trinitarios was created in the Wyoming Correctional Facility, Rikers Island prison of N.Y. in 1989, to defend against the Bloods, a gang of African Americans who abused Dominicans in prisons. As the author indicates, initially the Trinis were called "Dominican Power", a name that was later changed to "Trinitarios", in honour of the leaders of the independence of the Dominican Republic of Haiti. Duran became part of the Trinis in jail, so the story he later wrote is based on the personal experience he lived in the prisons of N.Y.

Another of the interviewees (former member of the NY prison group) indicated that when the group was created, it was done with the idea of "independence" of the Dominican prisoners in the prison, who would free themselves from the abuses that 
other prisoners committed against them. This idea of "independence" is based on that of the original Trinitarios who, as we indicated earlier, managed the independence of R.D. from the Haitian invasion.

An informant interviewed, serving a sentence in a state prison of N.Y. (accused of being the top leader of the Trinis in N.Y. and with a pending federal conviction) also comments that when the Trinis were created the DDPs had not yet been created. It indicates that these were created as a result of a dispute in the prison, since there were those who preferred the denomination of "Dominican Powers." When going out to the street one of those who did not agree with the denomination of the Trinis (nor with others situations), decided to continue on the streets with the "Dominican Power", which later became Dominican Don Play - DDP - ("you don't play with the Dominicans"), so, it seems, the DDPs were created in the streets of Manhattan (NY) in the eighties and not in jail. Apparently, there is greater evidence that the Trinitarios organization was created first. With the deportations of Dominicans in the US The phenomenon is exported to societies of origin (Dominican Republic) and societies of destination (as in the case of Spain).

Of the characteristics of these groupings we can highlight: forms of dominance and subordination; reproduction of power structures such as those of nation-states: patriarchal structures of superiority (invisibility of women); existence of regulations and norms (that come from the creation of the groupings); punishments exercised for breach of regulations; payment of fees; heterogeneous groups; existence of great cohesion; idea of group identity; support; protection, etc.

The informants of both groups indicated that they use the colours of the Dominican flag in their aesthetics, but while the DDP use black to differentiate themselves, the Trinis use green (which according to these informants is used by the olive branches of the flag shield Dominican). Initially both groups used necklaces, whose length gave an account of the place they occupied within the group. As well as scarves ("bandanas") of black color, the DDP, with three black dots (which referred to its acronym). The Trinis used a green bandana, but some informants indicated that they had seven points. DDP uses the acronym "AD3", which means "love of 3", to sign messages, in tattoos and as an expression when addressing each other. The "love of 3 " refers to the acronym DDP. While the Trinis use the acronym "DPL", which comes from "God, Homeland and Freedom", these three words appear on the shield of the Dominican flag. The Trinis also use these acronyms to sign their messages, as do the numbers "41216" which also means "DPL" (the numbers refer to the order of the letters D, P, L in the alphabet). The DDP uses a similar numerology: 4416, which refers to the acronym of the DDP, the order of these letters in the alphabet.

At the beginning of the field work (in 2014) when we accessed a neighbourhood where the DDP was supposed to have settled, we learned that both groups coexisted in the same district, separated by a street: the DDP belonged to the lower area of the 
neighbourhood and the Trinis belonged to the high zone. At the beginning confrontations happened frequently, because whoever dared to cross the land of the other group was attacked, which then caused the "vendetta" of the attacked member. But as we watched the situation and over time, we realized that clashes did not only occur in the neighbourhood, but could erupt anywhere where there was "a chapter" of any of the groups or where they will be summoned for a fight.

On the structure of the organizations: the informants of the Trinis interviewed in N.Y. agreed that when the organization was created, the same structure was established that (it is assumed) is currently conserved: supreme 1st, 2nd, 3rd - regarding Duarte Sánchez and Mella, the three parents of the Dominican homeland- (these positions are state-owned), flags, security, discipline, leading chapters $(1,2,3)$, people. The leader interviewed in the prison said that "in prison there are no chapters, prison is a town."

This structure varies in Madrid, in which the informants interviewed indicate that there are supreme $(1,2,3)$, security, discipline (in charge of punishments), those in charge of accounting and soldiers.

In the case of the DDP, the structure is as follows: the supreme 1st, 2nd and 3rd, "the pearl of" which is the "right hand" (trust positions) of the supreme and chapter leaders, in charge of discipline, Accounting, and the soldiers. The girls had a similar structure, but without supreme, since the leader of the DDP was the head of the group and the girls' group, but they empowered the leader in front of the other members.

Since we only had contact with former members or friends of the DDP in the neighbourhood where we did fieldwork, we only learned about things that had happened in the past, such as the murder of Isaac Nathanael, the rapper nicknamed Moren Black (in 2009), or that of Manu, the young man who was attacked in Villaverde in 2008, or the death of the 16-year-old teenager, a member of the Trinis killed in Vallecas (in 2012), or of the attacks that some of the guys that made up the group we studied. We were not part of the confrontation plans, nor of the compromising situations. On the one hand, we still did not have all the confidence of the boys and on the other, we were never at the centre of the group. The girls were excellent informants who, once their trust gained, made us partakers of everything that happened in the neighbourhood.

The initial stage of ethnographic work was rather a first immersion in the field, in which many important issues were not addressed among them, the role of girls in groupings. Once the second stage of the fieldwork began, contact was made with the girls around the DDP, who facilitated access to much more information in the field.

During the third stage of the fieldwork (2017), members of the Trinis were accessed in another neighbourhood of Madrid, which facilitated gathering first-hand information about that group. 
In May 2018, the opportunity to do field work in N.Y. to make contact with members of both groups in that country and learn about the history of how they were created, since they all said that both were created in N.Y. Access to one of the leaders who created the Trinis organization in N.Y. and two former members of the group provided us with access to information about the creation of the Trinis.

On the other hand, an approach was made to one of the girls who came to have an important status in the DDP. This girl became one of the key informants of the DDP research.

At the end of January, we began fieldwork in neighbourhoods of the Dominican Republic, until the end of March, to establish the transnational relationship of the groups: Madrid, N.Y. and Dominican Republic. At present, we continue with the field work in neighbourhoods of two districts of Madrid, where the Trinis and the DDP have settled. Unfortunately, the media continue to raise the alarm of "criminal groups", made up of young "criminals and highly dangerous", thus encouraging rejection and further exclusion of these young people.

\subsubsection{Girls in (trans)gangs}

The situation of women in the youth street groups referred to in this BP is different from one to another, but it has also changed since the groups started, both in their homelands and in Spain.

In the case of the DDPs and Trinitarios groups, girls have traditionally been banned from actually belonging to the organization, but have in fact accompanied men in the groups, have done tasks for them and have even been used to hide weapons as, at least at the beginning, they were less likely to be searched by police officers in case of a raid, for example. With time, however, the girls around these groups started creating their own groups, with their own structures and rules, but at the end always subordinated to the main male group around which they "orbited" (Núñez \& Torres, 2018). In the case of the Latin Kings and Queens and the Netas, girls are active part in the organizations, however subordinated to the male authorities of the groups, but they are as much members as male members are. The main difference between both situations is that in the first case women belong to the environment of the groups but don't have a say on their management, but at the same time are also in less risk of being found guilty of belonging to them in case of a judicial cause. Even when -or if- they create their own groups, these are not found dangerous or worth of attention by the police brigades specialized in gangs, and so they usually go unnoticed. In the second instance, as they belong to the groups, they are susceptible of being charged with belonging to a criminal organization and other charges, as it will be explained in the legal framework section. In both cases, however, and always in general terms, from our experience young female members are more accessible and less likely to be suspicious towards researchers, and have been a great source of information for Katia Núñez's PhD research, for example. 
There is a recurrent situation observed in the Latin Kings \& Queens groups, for example, in which the Queens have been repeatedly excluded from the group activities, and even from exercising their memberships when the situation in the streets and with the authorities experiences higher levels of conflict. In those moments, and always alleging the protection of the girls/women in the Nation, they are told by male authorities within the group to stay apart from it. This instruction is usually followed by female members of the group, who, in some occasions, never return to it again after that.

Although less research has been done on female members of gangs, there are some of them whose topics can summarize the main focus of interest for those who investigate their participation in youth street groups. Miller (2001) found three reasons why they entered in contact with the groups in the first place: social relationships, family problems and by means of a relative who was already a member; she also points out the exiting contradictions regarding girls, gender and equality in and out of gang environments. Kelly (2015) also explores the reasons why girls enter and persist in gangs, but she also has a deeper view on the reasons alleged to leave the groups, among which we can find pregnancy and separation of the physical spaces of the gang. Dr. William Q. Ross, also known as King Mission, has a particular view of the reasons behind the decisions of women to leave the group:

Within the Nation of the Latin Kings, a lot of women have understood that the lies they were told affected their lives negatively, and so they left the nation to better their lives. Instead of realizing bettering their lives is the truth of the Nation. (Member interview for TRANSGANG project, p. 15, 2018)

But he also offered a theory about why there is that recurrent idea in transnational youth street groups that women cannot lead the whole group, just the female section:

\begin{abstract}
I really believe in some actions that there is a lack of intelligence that keeps men stagnate within the Nation, a fear that women can take this Nation to a level that they couldn't. [...] we are talking about 78 years later, para que viene una mujer y en menos de un año hace todos los cambios que en 78 años tú no podías hacer ${ }^{21}[\ldots]$ So now eventually becomes "what the fuck, I've doing this for all this time, and here you come and la gente te hace caso, tú tienes buenas ideas, there is a privilege that comes with women, society tends to be a little more open-minded to women, it is a lot of social issues (ibid. p. 14).
\end{abstract}

This idea of a society that is more open minded to women, that they are not considered as menacing as men are, even when belonging to the same group or even gang, needs to be framed inside the social, patriarchal system we live in, that feeds in the public imaginary the image of women as warm-hearted, harmless, good-nature beings unable, for example, to lead a criminal gang; on the other side, there are some characteristics that, even though they are not necessarily innate but a consequence of female socialization, can be considered as positive and desirable for a different kind of

\footnotetext{
${ }^{21}$ So that a woman comes and in less than a year makes all the changes that you weren't able to do in 78
} years. 
leadership. Thus, the concept of "feminization of politics" has evolved from just meaning a higher quote of female politicians in government and public offices, to an actual difference in the interests and ways in decision-making: "Leadership styles will be influenced by women; democratic institutions will achieve greater credibility [...] feminization of political leadership could help contain the growing dissatisfaction with democracy and the possible return to authoritarian regimes" (Buvinic \& Roza, 2004, p. 12). As members of society, raised in the role of care-providers, there is a growing tendency to consider that women in leadership would help revert the raising levels of social tension and conflict the world experiences nowadays, and there is no reason why this same theory cannot be applied to leading women in youth street groups. There is a lot to be reflected upon and researched regarding women as agents of mediation, and on how the gender roles in which they have been raised can contribute to mediation processed, versus how those same roles can handicap their chances to leadership.

\subsection{6 (Trans)gang Spaces}

We have already mentioned in several occasions how one of the characteristics that are common to members of the youth street groups is their tendency to meet in public spaces, which usually in the practice means an appropriation and resignification by the groups of the physical spaces where they meet, live and interact with other members of their communities (Queirolo Palmas, 2017).

In the case of Madrid, as it has been exemplified with the case of the DDPs and Trinitarios, there are several imaginary borders that separate the territories in which the different groups operate, and in which, depending on the circumstances and the level of hostility, members of opposite groups will choose not to enter. Contrary to what it may seem, however, from the social alarm shown in the media, there is no routine in the city of constant fights or open disputes, but a tacit agreement not to intervene in other groups' physical spaces in order to avoid conflict, combined with a feeling of unease if they have, for one reason or another, to go to one of those neighbourhoods in which another group has predominance. Parks and public sport facilities are the most common spaces in which the groups meet for their leisure activities, but their "official" meetings have become less regular in public spaces due to the police presence and harassment, so they either meet more discreetly or, in the case of massive meetings, make use of private spaces provided by some of the entities that develop social work with them.

In the city of Madrid, we have knowledge of some associations, churches and even a university which provide these safe spaces for the groups to hold not only their private meetings, but also to receive formation - hairdressing and cooking, for example -- and to develop public activities. Although the spaces provided and the funds used for the formative actions are in no way reserved or devoted to gang members in particular, they are, in many occasions, the ones who profit more from them, because the social agents providing the activities and spaces are familiar with the gangs in their neighbourhood and put on a big effort to help young members to stay out of trouble. 
Regarding virtual spaces, a due again to the growing need of clandestinity the group members feel, it is difficult to find public profiles in which either the group as an entity or the members as individuals claim publicity. There are, in any case, some social media profiles in which the groups of the Latin Kings of Madrid, for example, publish the activities of their association and use to interact with similar profiles created in other countries, but they are not public. In Ecuador, where the group created a legal corporation some years ago, their public Facebook profile shows everyday activities, offers resources and gives publicity to the small business created around the corporation and that are run by members of the group. From that public profile ${ }^{22}$ members of the group from all over the world can communicate or establish contacts.

Youth street groups members, however, are not immune or aloof to the phenomenon of the social media, used by youngsters and adults alike to share images of their private lives and everyday activities, and even in their private networks, as WhatsApp States, Instagram of Facebook profiles is possible to find some representation of their symbology or affiliation, but their profiles tend to be private, only accessible by close contacts.

\subsection{Empowerment, Conflict and Mediation}

Although in public imagination gangs are usually associated with idleness and violence, they are, in their own way, a resistance tool for their members in a social system that has failed to provide them with real alternatives or opportunities. Youth street groups can be considered from the point of view of social sciences, with the example of the Birmingham School (Hall \& Jefferson, 1976) as one of the ways their young members have to resist in a hegemonic system in which they find themselves pushed to the margins. Belonging to a youth street group can be, therefore, empowering, both for individual members and for the group itself, though of course not in the same proportion. Power, hegemonic relationships are the base of Western societies, with the necessary acceptance of this hegemony by the subaltern populations (Gramsci 1935/1971), and youth street groups reproduce vertical power roles in their structures, but they also reproduce horizontal, caring ones, pretty similar to those of families. The feelings not only of belonging, but of being needed, respected, listened to and cared for are key to understand the internal cohesion of youth street groups, and the empowering ability they imply for their members: "an identity of resistance, an opportunity for empowerment both individually and collectively, of a possible 'voice' capable of challenging the dominant culture, of a refuge with respect to the tensions and sufferings of daily life in the ghetto" (Brotherton \& Barrios, 2004, p. 23).

From TRANSGANG project we share a vision on Mediation and conflict resolution that allows for the groups to be active agents in the processes in which they participate, and not mere subjects which constantly require external mediation. In this sense, we

\footnotetext{
${ }^{22}$ https://www.facebook.com/alkqncorp.ec92/
} 
understand mediation in its broad definition of a technique of conflict management that allows for the parties implied to reach agreements with the help of a third/external/neutral party. Regarding conflict, our perspective goes further than the most common perception of conflict as a negative situation or with only negative possible outcomes. Conflict understood from Folger \& Bush's (1996) transformative perspective is considered as an opportunity to challenge some pre-established assumptions, for example, or to revert an unequal social situation. We don't mean to be naive and obviate that usually conflict is the cause of situations that can go from uncomfortable to dangerous, we just aim to offer a wider set of developments and outcomes.

Regarding youth street groups-related conflict, we can apply Rubin, Pruitt and Kim's (1994) definition of conflict, "a perceived divergence of interest, or a belief that the parties' current aspirations cannot be achieved simultaneously" (p.3), to their relationship with other groups (inter-group conflict); to the relationships within the groups themselves (intra-group conflict) and their relationship with the administrations and stakeholders. We can also apply this definition to individual conflict, as in occasions the limit between individual and grouped are blurred. This classification exemplifies the one offered by Lewicki, Litterer, Minton, \& Saunders (1994), in our case applied to youth street groups. As it is stated in TRANSGANG's Concept Paper, we must not match mediation with conflict resolution, but to conflict management. It is possible to find conflicts without a clear or possible solution, in occasions, for example, a conflict in which one of the parts have suffered a much greater offence than the other or one that has been latent for an extended period of time. It is the case of old grudges in the case of the youth street groups from Latin American origin with which we will be working in Madrid. The Latin Kings and the Netas haven't forgotten the death of King Maestro in 2004, as the DDPs haven't forgotten the deaths of Moren Black (DDP) in 2009 and the Trinis the one of one of their members in 2012; these are still the reasons alleged by some members from any of the groups to keep the conflict opened.

The conflict situation is that of bitterness against members of other groups just for their affiliation to one or another, extending like that a local conflict to transnational levels. From the moment the hostility is learnt -by means of the literature or by the narrative of older members who have lived it in first person in their countries of origin- it becomes, however, a matter of time that new reasons to preserve those hostilities and conflicts in the new social environment. The worst-case scenario, in which there is no room for mediation anymore, has already happened more than once in Madrid, as it will be seen in next section, and is the murder of young members by rival groups. Lederach (1996) makes it clear that there are limits to mediation, and of course the perpetration of a crime as grievous as a murder is out of any mediation limit. Then, why are we referring to it in this section? The reason is that the consequences in the streets can go on in the form of vendettas for as many years as the members of the groups remember it, and, as in the case of the DDP's and the Trinitarios it is just a matter of time until there is a new 
disgrace on the streets. Learning what mediation is, having a clear idea of its limits, but also of the possibilities it offers, is therefore a great chance for youth street group members to make a change in the dynamics of their everyday relationship to other social agents.

Social projects put in practice in several different parts of the world regarding gangs, gang members or ex-members and mediation and conflict management have proven very effective in reverting long lasting conflicts and hostilities in the streets of the cities they have been applied. Thus, we have the example of Cease Fire project in Chicago ${ }^{23}$, Capital Conflict Management ${ }^{24}$ in London or Casa Kolacho and the Grafitours ${ }^{25}$ in Medellin. Although the details of each project are different and configured to fit the idiosyncratic characteristics of their social, economic and geographical conditions, they have some key features in common. To begin, the three of them share and understanding of a complicated social conflict situation to which Mano dura and even Supermano dura policies have not been able to put an end; the three projects have also been able to see gang members as more that conflict agents, but as part of the solution, and have taken a chance to work with them as active agents of change in their own communities; for the projects to be successful and lasting in time, the cooperation between group members, authorities and their communities has had to be that of a strong compromise and implication, taking into account the needs of all the parts, as well as the possibilities offered by the combination of spaces -social, geographical and gang spaces included.

Unfortunately, as it has already been mentioned before in this paper, the public policies on the region of Madrid have not been homogeneous and favourable towards inclusive, mediating and integrating policies that could result into long term measures regarding youth street groups, mediation and social transformation, and the perspective for the next four years is turning even more despairing; while for the last four years the city council of the city of Madrid was more left hand-oriented and open to allow, collaborate and promote initiatives from civil associations and NGOs oriented towards integration, mediation and conflict management -as it was the case of the initiatives mentioned in the next section- the government of the Community of Madrid region was right hand-oriented, so the policies and measures that could be taken were limited to the city of Madrid and the area of influence of the city council.

In this regard, we would like to highlight the Mediation Seminar that was carried out in Madrid, with a duration of 80h during the months of November and December 2018, organized by the UPF, RUMIÑAHUI Association and the UAM, in which TRANSGANG and the city council of Madrid collaborated ${ }^{26}$. The seminar had as one of its main objectives to introduce young people from youth street groups to the

\footnotetext{
${ }^{23} \mathrm{https} / / /$ ceasefirechicago.org/

24 http://capitalconflict.com/

${ }^{25}$ https://www.medellingraffititour.com/medellin-graffiti-tour-info/

${ }^{26}$ https://www.upf.edu/web/transgang/intercultural-mediation-seminar
} 
techniques and principles of mediation, as well as to establish a first contact with the group of Latin Kings and Queens of Madrid. Although it was not possible to gather members from different groups, we did gather members and non-group members, enriching the experience and opening communication experiences that could be considered as successful by all the parts implied. Once the formation was over, however, and with the information we have today, we know that even though the participants liked it and found it useful for their everyday management, it has not implied an improvement in their labour possibilities, for example, so they feel a little disappointed.

As mentioned before, the lack of continuity and of coordinated policies make it complicated to develop and obtain long term results and improvements, and that situation also has an incidence in the enthusiasm young people will show towards new initiatives in the future. It is one of the aims of our project to focus on the subjects' own agency and empowerment, and we firmly believe that to achieve that empowerment and to give voice and a public and social space for that agency to be developed and to gain recognition, it is necessary that the academy, the groups and the rest of stakeholders work in cooperation, collaboration and long term, left hand policies.

Now, however, in Madrid, the situation has changed since the last municipal and regional elections (May 2019), and the government of both the city council of Madrid and -with all probability- of the Community of Madrid, will be for the next four years in the hands of liberal, right wing parties, with the support -and consequent interventionof a far right party, which has already introduced itself in the city life by demanding a seat in the municipal boards of some of the most depressed neighbourhoods of the city.

\subsection{Conclusions}

Youth Street groups from Latin American origins have been recurrently studied by the academia and the authorities in several occasions and with different purposes, but TRANSGANG's perspective presents a novelty in both the methodology and the focus of research: in other to learn how "gangs" can be active agents of mediation in their own spaces and beyond, with other groups, within their own group and with other social agents and stakeholders, the city of Madrid has been proposed as a contrast case to offer data to be qualitatively analysed in the next stage of the project.

The principal groups chosen to carry out fieldwork in Madrid are the Latin Kings and Queens, the DDPs and the Trinitarios, although other groups of similar characteristics will also be directly approached, if possible, and in any case dealt with in relationship with the ones mentioned above. The main reason behind the election of groups is that they are the ones the local research team already has contact with, some fieldwork has already been carried on and, due to the timing of contrast cases, they it has been considered more appropriate to deepen in the knowledge of these groups that to try to establish new bonds with new groups from scratch. 
It is possible that research in Madrid is not facilitated by the local government, as it has already been explained, because of the change of figures that has just recently taken place, and therefore the local research team may need work with particular care and discretion in order not to compromise the privacy and anonymity of the subjects of study, when they require it. The complicated legal situation the youth street groups studied here face, with the menace of their members being charged with criminal organization just for belonging to them needs to be considered at all times to understand they reticence to talk, their voices being recorded and/or images taken. The previous links with authorities and stakeholders need to be revised, in some cases retaken, as it is the case of social entities, and in other cases, as with the new local government, they need to be created anew again. Of the outcomes of these new bridges the research team will try to establish will depend, in part, the development of the research, because if the authorities are hardening their mano dura policies regarding youth street groups, as it is foreseeable, our tasks may become, in turn, harder to develop if groups' members opt to keep a low profile for the time coming; that would imply more difficulties to develop participant observation and even to secure personal interviews and life stories. 


\subsection{References}

Aparicio, R., \& Tornos, A. (2009). Aproximación al estudio de las Bandas Latinas de Madrid. Madrid: Gobierno de España: Ministerio de Trabajo e Inmigración.

Auyero, J., Bourgois, P., \& Scheper-Hughes, N. (Eds.). (2015). Violence at the Urban Margins. Oxford: Oxford University Press. https://doi.org/10.1093/acprof:oso/9780190221447.001.0001

Botello, S., \& Moya, A. (2005). Reyes Latinos. Los códigos secretos de los Latin Kings en España. Madrid: Temas de hoy.

Bourdieu, P. (1977). Outline of a Theory of Practice. Cambridge studies in social anthropology (Vol. 16). Cambridge: University Press. https://doi.org/10.1590/S0103-20702013000100001

Bourdieu, P. (1999). Meditaciones pascalianas. Barcelona: Editorial Anagrama.

Brotherton, D. C., \& Barrios, L. (2004). The Almighty Latin King and Queen Nation. Street Politics and the Transformation of a New York City Gang. New York: Columbia University Press.

Butler, J. (2009). Performativity, precarity and sexual politics. AIBR Revista de Antropología Iberoamericana, 4(3), 1-13.

Buvinic, M., \& Roza, V. (2004). La mujer, la política y el futuro democrático de América Latina. InterAmerican Development Bank.

Campbell, H. (2016). Violence at the Urban Margins, edited by Javier Auyero, Phillipe Bourgois and Nancy Scheper-Hughes. Anthropological Forum, 26(2), 196-197.

Canelles, N. (2006). Jóvenes 'latinos' en Barcelona: la visión de los adultos. In C. Feixa (dir.) Jovens 'latinos' em Barcelona: espacio público y cultura urbana. Barcelona: Anthropos, Ajuntament de Barcelona.

Castells, M. (1997). The Power of Identity: The information age: economy, society and culture. Oxford: Blackwell Publishing.

Castro, F. V., \& Pérez Ruíz, M. L., García Aparicio, V., Gordillo Gordillo, M., \& Gallego Meseguer, P. A. (2012). Bandas juveniles violentas en España. International Journal of Developmental and Educational Psychology, 1(1), 383-391. ISSN: 0214-9877. Disponible en: https://www.redalyc.org/articulo.oa? id=349832342039

Comunidad de Madrid. (2018) Plan de inmigración de la Comunidad de Madrid 2019-2021. Retrieved from: https://www.comunidad.madrid/transparencia/informacion-institucional/planesprogramas/plan-inmigracion-comunidad-madrid-2019-2021

Corral, M. L. (2008). Barcelona y Madrid: Dos realidades distintas ante el fenómeno de las bandas latinas. Revista CIDOB d'afers internacionals, 191-206.

C's Madrid (2018). Retrieved from: http://ayuntamiento-madrid.ciudadanos-cs.org/2018/09/26/begonavillacis-critica-el-negacionismo-del-gobierno-de-carmena-ante-el-repunte-de-las-bandas-latinas-en$\underline{\text { madrid/ }}$

Delgado, M. (2010). Gli studi sulle migrazioni in Spagna. Un bilancio e alcune riflessioni. S. Palidda (Ed.), Il discorso ambiguo sulle migrazioni (pp. 21-38). Messina: Mesogea. 
Droit, R. P. \& Ferenczi, T. (1992) The left hand and the right hand of the State. Variant Issue, 32.

Durán, A. (2018a). Gang Exportation and the Reproduction of Violence: The Trinitarios in the Crucible of Mass Incarceration. Senior Project submitted to The Division of Social Studies of Bard College. N. Y.

Durán, L. F. (2018b). Las detenciones de miembros de bandas latinas suben un 35\%. Retrieved from: https://www.elmundo.es/madrid/2018/09/17/5b9eb24ee5fdea726c8b45a1.html

FEMP (Federación Española de Municipios y Provincias) (2019) Programa Agente Tutor: herramienta para la prevención de las drogodependencias en el ámbito municipal. Retrieved from: http://www.femp.es/noticias

Feixa, C., \& Porzio, L. (2004). Los estudios sobre las culturas juveniles en España. Revista de Estudios de Juventud, 64, 9-28.

Feixa, C., \& Canelles, N. (2006). De bandas latinas a asociaciones juveniles: La experiencia de Barcelona. JOVENes. Revista de Estudios Sobre Juventud, 10(24), 40-55.

Feixa, C., \& Canelles, N. (2007). De bandas latinas a asociaciones juveniles: La experiencia de Barcelona. Educação, 30(61), 11-28.

Feixa, C., Canelles, N., Porzio, L., Recio, C., Giliberti, L.., et al. (2008). Latin Kings in Barcelona. In F. van Gemert, D. Peterson, \& L. Inger-Lise (Eds.), Street Gangs, Migration and Ethnicity (pp. 6378). Devon: Willan Publishing.

Feixa, C., Scandroglio, B., López, J. y Ferrándiz, F. (2011). ¿Organización cultural o asociación ilícita? Reyes y reinas latinos entre Madrid y Barcelona. Papers: Revista de Sociología, 96(1), 145-163. https://doi.org/10.5565/rev/papers/v96n1.165

Feixa, C. (2015). Bandas latinas en Cataluña (y más allá). In M. Ledesma (Ed.), Justicia, derecho y sociedad. Debates interdisciplinarios para el análisis de la justicia en Perú. Lima: Centro de Estudios Constitucionales, Tribunal Constitucional de Perú.

Feixa, C. (Dir.), Sánchez García, J. (Coord.), Ballesté, E., Cano-Hila, A. B., Masanet, M.-J., Mecca, M., \& Oliver, M. (2019). The (Trans) Gang: Notes and Queries on Youth Street Group Research (TRANSGANG Working Papers No. 2.1). Barcelona: Universitat Pompeu Fabra \& European Research Council. DOI: http://dx.doi.org/10.31009/transgang.2019.wp02.1

Folger, J. P., \& Bush, R. A. B. (1996). Transformative mediation and third-party intervention: Ten hallmarks of a transformative approach to practice. Mediation Quarterly, 13(4), 263-278. https://doi.org/10.1002/crq.3900130403

Gramsci, A. (1935/1971). La política y el estado moderno. Barcelona: Península.

Goffman, E. (1986). Stigma: Notes on the Management of Spoiled Identity. New York, London \& Toronto: Touchstone. https://doi.org/10.2307/2091442

Hall, S., \& Jefferson, T. (1976). Resistance Through Rituals, Youth Subcultures in Post-War Britain. London: Routledge.

Kazyrytski, L. (2016). Las bandas callejeras latinoamericanas en España y el giro punitivo en el tratamiento de su problemática. InDret, (2). 
Kelly, A. (2015). Girls in Gangs: Listening to and Making Sense of Females' Perspectives of Gang Life (Doctoral dissertation, Université d'Ottawa/University of Ottawa).

Lederach, J. P. (1996). Mediación. Gernika: Centro de Investigación por la Paz “Gernika Gogoratuz”.

Lewicki, R. J., Litterer, J., Minton, J., \& Saunders, D. (1994). Negotiation. Illinois: Irwin Press.

Mahía, R., \& Arce, R. D. (2010). Impacto de la crisis laboral sobre la población inmigrante. Boletín Elcano, (122), 11.

Marin-Bevilaqua, J. O., Feixa-Pàmpols, C., \& Nin-Blanco, R. (2013). Jóvenes inmigrados en LleidaCataluña, España: transiciones escolares y laborales en un contexto de crisis. Revista Latinoamericana de Ciencias Sociales, Niñez y Juventud, 11(2), 493-514.

Martín, M. J., Martínez, J.M., \& Rosa, A. (2009). Las bandas juveniles violentas de Madrid: su socialización y aculturación. Revista Panamericana de Salud Pública, 26, 128-136.

Medina, E., et al. (2010). Inmigración y desempleo en España: impacto de la crisis económica. ICE, Revista de Economía, (854).

Mignolo, W. (2003). Los estudios culturales: geopolítica del conocimiento y exigencias/necesidades institucionales. Revista Iberoamericana, 203, 401-415.

Mignolo, W. (2012). Local histories/global designs: coloniality, subaltern knowledges, and border thinking. New Jersey: Princeton University Press.

Miller, J. (2001). One of the guys: Girls, gangs, and gender. Oxford University Press, Inc. New York.

Núñez Castillo, K. Y., \& Torres, M. O. (2018). Categorías hegemónicas de género, perspectivas de género y roles de género en el análisis de las denominadas "bandas latinas." Metamorfosis. Revista Del Centro Reina Sofia Sobre Adolescencia y Juventud, (8), 84-102.

Queirolo Palmas, L. (2013). Entre lo barbárico y el olvido. Los medios y la producción de las bandas en la España contemporània. Quaderns de l'Institut Català d'Antropologia, (29), 91-110.

Queirolo Palmas, L. (2014). El problema de las bandas en España como objeto de producción académica y de activismo etnográfico. Revista de Sociología, 99(2), 261-284. https://doi.org/10.5565/rev/papers.595

Queirolo Palmas, L. (2017). ¿Cómo se construye un enemigo público? Las “bandas latinas.” Madrid: Traficantes de Sueños.

Rodriguez G. R, C. (2010) Grupos juveniles de carácter violento: estrategias de intervención en el Congreso internacional de responsabilidad penal del menor, Madrid, 12-13 febrero 2008

Rodríguez, P. (2018). Los migrantes que han estado tutelados en centros de menores: "Basta de hablar de nosotros sin nosotros". Retrieved from: https://www.eldiario.es/catalunya/exmenas-colectivojovenes-migrantes-extutelados_0 840266123.html

Rubin, J. Z., Pruitt, D. G., \& Kim, S. H. (1994). Social conflict: Escalation, stalemate, and settlement (2nd ed.). New York, England: Mcgraw-Hill Higher Education. 
Ruiz Bosch, S. (2015). Organizaciones y grupos criminales. Noticias jurídicas. Retrieved from: http://noticias.juridicas.com/conocimiento/articulos-doctrinales/10446-organizaciones-y-gruposcriminales/

Scandroglio, B., \& López, J. S. (2010). Investigación-acción-participativa con la agrupación Latin King en Madrid: potencialidades y límites de una estrategia alternativa al control de los grupos juveniles conflictivos. AIBR. Revista de Antropología Iberoamericana, 5(2), 223-255.

Thrasher, F. M. (1927) The Gang: A Study of 1313 Gangs in Chicago. Chicago, IL: University of Chicago Press.

Wacquant, L. (2008). Urban outcasts: a comparative sociology of advanced marginality. New York: Polity.

Wacquant, L. (2011). Forjando el Estado Neoliberal. Workfare, Prisonfare e Inseguridad Social. Prohistoria, 16. https://doi.org/10.1007/978-3-658-18201-4_4

Wolf, S. (2017). Mano Dura. The Politics of Gang Control in El Salvador. Austin, Texas: The University of Texas Press. 


\title{
4 Youth street gangs in Marseille: Ethnicity, social mediation and multigenerational spaces
}

\author{
Juan Camilo Mansilla \\ Translation into English by Laura Styles
}

\subsection{Introduction}

The purpose of this study is to inscribe the research perspective of the TransGang project (Feixa et al., 2019) in two dimensions. The first is the theoretical output of studies of youth street gangs ${ }^{27}$ (bande des jeunes ${ }^{28}$ ) in France, with a focus on Marseille in particular, so as to understand the historical impulse of the current living spaces of young Maghreb-Europeans in Marseille's “cités" (marginalized neighbourhoods ${ }^{29}$ ). The other dimension is the particularities of social mediation of the youth in marginalized neighbourhoods in Marseille, a city with a stark socioeconomic contrast between those who live in the neighbourhoods in the north (immigrants) and those in the south (autochthonous people). The focus of the study is the dynamics of these youth street groups, their relationships with other agents of socialization (government, school, family, religion, associations, the Internet), the foundations of their subjectivities (ethnicity ${ }^{30}$, ghettoization), their spaces of interaction (transnational, face-to-face, virtual, political, illegal) and their forms of social mediation (community, institutional) 31. The overall objective is to understand the impact of multigenerational spaces in the

\footnotetext{
27 In the TransGang project, the term "gang" is defined as follows: "an informal youth group, typical of urban popular areas, characterized as being linked to a local territory, having situational leadership and a moral solidarity that is shared among its members " (Feixa et al., 2019, p. 115).

28 The term "bandes des jeunes" has been translated as "youth street gangs". However, it is important for the reader to understand that "youth street gangs" refers to a group of friends of young people from the marginalized neighbourhoods of big cities who are suffering from social, school or family breakdown but who are not necessarily involved in criminal activities. $C f$., section "3.1. [Background] Terminology of gang studies in France". In this study, the terms "youth street gangs", "youth street groups" or simply "gangs" are synonymous.

29 "Working-class neighbourhood", "popular neighbourhood" y "marginalized neighbourhood" - or simply "the neighbourhoods" (except unless indicated) are synonymous in this study.

${ }^{30}$ Ethnicity is not to be confused with xenophobia, Islamophobia or racism. In this paper, "ethnicity" is used as a strategy by those who are stigmatized to obtain "secondary benefits" (Goffman, 2006, p. 21), that is to say that ethnicity is the transformation of a stigma into an emblem. On the other hand, xenophobia, Islamophobia and racism refer to the forms that said stigma can take. It is clear that both processes are interdependent, given that "what is normal and what is stigmatized are not people but rather perspectives" (Goffman, 2006, p. 160). Cf., section "Ethnicity: The opposite of Maghrebi youth stigmatization".

31 These different forms of interaction between the actors being studied occur in the "campo banda", which "aims to incorporate all agents that form a part of it (including the State, academia, the media, the gangs themselves among others) in order to understand how this ecosystem works, what position each
} 
mediation of conflicts within youth gangs and as well as between them and their ecosystem (gang field). It is also intended to understand the impact of these mediation practices on the life trajectory of these young people and whether or not they can be considered as a "set of lasting changes in the lives of individuals" (Mohammed, 2015, p. 48).

In Marseille, urban marginality (the product of territorial regulations with the consequences of segregation and racism (D. Lapeyronnie, 2005), territorialisation of the immigrant working class primarily in the neighbourhoods in the north with some in the city centre as well as the impoverishment of certain neighbourhoods due to the precarity of living conditions) leads to ghettoization of this part of the population. Historically and because of its geographical location, Marseille has been a key link between the Mediterranean Arab world and Europe, being one of the main immigration hubs in the region for the Maghreb population, and in particular those from Algeria and the rest of Africa. In the 1960s, dormitory districts with social housing (made up of HLM blocks of flats ${ }^{32}$ ) began to appear. These were destined for the immigrant working class and weakened the solidary and community-focused way of life that was found in the working classes in the city (Chamboredon \& Lemaire, 1970; Coing, 1966; Schwartz, 1998). Over time and due to economic stagnation and the false perception of upward social mobility, some children of the working-class immigrants turned to crime ${ }^{33}$. This new generation, born in French territory to either one or two first-generation immigrant parents (mostly Maghrebi) did not allow the functional urbanism which gave their parents access to affordable housing be imposed upon them as a form of exclusion. In 1983, against a backdrop of Arab xenophobia ${ }^{34}$ which was marked by police brutality and ratonnades (civilian anti-Arab torture commandos) (Libération (newspaper), 1979), this new generation demanded equal political rights during the Arabs' March (Pigenet \& Tartakowsky, 2003), which was inspired by the US model of non-violent marches to defend civil rights.

In the early 1990s, the young people from the banlieues $^{35}$ of Paris and Lyon took the lead in violent urban revolts and clashes with police forces. In 2005, the most recent and disruptive revolt of them all took place in the outskirts of Paris and spread to more than 300 communes in the country, lasting for almost three months. Surprisingly, the

agent occupies (even though the position may vary) and also to see what dynamics are produced" (Feixa et al., 2019, p. 114).

32 Rent-controlled social housing, Abbreviation from term in French. HLM (habitation à loyer modéré).

${ }^{33}$ Crime is not only understood to be in the materialistic sense but also as an act of performance or one for pleasure. For more on this perspective, see Jeff Ferrel and his work on cultural criminology (Ferrell et al., 2008).

34 The term "Arab" appears in media and political discourses with the intention of homogenizing different non-Western cultural groups. From a critical perspective, the term Islamicate coined by historian Marshall GS Hodgson, is useful for referring to the "dynamic mosaic of social and cultural life forms that exist not only in Muslim-majority societies, but also in diasporic Muslim communities" (Saffari et al., 2017, p. 2).

35 Cf., Section "[Background] The banlieue and the cité in France and in Marseille". 
working-class neighbourhoods of Marseille remained on the fringes of the violent actions of the révoltes des banlieues $^{36}$. Marseille's popular associative network, managed by the young people from the neighbourhoods themselves and supported by the local government, was one of the reasons for stability in the area during this time of unrest (Cesari, 1994, p. 73). Since then, there has been a large number of economic and social changes in France, which have had an impact on the life of the young people in the cités and the way they organise themselves. Drug trafficking has brought with it new forms of crime, immigration and ethnic origin have taken on a new fundamental importance and Islamophobia (Hajjat \& Mohammed, 2013; Liogier, 2012), xenophobia (Althabe, 1985) and the topic of national identity are at the forefront of national debate. Obviously, it is not long before the combination of the cités and certain transnational drug trafficking rings present in France appear in the media and political debates. This reinforces the idea of criminality in cités and increases repressive measures.

An analysis of the social geography in Marseille indicates that the poverty rate in Marseille at $26 \%$ is the highest in the country and that the poverty rate for those under 30 is $34 \%$, which, along with Montpellier, is the highest in France (INSEE, 2020). The priority neighbourhoods in the city (a national government classification for homes with lowest incomes) are the poorest in the whole of Metropolitan France (Durieux, 2016). In the marginalized neighbourhoods of Marseille (which are mostly in the north of the city), between $21 \%$ and $34 \%$ of the young people between 15 and 29 years old have no formal qualifications from compulsory education (AGAM, 2015). A large proportion of young African immigrants aged between 15 and 24 do not go onto Higher Education, which conditions their work trajectories. This logic is reinforced by the location of the employment areas on the outskirts of the city, mostly in the north and east, since this is where the most-accessible sectors for low-skilled young people are over-represented: transport, construction and industry (AGAM, 2013). There are many reasons which make Marseille a relevant and highly complex case study of the formation and disaffiliation of youth street groups as well as on the experiences of cultural resistance, crime, neighbourhood solidarity and social mediation: its sociohistorical uniqueness, the living conditions (economic, school, work) of young people in popular neighbourhoods, its dense associative network, local institutional social mediation policies and its strategic location in drug trafficking into Europe.

In the gang field (Feixa et al., 2019, p. 65), a direct confrontation (illegal economies and violence) or the adaptive response (cultural resistance or youth associations) are not a specific or recurring event but rather they represent a system of communication (codified by nature) between the actors in the gang field and these actors and the surrounding society. The adaptive response leads to different experiences of social mediation in the neighbourhoods. The grands frères et grandes sœurs (GRAFS) (Big brothers and sisters) are an important figure in the social mediation that takes place in

${ }^{36}$ The most significant were Vaulx-en-Velin in 1990, Sartrouville in 1991 and Clichy-sous-Bois in 2005. 
Marseille's marginalised neighbourhoods (Duret, 1996). The autonomy of the youngest is the leitmotif of relationships with the GRAFS, who are "more like a reference than a model" (Soto \& Therme, 1999, p. 57), for both conflict mediation channels and the increasing intensity of forms of illegality. However, there are other forms of community mediation, such as informal sports meetings (outside in the street, in informal spaces, without adult supervision, not as part of sport associations). The logics of informal sport socialization, channelling adolescent violence and its possible effects on gang-related delinquency in Marseille have been studied very little, except for Duret's analyses on sports sociability in the cités (Duret, 1996) ${ }^{37}$. Football provides an interesting example of social mediation in Marseille, where other factors such as gender, age and social class converge. The social mediation of conflicts in the neighbourhood where these youth street gangs operate is part of a continuum. Community and institutional intervention are rarely separated and in fact, they are frequently combined to some extent depending on the political and social context. Nowadays, virtuality is another of the fundamental dimensions of gangs in that the gang field is being developed in a "hybrid public space" (face-to-face and virtual) (Mansilla, 2015, p. 615). The main characteristic of this hybrid space is its flexibility and the sensation that the young people from marginalized neighbourhoods have of "not being watched" (Mansilla, 2017, p. 380). This space changes the characteristics of the gang's other spaces (political, social, education, religious, family and neighbourhood) and places (street, neighbourhood, public transport and mosque).

This study is divided into five sections. The first section (State of the art) presents the main theoretical concepts that will be used in the study of Marseille and how they are thought to relate to each other. The second section (Empowerment, conflict and mediation) contextualises the experiences of social mediation in Marseille (institutional and community). The third section (TransGangs in Marseille) discusses the viability of the concept of advanced marginality and ghettoization of gangs in Marseille and analyses the ways gangs use virtual spaces. The final section (Conclusions) analyses the four main investigative dimensions in this study, presents hypotheses for future investigation and synthesizes the main theories of youth gang formation in France.

\subsection{Terminology of gang studies in France}

Despite the fact that the majority of studies on young people and the streets in France agree on the multifaceted nature of these groups and their activities (as explained below) the terms used in these studies do not reflect the alleged neutrality that is sought by using of "youth street groups" (Feixa et al., 2019, p. 118). In France, the most

\footnotetext{
${ }^{37}$ Research by Gaspar Maza (Maza \& Sánchez, 2012) on the role of sport in inclusion and segregation of immigrant populations in Catalonia are an important reference of the phenomenon in multicultural societies.
} 
commonly-used term is bandes des jeunes (gangs of young people) (Mohammed, 2016), which implies the deviant character of said socialization: groups of young people who are considered to be delinquents (due to stigmatization from society) in social, family and school ruptures. Sometimes the term bande d'adolescents [youth gangs] (Robert \& Lascoumes, 1974) appears, which highlights the age of its members and carries the same connotation of social deviation. The term jeunes des cités (young people in poor neighbourhoods) (Sauvadet, 2005) transfers by metonymy the conditions for their exclusion from young people's living spaces to their forms of socialization. Apart from "youth street groups", the most neutral term is jeunes en groupes non encadrés (young people in unsupervised groups) (Boucher, 2015), which refers to groups of young people who are not under the social control of adults (family, school and institutional). In the collective and media imagination, the first three terms identify a group whose members are under 30 years old, are the product of waves of immigration (likely from French ex-colonies in Africa), pose a danger (to their environment and to themselves) and live in the outskirts (both spatial and social) of the big cities. However, the term gang does exist, although it is usually associated with organized crime, delinquency and illegal businesses with leadership and hierarchies similar to the gangs in North America (Fize, 2008; Mohammed \& Mucchielli, 2007). In French collective imagination, les bandes des jeunes are considered actors of petty crime (drug micro-trafficking and dealing) while gangs "are in the big leagues" (in that they are armed and are mentioned once or twice a year on television). A study which looked at students aged between 12 and 16 in secondary schools in France showed that the participants used the term gang to refer simply to their friendship group (Blaya \& Gatti, 2010). This highlights that young people may refer to themselves as gangs but they are not always involved in criminal activity (Fize, 1993, 2008). Other ethnographic studies of the peripheral neighbourhoods of Paris have shown that young people perceive the term gang as an extra-stigmatization of the fact that their neighbourhoods are marginalized and prefer to refer to themselves as team, clique or crou (Moignard, 2007).

\subsection{The "banlieue" and the "cité" in France and in Marseille}

The word banlieue (suburb) is used to refer to a part of an urban agglomeration outside the administrative limits of the city centre (Rey, 1998). The term banlieusard refers to a person who lives in the banlieue of a large city. However, it is frequently used as a synonym of young people in popular neighbourhoods and is highly pejorative. During the first half of the $19^{\text {th }}$ century, while most European cities were knocking down their defensive walls, Paris, under the July Monarchy, decided to build them. This logic of separation between Paris and its surroundings had a significant socioeconomic consequence: industrialization, much like the population flow that this entails, took place in the periphery, in the nearby banlieue. The current idea of the banlieue as a peripheral space stems from the Parisian collective imagination, which has developed in 
all large cities in France. Between 1957 and 1970, neighbourhoods of social housing were built in the outskirts of these large cities. These "priority urban development zones" (ZUP in French) replicated the Parisian model (Mesure \& Savidan, 2006). One such case is Lyon, where the social housing (habitation à loyer modéré or HLM) was built to the east of the city, far from the centre. In France, generally speaking, popular neighbourhoods are synonymous with those on the periphery, far from the city centre. However, Marseille is an exception to this. Many of its poorest popular neighbourhoods (les quartiers) are located in the city centre itself, which corresponds more closely to the inner city model of the large cities in Britain (Harrison, 1985; J. Moore, 1992) or North America (Wilson, 2006). F. Dubet (1995, p. 143) described the feeling of exclusion and marginalization in the most disadvantaged banlieues as:

To this spatial marginality, it must be added that the inhabitants of the "difficult" banlieues also constitute captive audiences of certain urban facilities. There is only one school or college that must deal with the reputation and all the problems in the neighbourhood. There is also one single shopping centre and sometimes just a coffee shop and a single recreation centre. And if the presence of these facilities leads us to likening the quartiers in the north of Marseille to the ghettos of Washington, the fact is that the sensation of exclusion and marginality weighs too heavily on the lifestyle of those who live in the French quartiers. ${ }^{38}$

\subsection{Introspection of the act of investigating and shared knowledge}

Adapting to the field of youth street groups and gaining the trust of those being interviewed requires a certain level of understanding of the codes used in street interactions. An ethnographer must be able to "slip seamlessly into the environment that they study, make themselves forget" (Sauvadet, 2010). My personal story has given me the chance to learn about certain codes of interaction in the street culture of young people from the Maghreb and Africa in France. This does not mean that I am able to understand everything in their interactions, especially considering that their ways of socialization are constantly evolving and being updated. Rather, it allows me to understand the how, the when and to what extent the lines of respect and value are applied to my interactions with these young people. It is a type of savoir-être of the street that can be adapted to different situations.

When I arrived in France from Colombia, I spent my first years in Paris living in a residence for working young people, where I met other immigrants from abroad. The residence (le foyer) was a special place for us: a refuge in a new environment in which we were all young and immigrants. In the foyer, I learned first-hand about the African and Maghrebi culture of those in the banlieues of France, embodied by young workers who settled in Paris and with whom I would go on to maintain close friendships. Years

38 Translated into English for the purpose of this paper. 
later during my doctoral research, I stayed in touch with young immigrants from subSaharan Africa and the Maghreb who lived in the popular neighbourhoods in Paris. The year prior to becoming involved in the TransGang project, I worked as a "Learning Assistant" in a priority neighbourhood in the Parisian banlieue, in a public technical high school. Basically, I had to keep an eye on the students and remind them of the rules as they arrived and left the school, during breaks and during lunchtime in the canteen. The students were mostly male aged between 14 and 18 years old, and were black and Arabs from working-class immigrant families. The absenteeism rate was very high. Many of the students were considered "difficult cases" with disrupted schooling and a dysfunctional family background. I had very good relationships with the students, perhaps because I was the youngest learning assistant. The fact that I was Colombian was always a good conversation starter, given that the students wanted to know if Colombia was as dangerous as it was depicted in television shows. Against the backdrop of national demonstrations by the yellow vests, many of the students threw stones through the school's windows, burned rubbish bins and blocked access to teaching rooms. It was traumatic for many teachers and some administration staff.

The purpose of this reflection is to make clear the advantages and dangers of this street savoir-être for this study. Perhaps the greatest advantage lies in being able to have access to the research field in a more discreet way. On the other hand, the main disadvantage may be not giving certain interactions or behaviours as much attention as necessary because they are classified as "normal" or "common" for all young people in popular neighbourhoods in France and they are therefore considered "of little importance" or "annoyances" for a clear analysis. J. Monod stated that young people in gangs were much more advanced than he was at the time of conducting his research on the blousons noirs (Monod et al., 2008, p. 47). This argument is equally valid regarding my research in Marseille.

\subsection{State of the art: Studying (trans)gangs in Marseille}

Gangs of young people (bandes de jeunes) in France have historically been defined on the basis of multiple factors, mostly in relation to the social, migratory, territorial, ethnic and economic context. Young people from working-class neighbourhoods form gangs based on the common history that they have shared since their childhoods (the neighbourhood), the similarity of their socioeconomic conditions (immigrant and working-class populations) and the conflicts that they have with adult institutions (family, school, police) (Esterle-Hedibel, 1996, p. 121). The rupture with social norms in relation to their immediate environment (neighbours, institutions, other young people) (Robert \& Lascoumes, 1974, p. 48) in response to the socio-spatial marginalization that they suffer is one of the characteristics which defines them. The purpose of this transgressive dynamic is two-fold: "identity and conflictual" (Mohammed, 2016, p. 17). This means that it is possible to consolidate the collective 
identity among peers while rejecting the legitimacy of the logic "suffered" by their social environment.

Like any space of sociability, "the gang space is a place of exchanges, confrontations and ideological development" (Mohammed, 2007, p. 4). The discourse of victimization is extremely widespread among the inhabitants of popular neighbourhoods, mainly among youth street gangs (Mohammed, 2007, p. 6) and not without reason. In the heavy media coverage of the révoltes des banlieues ${ }^{39}$, youth gangs were portrayed as criminal actors, depriving them of all political consciousness (Mohammed, 2007, p. 1). The urban revolt in the cités, a corollary of endemic violence caused by racial segregation, poverty and economic exclusion (D. Lapeyronnie, 1993, p. 10), was reduced to a simple act carried out by criminals for which the solution was police intervention.

Youth gangs are also characterized by their volatility to form and dissociate (Robert \& Lascoumes, 1974, p. 51). Their informal nature does not mean that their social interactions are anomic. It is quite the contrary. The social norms of gangs are highly encoded and failure to follow them is often punished by exclusion from the group. Unlike the ritual practices sought by the structuralist current in the 1960s, the "primary rite" of the youth gangs is "the periodic reinvention of the negative myth that is substituted by the living conditions imposed on them"40 (Monod et al., 2008, p. 50). It is also important to remember that the marginality of these young people, as well as the performative nature of their actions (both in real life and virtually) are the primary fuel of the gang phenomenon. The practice of the supposed "blind violence" by gangs of young people with popular roots in large French cities therefore has a social function. The phenomenon of violence in these gangs, their territory disputes with other gangs in the area and the culture of the cité (which is a volatile atmosphere in itself) fulfil positive social functions of solidarity within the group (Monod et al., 2008, p. 50). This violent behaviour changes the hierarchical positions of the members within the gang, and of the gang itself with other actors in the neighbourhood, as explained by $\mathrm{T}$. Sauvadet (2005, p. 118):

Therefore, [the gang's violent behaviour] takes on a rational and relational character and creates social ties. Over time, physical violence causes the formation of defence and attack networks, and creates war-like solidarity and generates social control.

Violent actions express the social structures within gangs, the group's position in the gang field and several cultural references: their relationship to the body, the way men

\footnotetext{
${ }^{39}$ Translation: Riots in the suburbs of Paris. In October 2005, during a police chase, two young people from Clichy-sous-Bois, a popular neighbourhood in the outskirts of the north of Paris, went into a highvoltage power station and were electrocuted. Their death provoked three weeks of violent confrontations between the police and the young people in the popular neighbourhoods, followed by riots in more than 300 communes throughout the country.

${ }^{40}$ Own translation from Spanish for the purpose of this paper
} 
and women behave towards each other, strategies for resilient resistance, coming of age and the conceptions of instantaneity and the future. For example, hip hop culture (graffiti, tags and rap) are evidence of how highly encoded social norms (language, clothing and graphism) are in youth street groups (Masclet, 1990, p. 122) and are something that can appear meaningless from an outside perspective.

A paradox defines the field of youth street groups: These young people are visible insofar as the more their social breakdowns increase, the more their violent behaviours are mediated. Monod (Monod et al., 2008, p. 45), a pioneer in the ethnography of youth gangs in France, argues that these young people live in a state of deficiency and rupture and that they are constantly alternating between attempts at freedom and compensation (due to peer solidarity and territorial proximity) and repression (from the world that is imposed on them). In addition to this, these young people also have symbolic identifications that allow them a feeling of belonging and trust within the group (being valued $^{41}$ ). The ruptures mentioned above (family, school, cultural, social, ethnic, residential, penal) accumulate and become deeper as they are repeated. According to Monod, this confirms Lévi-Strauss' hypothesis in that "new cultures are formed in an industrial society, exactly where these ruptures are" (Monod et al., 2008, p. 54). In the current context with migratory movements between industrialization and deindustrialization, urban youth groups take shape in the interstices of a post-migration society (Queirolo Palmas, 2017, p. 23).

Age solidarity is another factor which affects the formation of youth gangs in popular neighbourhoods. They are often considered to be homogenous groups (Robert \& Lascoumes, 1974) in terms of the age of their members. Divided into gangs based on age (child, adolescent, young adult), each group has its own meeting point, name and specialization (taking drugs, delinquency, partaking in a sport or cultural activity) (Sauvadet, 2005, p. 115). However, these divisions by age are porous. Young people belong either successively or simultaneously to multiple age groups and perform multiple activities, not only based on their age. If it is understood that "gangs are a continuum" (Feixa et al., 2019, p. 45) with groups dedicated to illicit activities and others to leisure activities, all of which are susceptible to combining at any given moment, it remains pertinent to consider therefore that gang practices involve individuals of different ages. Thus, the gang is part of a social environment and intergenerational by definition.

In Marseille, the young members of gangs create solidarity in ways beyond age categories. This "intergenerational sociability, similar to that of family ties" brings together young people between the age of five and thirty around a common story: that of the neighbourhood (Sauvadet, 2005, p. 115). Thus, defining a gang by its

\footnotetext{
${ }^{41}$ Fatema Mernissi emphasizes the role of Karama (dignity) in the cases of the young people that made the Arab Spring a reality in 2011 (Mernissi, 2016, p. 15).
} 
homogeneity would be equivalent to depriving it of access to the material and symbolic resources that structure it and which are found in other age groups present in the neighbourhood (families, schools, associations, institutions and even other gangs of different ages). More than being homogenous, gangs are groups that emerge at the interstice of different age groups in the neighbourhood. The most problematic aspect of studying gangs is defining the limits of action, either continuous participation or sporadic presence of members, depending on the type of activity. In Marseille, a clear example of the intergenerational character of youth street gangs is the retail sale of marihuana. In these circumstances, it can be observed that the youngest in the groups (choufs) alert others members to police presence in the neighbourhood. The sellers (charbonneurs), only slightly older, wait inside the building. An elderly person, usually a family member or neighbour, hides the stash and the money from the sales (to avoid suspicion). Sports or cultural associations, with former gang members as well as other young people from the neighbourhood, are also an example of the intergenerational activities of youth street groups.

The street, the corner, the park, the basketball court, all in the neighbourhood, are the spaces where youth gangs live. The (re)appropriation of these public spaces, not only because of the initial use as determined by institutionality, represents the possibility of moving from a "lived social space" to an "imagined social space" for these young people (Mauger, 1994). This "street culture" typical of adolescence (Lepoutre, 1997) is built using resources that compensate for its deficiencies (both material and cultural) in comparison to the dominant society which stigmatizes them. In addition to physical capital, these young people build a "warrior capital" which directs their socialization processes. It is a "form of moral discipline (of not submitting, of defending their honour, of knowing the rules of the street) in order to be able to handle violence and vice $^{42}$ " (Sauvadet, 2005, p. 118). To a lesser extent, warrior capital is invested in processes of cultural resistance (associations and medication). For these young people, the deficiencies (scholastic and material) generate "pillars of social compensation" such as the phenomenon of gangs, which are inversely proportional to their degree of integration in school and family contexts (Mohammed, 2011, p. 22). These compensations are closely linked to reputation and materialize both in hybrid socialization networks (in real life and virtually) and in the collective identity that the gang offers.

\footnotetext{
${ }^{42}$ For the young people in these neighbourhoods, when someone has "vice", it means they know how to get away with their misdeeds. "Vice" is the difference between the neighbourhood fools and those who really know how street culture works.
} 


\title{
4.6 Empowerment, conflict and mediation
}

\subsubsection{Social mediation in marginalized neighbourhoods in France}

In 2000 in France, the Ministère de la Cohésion des territoires et des Relations avec les collectivités territoriales (Ministry for Territorial Cohesion and Relations with Local Government) adopted a definition of social mediation that highlights both the social ties and the conflicts between communities and institutions (Comité interministériel des villes, 2011, p. 10):

\begin{abstract}
Social mediation is a process of creating and repairing social ties and resolving conflicts in everyday life. During this process, an impartial and independent thirdparty attempts to help people or institutions improve their relationship or resolve a conflict that stands in their way through attempting to organise dialogue. ${ }^{43}$
\end{abstract}

Regardless of the type of mediation (institutional, criminal, judicial, family, commercial, social or neighbourhood), a series of elements are necessary. First, the intervention of a neutral and independent "third party", that does not impose a solution but rather acts as a "catalyst" (Touzard, s.f., p. 87). Second, the parties need to be autonomous and be able to initiate, interrupt or abandon the mediation. Third, there needs to be legitimacy, a cross-cutting element so that parties attribute a degree of trust and validity to the mediation process. The question of legitimacy in social mediation is of great importance in the areas of migration, particularly in the banlieues of Paris and the quartiers (cités) in Marseille, as explained below. In the 1990s, several actors in social mediation flourished in popular neighbourhoods in France. They were mostly young people of immigrant origin (second generation) who volunteered in sport or socio-cultural associations or municipal delegations located in the neighbourhoods. Some actors were institutionalised thanks to laws, such as the Agent Local de Médiation Sociale (Local Agents of Social Mediation) (ALMS) and the "night correspondents". Others enjoyed community legitimacy and progressive institutional rejection. One such example is the "grands frères et grandes sœurs" (Big Brothers and Sisters). A final group occupies the space somewhere between community and institutional legitimacy, an example of which is the femmes-relais médiatrices interculturelles (link-women for intercultural mediation).

Since the end of the 1980s in the Paris region, immigrants who had arrived years earlier and who are fluent in French have provided support for new immigrant women and families during their interactions with institutions. The femmes-relais decode a whole

${ }^{43}$ Own translation for the purpose of this paper. 
new social universe that is often contradictory and overwhelming for immigrants ${ }^{44}$. It is a "horizontal" mediation function that has broad legitimacy, as opposed to the "verticality" of specialised service, that are bureaucratic by definition (Duclos et al., 2008) The femmes-relais encourage social dialogue between the actors in the neighbourhood. On the one hand, immigrant communities have access to an interpreter, who is especially adept at explaining the French mindset and cultural codes. On the other hand, institutions are able to find out more about the people of these neighbourhoods in terms of their culture, values, needs and demands (Madelin, 2007, p. 122).

The actions that the femmes-relais associations perform range from mediation with private and public bodies (accompanying and representation) to sociocultural animation (literacy, expression workshops, cultural visits, neighbourhood parties and helping young people with their schoolwork). This shows that the legitimacy of the "third party" in the social mediation process is inscribed in a double dimension of action: the creation or repair of the social bond and the prevention or resolution of conflicts (Comité interministériel des villes, 2011, p. 12). The legitimacy of the femmes-relais in the eyes of the immigrant population is given, first of all, by the condition of being an immigrant, which is something that both parties share, and also because of the knowledge of mutual cultural references that fosters a space of trust and understanding. To a large extent, this community legitimacy is based on the expertise that the femmerelais have developed in intercultural processes and their ability to create links between the French universe and the immigrant. They do not receive a certificate to demonstrate their competencies (because such a certificate does not exist) but their skills are validated by their life trajectory. Thus, the lack of institutional legitimacy given to the femme-relais condemns them to a series of precarious jobs in civil associations, further weakened by the intermittency of public funding. However, by professionalizing their activities, there is a risk that they turn into dossier managers and that they are distanced from the popular education that they promote (Comité interministériel des villes, 2011, p. 18).

In Marseille, the Centre for Ethnoclinical Mediation plays a similar role of supporting social mediation between the parents of recently-arrived allophone students and their new urban space. The objective of this centre and its mediators is to establish a dialogue between the school, the allophone students and their immigrant families. Mediation is

${ }^{44}$ In 1971, L. Felt described a similar Dynamic in Chicago's poor African-American neighbourhoods. Given the impenetrability of government bureaucracy, several women from the neighbourhood asked for help from an elderly woman who had the only public laundry in the area. She helped them fill out forms and start different bureaucratic processes (for school, government, hospitals, banks). Then, to thank her for her help, the women in the neighbourhood gave her presents. She acted as a sort of consultation service for poor black women. H. Becker $(2014$, p. 17) described something similar regarding the despachantes in Brazil, who knew ways to speed up government procedures such as applying for passports or official certificates. Of course, both figures were in different contexts but they belong to the same category of analysis: "someone who serves as a messenger/lawyer/consultant in the management of difficult-to-deal-with bureaucracy" (Becker, 2014, p. 18). 
based on various topics such as childhood, family, the French educational system, exile and beliefs.

\subsubsection{Community integration and social mediation in Marseille}

The grands frères et grandes sœurs (GRAFS) are an important figure in social mediation for French youths of North Africa origin in the popular districts of Marseille (Duret, 1996). Institutionality prompts criticism for being "self-proclaimed mediators with no training and are not even supervised" (Comité interministériel des villes, 2011, p. 12). Despite this, the GRAFS are essential actors in their neighbourhoods. Their role as mediator and as examples in the socialization of the youngest is evidence of the social and family dynamics of youth street gangs. The GRAFS build a relationship with younger children based on the idea of respect owed to the more experienced person (les aînés), trust and emotional bonds. They are distinguishable from parents primarily due to their use of a non-prescriptive authority (Duret, 1996).

The autonomy of the youngest is the leitmotif of relationships with the GRAFS, who are "more like a reference than a model" (Soto \& Therme, 1999, p. 57), both for conflict mediation channels and for the increasing intensity of forms of illegality. The grand frère inseré (someone who has made the conscious decision to leave illegality behind him) helps to improve and value the atmosphere of the neighbourhood, intervenes in disputes between gangs, their families and school, and even gives material resources to help the youngest members. The grand frère inseré is professionalized in his role as a mediator in that, despite its contractual instability, the post is integrated into sport and sociocultural public institutions and associations in the neighbourhood.

Since the 1990s in Marseille, the second generation of Maghreb immigrants have organized themselves into civil associations (in accordance with the loi 1901 regime) as a strategy to anchor and dignify their territories (Cesari, 1994). This has also granted them access to some material resources through being awarded grants for sociocultural projects within their initiative. Most of these associations were dedicated to leisure activities (such as sports, dance, music and hip-hop culture). From an institutional point of view and thanks to direct contact with the population, the associations became the primary cog in urban development policies in socially isolated neighbourhoods. More than elsewhere, Marseille has a tradition of sociocultural intervention which is adapted for young people of foreign origin. Every neighbourhood has a social centre and at least one youth association which is supported by public bodies ${ }^{45}$. The local government considered the presence of associations in popular neighbourhoods as a sign of youth street gangs evolving, and moving towards a controlled and organized model of subsidized associations (Blöss, 1989). For institutions such as housing managers, social

45 But this does not prevent the contradictions between the national republican discourse and the "officially non-declared" management of ethnicity in local public bodies. (D. Moore \& Cesari, 2003, p. 267). 
service and the police, the associations were a means of negotiation with an interlocutor who is considered responsible. They were also considered a tool to regulate life in a neighbourhood which is considered difficult (Cesari, 1994, p. 73). From the young people's point of view, associations could be an accessible tool for social mobility.

Most youth associations are made up of people from local networks, a group of friends or a gang (Cesari, 1994, p. 73). The main objective of these associations is "to promote the socialization of the new generation in their immediate environment and to develop a dynamic of mobilization based on attachment to the neighbourhood" (Cesari, 1994, p. 74). The common denominator of the members of these associations was youth and shared life experiences in marginalized areas with a high immigrant population, rather than religious, ethnic or linguistic similarities. They were youth associations independent from Islamic networks or any foreign political influence ${ }^{46}$ that focused on hyperlocal action in the neighbourhood or residential buildings. This is different from associations for the first generations of Maghreb immigrants in the early 1980s, which were similar to the leftist movements of the 1970s, and therefore had an eminently political function of legitimizing citizens of Maghreb and African origin (Cesari, 1993, p. 87, 1994, p. 74; D. Moore \& Cesari, 2003, p. 264). Despite this, young people of the second and third generation have maintained their Franco-Maghreb identity (beurs, rebeus) when it came to decisions regarding grant allocation for their association projects (Cesari, 1993, p. 88; D. Moore \& Cesari, 2003, p. 265). Foregrounding one's own stigmatization ${ }^{47}$, attributing the idea of opportunity to an informational resource (the public policy of positive discrimination) which comes from a stigmatizing actor (the State) therefore turns into a strategy to reaffirm their collective identity (Mansilla, 2017, p. 370).

The world of the cités has frequently been characterized by its fractures and antagonisms of a social nature, including the generational one (between "young" and "old", "first", "second" or "third" generations of immigrants) (Merklen, 2006). One of the peculiarities of the associations of the second and young third-generation North Africans in Marseille is "the absence of cohabitation of generations, unlike the Comorian, African or Portuguese associations, which mix adults, parents and adolescents" (Cesari, 1993, p. 85). The most recent generation of Maghrebis is organized not to "change the world" but rather their immediate environment, which is that of their neighbourhood, as J. Cesari (1993, p. 85) explains:

These 16 to 25 -year-old individuals, when mobilized, have the objective, not to "change their lives" but to act in their neighbourhood to obtain consumer goods,

\footnotetext{
46 These associations occupy "border spaces" in that their members occupy not only a physical space (which can be peripheral) but they also have a political and social position within the modern/colonial world, which seeks to break either consciously or unconsciously with epistemic and ontological forms that are decreed as unique (Mignolo et al., 2015).

${ }^{47} C f$., section "Ethnicity: the opposite of Maghreb youth stigmatization".
} 
those related to leisure in particular, to which they do not always have access, or to fight against the effects of exclusion (drug addiction or delinquency) ${ }^{48}$.

Similar studies have shown that young people from marginalized neighbourhoods in Paris and São Paulo at first do not conceive their actions of visibility and appropriation of public space as an explicit process of assertion outside the neighbourhood (Mansilla, 2017, p. 441). As in Marseille, young people from these cities consider their actions from a local perspective, aimed at a local network of influence (neighbours, friends and family). It should be noted that access to the internet creates an external dimension, even if such a view is not included at the start of the production of referential objects for these young people (Mansilla \& Schwartz, 2017, p. 176).

The role of the grands frères et grandes sours (GRAFS) is crucial in the management of these associations in Marseille. In the 1990s, a dozen individuals aged between 30 and 40 brought about the emergence of a popular associative network which acted as an "intermediary sphere" on the periphery of local political bodies (Cesari, 1994, p. 76), and a spokesperson for the needs and aspirations of second generation Maghreb immigrants. In the context of the révoltes des banlieues in France, the popular neighbourhoods in Marseille remained relatively peaceful, in stark contrast to the large fires and acts of debasement that occurred in other cities. Furthermore, gang conflicts do not take on the spectacular form of territorial battles like in the Parisian territories (Sauvadet, 2006). The popular associative fabric in Marseille, managed by the GRAFS and the young people themselves and supported by the local government, was one of the reasons for the stability in the neighbourhoods in Marseille during the révoltes (Cesari, 1994, p. 73). The integration of the local community and the legitimization of living spaces for the second- and third-generation children of immigrants have therefore been key in all social mediation processes. Other economic, employment and identity causes are often suggested (Cesari, 1994, p. 69). M. Samson, quoted by Mohammed (2007, p. 11), listed the reasons for stability in these neighbourhoods in Le Monde on the 14/12/2005:

(a) The position of association managers (animateurs), which accounts for $74 \%$ of the jobs in sociocultural structures [community associations], are mainly occupied by young people between 17 and 25 years of age. It is a true professional sector and a real economy for the cités, areas that are often thought to not have access to legal and formal resources. The development is as strong as it is recent: jobs in the sector of urban association managers (animation urbaine) in Marseille have increased by $661 \%$ in less than 20 years. This is in contrast to the drastic reduction of funding for associations in the Îlede-France $[$ Paris $]$ region.

${ }^{48}$ Own translation for the purpose of this paper. 
(b) The free zone that spans across districts 15 and 16 [the most disadvantaged neighbourhoods] has attracted almost 2000 companies and created 10,600 jobs since 1997. More than a third of all employees that have been hired come from the surrounding neighbourhoods.(c) Samson cleverly highlights the dimension of identity. He points out that cités are not very competitive with each other and the experiences of collective violence is tempered by a regional culture. Apart from general or circumstantial reasons, all actors, and it is incredible that this is a unanimous sentiment, evoke a "feeling of belonging" to the city. This acted as a buffer between the lack of affiliation with the national identity and the excesses of territorial over-affiliation (at the neighbourhood level). ${ }^{49}$

Similarly, local government programmes for employability in disadvantaged neighbourhoods in Marseille are more developed than in other regions of the country. The Marseille Local Mission (an organization which supports young people as they seek employment) is currently the largest organization of this type in France, with 29 office locations in the municipality and 197 employees (AGAM, 2015). The awarenessraising actions of teachers in schools in popular neighbourhoods, along with family and religious networks, are also other reasons for the lack of civil unrest in Marseille during the révoltes des banlieues. Teachers held debates on the riots and the violence involved (Allemand, 2013, p. 168) and during Friday prayers, the imam warned of the risk and the illicit nature of the acts of destruction, even though the influence in Marseille was minimal (Mohammed, 2007, p. 13). Teachers were also involved in civic and extracurricular initiatives to help immigrant families, such as Le réseau éducation sans frontières (Education Network Without Borders) (RESF), which is particularly active in schools in the centre and the north of the city. These actions are also a deciding factor for young people and their parents when it comes to having a feeling of social integration into the city and public bodies (Mohammed, 2007, p. 18).

Currently, Marseille has a network of community associations led by young people from marginalized neighbourhoods that claim positive forms of socialization of nonviolent collective resistance to the logic of domination. For example, the Maison Blanche collective in the neighbourhoods of the $14^{\text {th }}$ district in the north was created in September 2018 after a $12^{\text {th }}$-floor balcony collapsed, causing the death of a minor (Carle \& Olmedo, 2019, p. 9). This event was the corollary of the municipality's historical neglect of insalubrious conditions, lack of maintenance of public spaces and the degradation of housing in these neighbourhoods. In September 2019, a fire in a poorlymaintained building that did not meet the minimum safety standards left 17 families homeless.

The search for alternative interventions to repression and to the criminalization of young people in these neighbourhoods is another important aspect of social mediation in Marseille. For example, the association Médiation Sociale Marseille (AMS) performs

${ }^{49}$ Own translation for the purpose of this paper. 
social mediation outside schools, on beaches and in neighbourhoods. For example, social mediators from AMS carry out their work in Sormiou Cove, one of the most touristic locations in the city. For several years, this cove was guarded by the repressive Republican Security Companies (CRS), a special anti-riot division of the national police. Today, Sormiou Cove is an example of alternative social intervention (Duclos et al., 2008, p. 72). Of course, despite the proclaimed independence of their interventions, the AMS mediators remain subordinate to the police framework, which often casts doubt on their legitimacy in the eyes of young people from the neighbourhood. In 2008, the AMS produced an average of 10-30 "field notes" on the situation every month. These were sent to its partners in the SLSPD (Local Council for Security and Crime Prevention) (Duclos et al., 2008, p. 54), which is the security strategy led by the Ministry of the Interior and applied by the prefects and local police commanders. The police's legitimacy strategy with regard to the young women in popular neighbourhoods is a constant challenge. For example, the association Centre Loisirs Jeunes 13 Police (CLJ) proposes that the interaction between young people from Marseille and the police should be through sports and nautical activities. Its aim is to consolidate the dialogue between law and enforcement forces and young people, using sports to teach about crime prevention and the way to leave delinquency (Source: https://www.clj13-police.fr/association).

\subsubsection{Football and young people: sport as a tool for social mediation}

Sport has been recognized as a form of integration and social mediation in Marseille's popular neighbourhoods. Several actors involved in the city's social mediation organize events related to sports. For example, the AMS and community organizations coorganize a soccer tournament for students from popular neighbourhoods. Since 2003, the sports event Le Tourni MédiaFOOT has brought together around 250 young people aged 12 and 13 years old from different neighbourhoods. The aim of the event is to "sensitize young people to mediation, prevention and respect" through playing football (Source: http://www.ams-association.com/mediafoot.html). Associative sport, which fits into a framework of a legal structure created for this purpose, aids the integration of young people into their immediate territorial community, that of their neighbourhood (Gasparini, 2005, p. 247). Playing sport can be considered a type of social affiliation which is the beginning of a dynamic of identity for young people (Le Breton, 2003).

With regard to juvenile offenders, the socio-educational potential of associative sport (Charrier \& Jourdan, 2015, p. 58) is likely to have a positive impact on channelling their violence and volatility of their impulses (Chiron, 2018, p. 81). According to this approach, sport not only fosters social dialogue but it also "normalizes" and "integrates" a group of young people in a state of "total social disaffiliation" into a group defined by the practice of a common sport (Chiron, 2018, p. 79). However, there are two aspects that this perspective does not account for: a) there is little information on female participation and interaction between different social classes (Gasparini, 2005, p. 247), 
and b) there is a lack of knowledge about the experiences of informal sport, its logic and impact on the social life in the neighbourhood. Informal sport as a possible stage for conflict mediation in the gang field in Marseille has been studied very little with the exception of an analysis by Duret (1996) of sport sociabilities in the cités.

In Marseille, football is considered to be an essential factor for social cohesion (Soto \& Therme, 1999, p. 59) and "the symbol of a specific mode of collective existence that embodies the team's style of play" (Bromberger, 1987). The information that is of interest to youth gangs, after the "specific news about gangs in the area and the local reputational space" is football, "their results, player transfers and comments on performance" (Mohammed, 2007, p. 5). The local team that plays in the first division of professional football, L'Olympique de Marseille (L'OM), forms part of the collective identity of these young people, regardless of their ethnic origins. L'OM thus constitutes "an essential factor of its social cohesion" (Soto \& Therme, 1999, p. 59). In 1998, when the French national football team won the World Cup, several of its star players were or had been a player of L'OM (Makélélé, Barthez, Deschamps, Blanc, Desailly). Contrary to what might be expected of a city known for being a mosaic of foreign cultures, the news of the national team's victory brought together young people of different ethnic origins in the same celebration. When asked about their affiliation to the national team, the young people from popular neighbourhoods in Marseille claim first of all a local identity, that of Marseille, "as if identification with the équipe de France were only possible alongside the representation of Marseille" (Soto \& Therme, 1999, p. 59). Zinédine Zidane, the then figurehead of the national team, is even more relevant to the story of second and third generation immigrants from the Maghreb in Marseille. Son of Algerian parents and a working-class immigrant father, Zidane was born in La Castellane, one of the popular neighbourhoods in the north of the city. "All these young people from the quartiers who have come to see us, it's impressive, different from the parade after winning in Paris" Zidane exclaimed in front of a crowd in the Vieux-Port of Marseille, under a giant banner which read "Proud to be from Marseille" (Tonneau, 1998). 


\section{7 (Trans)gangs in Marseille}

"Allez à Marseille. Marseille vous répondra. Cette ville est une leçon. L'indifférence coupable des contemporains ne la désarme pas. Attentive, elle écoute la voix du vaste monde et, forte de son expérience, elle engage, en notre nom, la conversation avec la terre entière. Une oriflamme claquant au vent sur l'infini de l'horizon, voilà Marseille". ${ }^{50}$

Albert Londres (Londres, 1927), Marseille, Porte du Sud

\subsubsection{Analysis of social, political and historical conditions}

\subsubsection{National context}

The current neoliberal system deepens the instability of labour relations, a consequence that allows for its consolidation to continue. In France, young people from workingclass neighbourhoods do not escape the global market system and its effects. The difficulty for these young people to find a stable job, in addition to ethnic-religious and territorial discrimination, creates a context of precarity and poverty from which their social world is (re)created. Among the less-favoured communities, historical processes have generated the loss of legitimacy in institutions (school, police, justice). The use of violence (family, neighbourhood, state) and the trivialization of illicit economies are part of the daily life of these populations. These conditions are exacerbated within the framework of a French society that, following the Western model, is based on business competitiveness and (socioeconomic) inequality between individuals. The precarity, not only of income, but also "of status, of uncertainty" is experienced by these inhabitants as social isolation (Kokoreff, 2009, p. 572).

Since 1988, faced with institutional weaknesses and seeking more effective social control, France has intensified public policies of "urban social development" in sensitive neighbourhoods (due to their material and economic precarity) (Cesari, 1993, p. 87). However, since the beginning of 2000 , repressive management policies in these neighbourhoods have increased, degrading relations between their inhabitants and the police forces. Since then, a large number of economic and social changes have taken place in France, impacting the lives of the young people of the cités and their forms of organization. Drug trafficking has introduced new forms of crime, the issue of immigration and ethnicity have now taken on a fundamental importance, and Islamophobia (Hajjat \& Mohammed, 2013; Liogier, 2012), xenophobia (Althabe, 1985) and the question of national identity are at the forefront of national debates.

\footnotetext{
${ }^{50}$ Go to Marseille. Marseille will answer you. This city is a lesson. The culpable indifference of contemporaries does not pull her apart. Attentive, she listens to the voice of the whole world and, with the strength of her experience, she engages, on our behalf, in conversation with the entire world. A banner flapping in the wind on the infinity of the horizon, this is Marseille. (Own translation for the purpose of this paper)
} 


\subsubsection{Immigration stories: Marseille, a working-class city, a popular city}

Historically and thanks to its geographical position, Marseille has been a key link between the Mediterranean Arab world and Europe and it is one of the areas in the region that has most immigrants from North Africa. During the 1960s, massive flows of immigrants from Algeria arrived in Marseille. The most significant took place in 1962, just after the Evian agreements that ended the French occupation of Algeria and declared its independence were signed. France opened its borders to attract new labour and there was an exodus of families and workers seeking better living conditions in France. Marseille was their first port of all. "In May 1962, 101,250 people left Algeria, 354,914 in June, 121,020 in July and 95,578 in August" (Moumen, 2010). The years of mass arrival of an Algerian labour force show the colonial logic in multiple ways: the birth of a social policy (Viet, 1998), accommodation of immigrants (Bernardot, 1999), emergence of colonial racism (Gastaut, 2000) and categorization of French Muslims (Spire, 2003). In the late 1990s, the first papers on the "decolonization" of research on immigration appeared (Gallissot, 1997; Liauzu, 2002; Liauzu \& Blili, 2004).

Marseille remained an important port city until the mid- $20^{\text {th }}$ century but has experienced a double economic and social crisis since the 1970s, which was mainly linked to the decline of its maritime function and abrupt deindustrialization. Its local industry (soap factories, olive oil, ship maintenance, metallurgy, food and agriculture) almost disappeared. With more than $90 \%$ of HLM built in the east and north of the city (as a result of the 1959 urban plan), the workers primarily settled in the $13^{\text {th }}, 14^{\text {th }}, 15^{\text {th }}$, and $16^{\text {th }}$ districts (Dell'Umbria, 2008, p. 44) and in Belsunce in the city centre. The construction of the HLM coincides with the port and industry crisis and the increase in unemployment, mainly among young people (Dell'Umbria, 2008, p. 44). The living spaces in the HLM weakened the solidarity and neighbourly way of life of the popular classes in the public city (Chamboredon \& Lemaire, 1970; Coing, 1966; Schwartz, 1998). In Marseille, the development of the domestic sphere of the popular classes, together with the emergence of HLM housing, was the response to the lack of collective consumption and the lack of transportation (Donzel, 2014). The social changes were drastic. Residents had everything they needed in the new residences (heating, bathrooms and kitchens) and this accentuated the sphere of private consumption and consequently limited neighbourhood interactions (Dell'Umbria, 2008, p. 47).

In the 1970s, the rise of the communist party and the socialist party in the popular neighbourhoods of Marseille (Bon et al., 1988) earned it the distinction of "Marseille, working-class city, popular city". From the mid-1980s, the right-wing parties (UDF, RPR, FN) began to consolidate an electorate in the Marseille neighbourhoods that had high proportions of the Maghreb immigrant population. The main reason for this was "high unemployment, the crisis of local industries and social marginalization" (Cesari, 1994, p. 71). This indicates that the political action of these Maghreb populations responded more to an opportunity for adjustment and eventual compensation for 
deficiencies than to an ideological alignment in the traditional terms of political exercise $^{51}$.

Marseille was popular, working-class and highly unequal but it has become a place of arrival (via railway and sea), of transit (to other cities in France and northern Europe) and of settlement (in the city centre and neighbourhoods in the north) for the immigrant populations coming mainly from the Mediterranean basin. Marseille's city centre is a space of resources for the Maghreb population (Jordi \& Témime, 1991): low-cost furnished hotels, (hôtels meublés), prayer rooms, bazaars, open-air markets, halal shops and restaurants, hairdressers, associations and institutions for daily support and guidance. It is therefore a space of high sociability and solidarity of successive generations of immigrants (Audren et al., 2018, p. 95) with continuous movement to the northern neighbourhoods. For immigrants who arrive in Marseille, "access to the northern neighbourhoods is a second step. First you get to the city centre and from there, mobility continues" (Audren et al., 2018, p. 99). The neighbourhoods in the north are where most of the social housing (HLM) is located and this facilitates access to more stable housing for immigrant populations. The city centre has also been neglected by public policies.

In Marseille, the division between urban groups is not between "popular classes" and "bourgeois classes" but rather between those from Marseille and immigrants (Cesari, 1994, p. 70). The idea of the immigrant, and their space of residence, work and recreation is associated with the idea of the Maghreb, accentuating the social gap between the northern neighbourhoods (mostly immigrant) and the southern neighbourhoods (mostly those from Marseille). The equation is unerring in the collective imagination of the city: "northern neighbourhoods = immigrants = Maghrebi" (Cesari, 1994, p. 70), although it is necessary to clarify that families of various origins (sub-Saharan Africa, Comoro Islands, etc.) reside in these neighbourhoods. In November 2018, two residential buildings on Aubagne Street in the historic and popular neighbourhood of Noaille collapsed, causing the death of eight of its residents, all of whom were immigrants. The event highlighted the precarious housing conditions of these populations in Marseille. Since then and in a context of popular marches denouncing the indignity of life in Marseille for the poorest, some 1500 people have been relocated by order of the local government (Marcelle Media, 2018).

\subsubsection{Youth unemployment in "priority" neighbourhoods}

Marseille is frequently presented as a "dual" city (Donzel \& Moreau, 2005), marked by the socioeconomic differences between the southern neighbourhoods with its

\footnotetext{
51 A similar phenomenon occurred with African Americans after the Civil War in the United States, when Abraham Lincoln, a member of the Republican Party, proclaimed the emancipation of black slaves. African Americans voted for the Republican Party candidates for many years, thus, responding in a coherent way to the promoter of the recent measures in their favour, while rejecting the influence of the Democratic Party, which at the time opposed Lincoln and his policies on racial issues (Becker, 2014).
} 
autochthonous inhabitants and high-income households and the northern neighbourhoods, which are historically territories of immigration and have a popular character. The socioeconomic conditions of the neighbourhoods in the city also reflect the divide between the north and the south. Young people in disadvantaged neighbourhoods in the north and northeast have the most difficulty accessing employment. Several factors play a decisive role in this phenomenon. The first is the national context. In France, young people whose parents were born abroad (issus de l'immigration), are twice as likely to be unemployed than those whose parents were born in France, despite having an equivalent academic level and trajectory (Brinbaum \& Guégnard, 2011). The second is territorial segregation. The risk of unemployment is 1.5 times greater for young people who live in areas classified as "priority neighbourhoods of city policy (QPV)" 52 . In the districts of Marseille, there are 50 of the 128 QPVs of the PACA region, most of which are in the area to the north and northeast of the city (28) and very few are in the districts in the south $(4)^{53}$. The third is socioeconomic inheritance. In schools located in Marseille's priority neighbourhoods, $66 \%$ of the students come from disadvantaged social groups, compared to only $19 \%$ of students in disadvantaged groups in schools that are located outside a priority neighbourhood (AGAM, 2015). All three factors combine to place obstacles in the job search trajectories of these young people.

\subsubsection{Islamophobia: The French case}

Islamophobia, as a current phenomenon, is caused by the presence of minority Muslims that are no longer in transit in French territory. Unlike those of the last century, today, these minorities have settled, become sedentary and make up a significant part of the French population (Liogier, 2012). The fundamental issue is the legitimacy of Muslims in French territory in the postcolonial era. The "Muslim problem" (Mayer et al., 2013) is the result of how the French authorities have handled the "migration problem" in the past, predominately in three main phases: the post-WW2 era in the late 1940s, after Algerian independence in the early 1960s and during deindustrialization beginning in

\footnotetext{
52 Since January 1, 2015, public action has been refocused on the most disadvantaged neighbourhoods (referred to in French as QPVs, quartiers de la politique de la ville). The QPV are areas of urban concentration of low-income populations. Low-income is defined by an approach that combines two factors: The first is the gap in comparison to the income of others in the agglomeration that the neighbourhood is situated in and the second is the comparison with the average income of homes in metropolitan France. This identifies approximately 1300 priority neighbourhoods with more than 1000 inhabitants each, located in agglomerations of more than 10,000 inhabitants. These neighbourhoods are characterized by high unemployment rates, a large proportion of young people without formal qualifications, a large number of single-parent families, low fiscal protection and a significant immigrant population by percentage.

5313 are in the centre-east periphery $\left(10^{\text {th }}, 11^{\text {th }}\right.$ and $12^{\text {th }}$ districts $), 28$ in the north and north east $\left(13^{\text {th }}, 14^{\text {th }}\right.$, $\left.15^{\text {th }}, 16^{\text {th }}\right), 5$ are in the centre $\left(1^{\text {st }}, 2^{\text {nd }}, 3^{\text {rd }}, 6^{\text {th }}\right)$ and there are 4 in the south $\left(9^{\text {th }}\right)$. The rest of the districts in the central zone (4th, 5th) and the southern zone $\left(7^{\text {th }}\right.$ and $\left.8^{\text {th }}\right)$ do not have QPVs. Source: Système d'Information Géographique (SIG) and Agence nationale de la cohésion des territoires (ANCT) : https://sig.ville.gouv.fr/
} 
the 1970s. The most noticeable recent event in this regard is the 2003-2004 regulation of the "new secularism" ideology, as explained by (Hajjat \& Mohammed, 2013, p. 145):

[It's a matter of] "a reconfiguration of the division between the public and the private by rejecting the expression of conspicuous religious signs in the public space, and by the intrusion into the private space in order to measure respect for republican values."

Because of this, Muslim women are prohibited from displaying any expression of Islam at work, university and in healthcare services. Muslim girls, adolescents and mothers cannot wear the veil in public schools. The wearing of any kind of veil covering the face, such as the niqab or burqa, in public spaces is punished. Gender discrimination is therefore included in the debate on Islamophobia (Mirza, 2013). In the case of France, Islamophobia is anchored in a value system that sustains the construction of the "Muslim problem", according to "a norm of homogeneity within which men and women are coordinated based on secularism and equality" (Baubérot, 2012).

In the research field, Islamophobia is more than a concept; it is a political exercise from the State which seeks to avoid the "risks of instrumentalization" of a racialization phenomenon. Islamophobia is defined as a "complex social process of racialization or alterization based on a sign of belonging (real or imagined) to the Muslim religion" (Hajjat \& Mohammed, 2013, p. 20). In other words, Islamophobia places a category of individuals in a homogenous, static group, which is different from "us", one that is based on stigmatization of religion and race. In political and media discourse, the question of religion has overshadowed other cultural foundations that define this minority as individual Arabs and Muslims. In a reductive way, "it is believed that religious affiliation is the final determinant of individual and collective behaviour" (Hajjat \& Mohammed, 2013, p. 183). Islamophobia fuels the perception of unworthiness of young Maghrebis because "it forces them to think that it is not only the religion but also Arab origin that is placed outside the law [and normality] in French society (D. Moore \& Cesari, 2003, p. 260).

\subsubsection{Ethnicity: the opposite of Maghrebi youth stigmatization}

The question of ethnic or racial delimitation of territories is a relatively recent debate in France - and it goes beyond the problem of youth gangs. For some, peripheral neighbourhoods have become "reserves for indigenous people and cheap labour" since young people have the feeling that they live in ghettos, are treated as indigenous, in lawless and precarious territories (Monod et al., 2008, p. 53). Faced with a French integration model that does not correspond to postcolonial reality, "the ethnic principle appears [in these neighbourhoods] as a kind of aggregating element" (Masclet, 1990, p. 121). In equal circumstances, the law grants the same rights to all people, although in reality, not everyone is offered the same possibilities; an exacerbated aphorism for young people from popular neighbourhoods. The territorialization of the social question 
and the ethnic delimitation of these spaces generate a differential vision between "us" (black, North African) and "them" (white, French by birth) in these relegated communities (Monod et al., 2008, p. 52).

In Marseille, the ethnic question is of particular importance. Different forms of affirmation of cultural and ethnic identity occupied the political space of the city. The first generations of Maghreb immigrants sought recognition of Islam in the local space. However, the second and third generations mobilized, no longer for an Islamic cause, but in order to demand equal rights and living conditions. In this sense, they developed a network of youth associations to consolidate the appropriation of their territories (the neighbourhoods). Therefore, the political action and social integration of their communities do not occur due to the concretization of a national citizen ideology but rather by the creating identities of proximity (neighbourhood, ethnicity, or religion), as in the French case it would be a type of community republicanism, as explained by J. Cesari (1994, p. 69):

The Maghrebi populations of Marseille are no different from the Jewish, Armenian or African populations. Links to primary neighbourhood groups, religion, ethnicity are considered more "authentic" and more significant, and since then the local community has become a mosaic of differentiated groups that expect the local authorities to equally distribute resources and symbolic recognition. This raises a number of questions at the national level about citizenship laws ${ }^{54}$.

For young Maghrebis in Marseille, ethnicity represents both a factor of stigmatization and a resource for political action of vindication. For these new generations, the postcolonial memory of their families is expressed in the affirmation of difference. This is either imposed when they are subjected to xenophobia (Althabe, 1985), or staged by themselves when positive affirmation policies can favour them (Kokoreff, 1996, p. 170). The defence of cultural values of their group as minority immigrants is about more than the vindication of the Maghrebness and Muslimness. It should be noted that these young people are generally non-practicing Muslims, but religious reference is used as a structural element in the dialogue they have with the French (Cesari, 1993, 1994). Thus, for young Maghrebis in Marseille, religion and culture become tools of rupture, resistance and affirmation in the face of the "dominant assimilationist ideology" (Cesari, 1993, p. 91). Non-Western cultural frameworks are mixed with those of global popular culture and those of French national culture, "negotiating the adequacy of one framework or another according to its objectives" (Sánchez García, 2010 , p. 137). From a psychosocial point of view, these young people experience a "bivalent empathy" 55 that shows their ability to adapt their cultural discourses and practices in specific contexts based on their multiple identities (Mansilla, 2017, p. 210).

\footnotetext{
${ }^{54}$ Own translation from Spanish for the purpose of this paper.

55 The logic of bivalent empathy allows young people to adapt to different situations through a cognitive process called "dynamic systemic coordination" (Oullier \& Kelso, 2006, p. 353).
} 


\subsubsection{Drug trafficking and youth gangs in Marseille}

Since the beginning of the 1980s, the trivialization of drug use, the crisis of the working-class labour market and the increased unemployment among young people from popular neighbourhoods have been the new living conditions of marginalized neighbourhoods in France. Small-scale drug trafficking (the deal, wholesale) becomes the door to a way "out of crime" for youth gangs (Chottin et al., 2009, p. 49). From an economic view, continuing to be involved in fights and vandalism is not fruitful for gangs. Obviously, the amalgam between the cités and certain transnational drug trafficking networks in France does not take long to appear in the media and in political settings. This makes the criminal approach to cités complicated repressive policies against gangs.

In the case of Marseille, the term mafia is frequently used in the media sphere, alluding to a whole world of settling scores, marginalized neighbourhoods (mostly those in the north of the city) and networks of dangerous young people as figureheads of lawless territories. However, in this case, fantasy trumps reality. It is true that Marseille is one of the entry points into Europe for drug trafficking coordinated by transnational criminal organizations. For example, according to OFAST and in collaboration with the Italian police, 3313 kilos of cocaine were seized in the port of Marseille on Feb $27^{\text {th }}$, 2020. Despite this, analysis of court cases held at the Marseille Judicial Court shows that Marseille's criminal networks cannot be considered mafias, for several reasons: a) they are not organized as capitalist-type companies at the local level, b) they do not have relationships with public powers and c) are not positively recognized by a part of the population (Mucchielli et al., 2013, p. 72). This does not mean that the effects of such criminal networks, mainly the porosity between them and the local youth gangs, are insignificant in the social life of the marginalized neighbourhoods of the city. In 2011, two thirds of those accused of activities related to drug trafficking in Marseille were young adults between the ages of 18 and 40, of which a significant part were foreigners (23\%), mainly from Maghreb countries (Mucchielli et al., 2013, p. 43).

\subsubsection{Advanced youth marginality and "ghettoization"}

In France, the debate on the territorialization of social exclusion and its ghettoizing effects has been widely documented. Some argue that talking about ghettos in the working-class neighbourhoods of France is a double "counter-sense", in both historical and sociological terms (L. Wacquant, 2006, 2007). On the other hand, others claim that ghettos in France are a true phenomenon in France and that racism and discrimination are the causes (D. Lapeyronnie, 2005, 2008). In between these two poles are those who consider that the banlieues, the cités or the quartiers (the neighbourhoods in Marseille) are not ghettos but rather "ethnic enclaves" (Kokoreff, 2009, p. 557). The main argument against the ghetto thesis in France lies in the opposition between racial division and social exclusion. Several factors support the thesis of the " antiquity " in 
French cités: the mechanisms of socioeconomic exclusion, the multi-ethnic nature of their populations (the population is not solely black, as is the case in the poor neighbourhoods of Chicago), the levels of violence and crime and, finally, the interventionist role of the State through public policies (L. Wacquant, 2005, 2007). However, the counterexample of the French cités in this thesis was the Chicago slums, being an "extreme" case study (Duneier, 1992), whose weak organizational and institutional density is not representative of all American black slums (Small, 2008).

The concept of the ghetto, "ideally-typically characterized as a racially or culturally limited socio-spatial constellation, founded on the forced relegation of a stigmatized population" (L. Wacquant, 2007, p. 54), and the idea of advanced marginality, determined by the racial question, are outdated in France, and in Marseille in particular. A multifactorial approach focused on the heterogeneity of the social worlds that coexist in these relegated spaces is more appropriate. In this sense, the ghetto becomes a "counter world", a "segmented social organization", and a "category of action in the set of social relations" (D. Lapeyronnie, 2008, p. 23). This ghetto does exist in France. It exists in Marseille. Ghettos can then be racially determined spaces (L. Wacquant, 2007) or segmented social organizations (D. Lapeyronnie, 2008). Such conceptualization reveals the diversity of the ghetto, not only in terms of the type of groups that comprise it, but also in terms of their causes, processes, and consequences. It is true that the historical origin of the ghetto is precise and anchored by definition in a racial divide. However, it is more sociologically useful to consider the convergences between Wacquant's and Lapeyronnie's concepts of ghettos (interaction logics, causes and consequences). This was in order to overcome the impasse of tracing the historical configuration of the ghetto in different contexts. The thesis and the antithesis of the ghetto in France converge when affirming that its inhabitants develop their own "values" or "institutions" that allow them to face the difficulties and deficiencies imposed by society. Both arguments claim that these stigmatized territories face deficiencies in public services, have informal economies, attribute a social function to violence, suffer from experiences of indignity and find it difficult to convert feelings of injustice into collective action (Kokoreff, 2009, p. 561).

Regarding Marseille, it can be affirmed that urban marginality (a product of territorial arrangements with segregation effects), racism (D. Lapeyronnie, 2005) and Islamophobia, the territorialization of immigrant working classes (mainly in the northern neighbourhoods and some in the city centre), the impoverishment of certain neighbourhoods (due to precarious living conditions) all lead to the ghettoization of these populations. Today, the confusion between social and ethnic exclusion is added to the context of marginality in these neighbourhoods where youth street gangs receive training and undergo socialization.

The advanced marginality suffered by the young people from these neighbourhoods revolves around the deprivation of recognition, self-esteem and sense of life imposed by 
society. We must ask ourselves, like N. Elias did in his Logiques de l'exclusion (Elias et al., 1997), undoubtedly the greatest contribution of this author to the question of marginality: what are the excluded groups deprived of? ${ }^{56}$ Are they deprived of access to the means of production (a Marxist vision in which economic corrective measures would suffice)? In many cases, the answer is yes. But as the author argues, while recalling the example of the Burakumin minority in Japan, if the excluded are not significantly poorer than most, " the main deprivation suffered by the excluded is not a deprivation of food [or access to work or forms of economic production]. What should it be called? Deprivation of value? Of meaning? From his share of self-esteem and human respect?" (Elias et al., 1997, p. 67). N. Elias recalls that "the great discovery of Marx" has "obscured" the nature of human beings', since he has a tendency "to see it as the last word in research on human societies" (Elias et al., 1997, p. 19).

\subsubsection{Youth street groups' use of virtual spaces}

"Cities are transformed by the interface between electronic communication and physical interaction, and by the combination of networks and places" (Castells, 2004) ${ }^{57}$.

Access to information is a crucial issue in all types of action and social construction, including youth gangs. The ways young people make use of the New Information and Communications Technology (nICT) modify socializations in the gang field. A common misunderstanding consists of affirming that nICTs generate a "space independent of the geographic one, a kind of 4D", whose nature is "virtual" (Zreik, 2012, p. 13). This suggests that there are two independent spaces (physical and virtual) and that the intersection between the two would be more of a deliberate matter for individuals. However, it should be understood that the "virtuality" offered by ICTs is not independent of either the (physical) territories nor the values (manifested or implicit) of the collective identity of the groups that live in them, including gangs. In a world with a constant Internet connection such as the one we live in today, the causes and consequences of social interactions are found both in the virtual and physical spheres, both being part of the social reality of individuals. Therefore, virtuality is a fundamental dimension of our reality, since today the reality is virtual and real at the same time (Castells, 2008). This leads us to a new conception of the public space of youth gangs, that of "hybrid public space", where social actions are sustained concurrently in a physical and virtual (Mansilla, 2015, p. 615). The main characteristic of this hybrid space is its plasticity and the feeling of young people from marginalized neighbourhoods "of not being watched" (Mansilla, 2017, p. 380). This hybrid space is then formed "by lived experiences, memories and collective emotions" (Livet, 2002).

\footnotetext{
56 As L. Queirolo Palmas points out, it is also worth asking" What do the excluded groups have? What capital can be accumulated while being a member of the gang? this is to not fall into a perennial deficit theory when we speak of subordinate groups"

57 Own translation from Spanish for the purposes of this paper.
} 
The youth street groups in Marseille use digital social networks within the logic of such hybrid interactions. They create new meanings of the physical spaces of the neighbourhood from virtual exchanges that take place before, during and after face-toface interaction. In this way they reconfigure the restrictions and functionalities of their living spaces. In this regard, based on the publications of these young people on three online social platforms (YouTube, Facebook, Instagram), it is possible to identify two logics of interaction between Internet users:

> Publish their actions to build their reputation. The "like", "followers", "comments" and "share" functions of these platforms affect the field of reputations (Sauvadet, 2005) of the individuals involved. This acts as a structuring dimension of the phenomenon of youth gangs. Young people multiply their efforts to make themselves visible in the virtual field of reputations by reminding their followers to value them (through "like") and to visit them on other platforms (through links).

> Appropriate the informational resource that has (or aims to have) an impact on their daily lives. Some young people seek to percer (succeed, make themselves known) in musical careers by publishing their own content (video clips, texts, photos). Others promote and organize illegal economies (sale of marijuana, synthetic drugs) by taking advantage of popular encrypted (WhatsApp) or ephemeral (Snapchat) communication channels. In this way, they retain their clientele and avoid police surveillance (Amelin, 2019). The strategy of the informational resource offered by nICTs, regardless of any legal or illegal objective, thus becomes a vector of life for youth street groups.

Four categories of cases representative of how these young people use social networks (YouTube, Facebook, Instagram) have been studied: music, fiction short film, the current state of the ethos of honour, and the educational message from the associations present in the neighbourhood.

\subsubsection{Succeed in the music industry: videoclips from young people in gangs}

Some examples of posts by youth gangs in Marseille ${ }^{58}$ show that gangsta-style rap music is central in their interactions. Originally from the west coast of the United States, gangsta rap chronicles the life of gangs (their violent life and drug use). The folklorization of the gang social universe in the media, even in social sciences, accentuates the relative otherness of the gang phenomenon (Monod et al., 2008, p. 40) and converts gangsta rap into a tool against stigmatization that also creates a strong collective identity in the popular neighbourhoods of Marseille. These young people publish video clips of famous rappers, mainly French, share publications of other rappers in the neighbourhood with each other and create virtual communities around

${ }^{58}$ Crews of young rappers analysed: Jeune Rex, Mze Le Guirri, K2K, Said Ntc, LS143. All are groups of young people from neighbourhoods (quartiers) in the north of Marseille. 
current events in the hip hop world. However, the most remarkable point is the production of their own video clips (mainly of gangsta rap). On repeated occasions, allusions to a gangster atmosphere in the city are heard in their songs, "Marseille is not an easy place!", "Marseille is hot!", thus issuing challenges and warnings to other rappers as to which is the most dangerous gang in the neighbourhood. However, this conflicting logic does not necessarily indicate conflict between neighbourhoods or enemy gangs but rather should be understood as an aesthetic heritage of the American gangsta musical style and as an effect of the folklorization of youth street gangs in France. Two main trends in the production of the video clips of these young people have been identified:

> Trial and error, creating a community of followers. [all cases] Young people record their first video clips using amateur audio-visual equipment (ultra-compact cameras, mobile phones, laptops) at their disposal through networks of family or friends. The objective is to "send a first video" and be attentive to the possible comments ("the buzz ") on social networks. The group develops around family ties (brothers, cousins, cousins) or neighbourhood ties (neighbours).

> Between amateurism and professionalization ${ }^{59}$ of content. [The cases of Jeune Rex (Jean Jaure neighbourhoods) and Mze Le Guirri (Feliz Pyat neighbourhood)] One or two of the group members are the "rappers", who write, sing and compose the beats. Several members are featured in the video clip, and friends and neighbours re-enact the song's story and help with the staging. Other members of the group are responsible for the filming and editing. [The case of K2K (Parc Kalliste neighbourhood, Castellas)] They recorded their first songs with the help of solidarity networks of proximity. Later, they recorded their songs in recording studios, where they paid for the services and the rental time of audiovisual equipment. K2K did their recordings in the Studio Crampella Production. The manager, Malko, is part of a network of young music producers (aged between 25 and 40) and from different districts of the city (Astral Gang Records). These recording studios, which can be in commercial premises or even in homes, specialize in the production and promotion (via online social networks) reproducing and promoting (via online social networks) street videoclips in a gangsta rap style.

\subsubsection{Staging of violence and fictional content}

The case of Drive by Productions one-of-a-kind in Marseille. In 2018, the group created 6 "episodes" of an average of 5 minutes each, recreating stories of conflicts between

\footnotetext{
59 Professionalization refers to productions where professional technicians participate. Amateurism, for its part, indicates that productions are supported by proximity solidarity networks, without necessarily an immediate commercial logic. In neither of the two cases can the trajectory of young people be classified as professional. The logic of trial and error imposes that, once a project is finished, how and when to continue the musical trajectory is uncertain.
} 
gangs: settling scores, drug sales, romance, friendship and young rappers. Everything that happens in the marginalized neighbourhoods of Marseille. The fictional stories, without words and on a musical background of rap and original instrumental music, are interpreted by natural actors (who they are in touch with thanks to their local solidarity networks). The content generated a community of followers and was published on YouTube. To date, no new episodes have been published.

\subsubsection{Ethos of honour of young people in hybrid spaces}

Taking advantage of the immediacy of transferring digital information among Internet users, various young people post videos of less than three minutes long showing recent local events that they filmed using their mobile phones. These videos show mostly confrontations or physical violence: involving the police (fleeing identity checks, violence and police abuse), other young people or individuals (on public transport or in the street). Similarly, the videos serve to reaffirm values of collective status (consumption of drugs, motorcycles and cars). The virtual space of digital networks updates the field of reputations of the gang field, a space of hybrid interactions (between the face-to-face and the virtual).

\subsubsection{Youth empowerment: associations and State grants}

In this case, the use of social networks has been defined jointly, in a best-case scenario, between the youth of the neighbourhood and the associations that intervene in their territories. Boulègue TV is a participatory television network that films cultural and citizen projects in Marseille's 3rd district (where several of the most marginalized neighbourhoods of the city are located). According to its leaders, Boulègue TV is "free of any format, duration or transmission restriction and is open to all residents of the 3rd district or of Marseille without exception, thanks to the support of volunteers" ${ }^{60}$. Young people from the neighbourhood appear in their videos on YouTube promoting, for example, critical analysis of media communication sensitizing users on gender equality. Other structures create audio-visual content for online social networks to promote their actions in the marginalized neighbourhoods of the city. L'OM, for example, created a series of short films showing the work of neighbourhood associations for associative football for minors from disadvantaged neighbourhoods (Marseille terre de foot, YouTube). The Apprentis d'Auteuil Foundation, a structure with national outreach, leads the Impact Jeunes project. Funded by the national government, Impact Jeunes seeks to intervene "in all stages of the professional integration process of young people from priority neighbourhoods [of which there are currently three in Marseille] from 13 to 30 years old". Thus, in both examples, the empowerment of these young people, as well as the free use of content on digital social networks, is subject to the logic imposed by each institution to a greater or lesser extent.

\footnotetext{
${ }^{60}$ Source: https://www.helloasso.com/associations/les-tetes-de-1-art/collectes/open-tv
} 


\subsubsection{Articulation of the theoretical aspects}

The study of TransGang spaces in Marseille is developed based on the theoretical aspects and contextual factors discussed in this section (6. TransGangs in Marseille), as well as those discussed in the previous sections (4. State of the art: investigating (Trans)Gangs in Marseille and 5. Empowerment, conflict and mediation). All aspects and factors are interrelated and together make up the subject of study: the formation of youth gangs and social mediation. The articulation of these aspects can be summarized in a conceptual journey (Figure 6, next page). Beginning with the factors that promote urban marginality and ghettoization ${ }^{61}$ (in blue), and passing through the pivots that give feedback on the causes and effects of the gang phenomena and social mediation (in yellow), these components culminate in two interdependent scenarios: direct confrontation (in brown) and the adaptive response (in green). Of course, such a dichotomy of the phenomenon of social mediation in the gang field represents a research hypothesis that must be supported with ethnographic work. The porosities between the two scenarios, indicated as back and forth movements, show the particular attention that will be paid to the limits and roles assumed by young people and actors from the gang field in both scenarios. It is therefore a first attempt to explore the "mysterious device" at the origin of the phenomenon of study, a look inside its "inputoutput machine" and of its multiple interdependent variables (Becker, 2014, p. 62):

${ }^{61} C f$., section "Advanced youth marginality and ghettoization". 
Figure 7: Interdependent theories and local variables (TransGangs in Marseille)

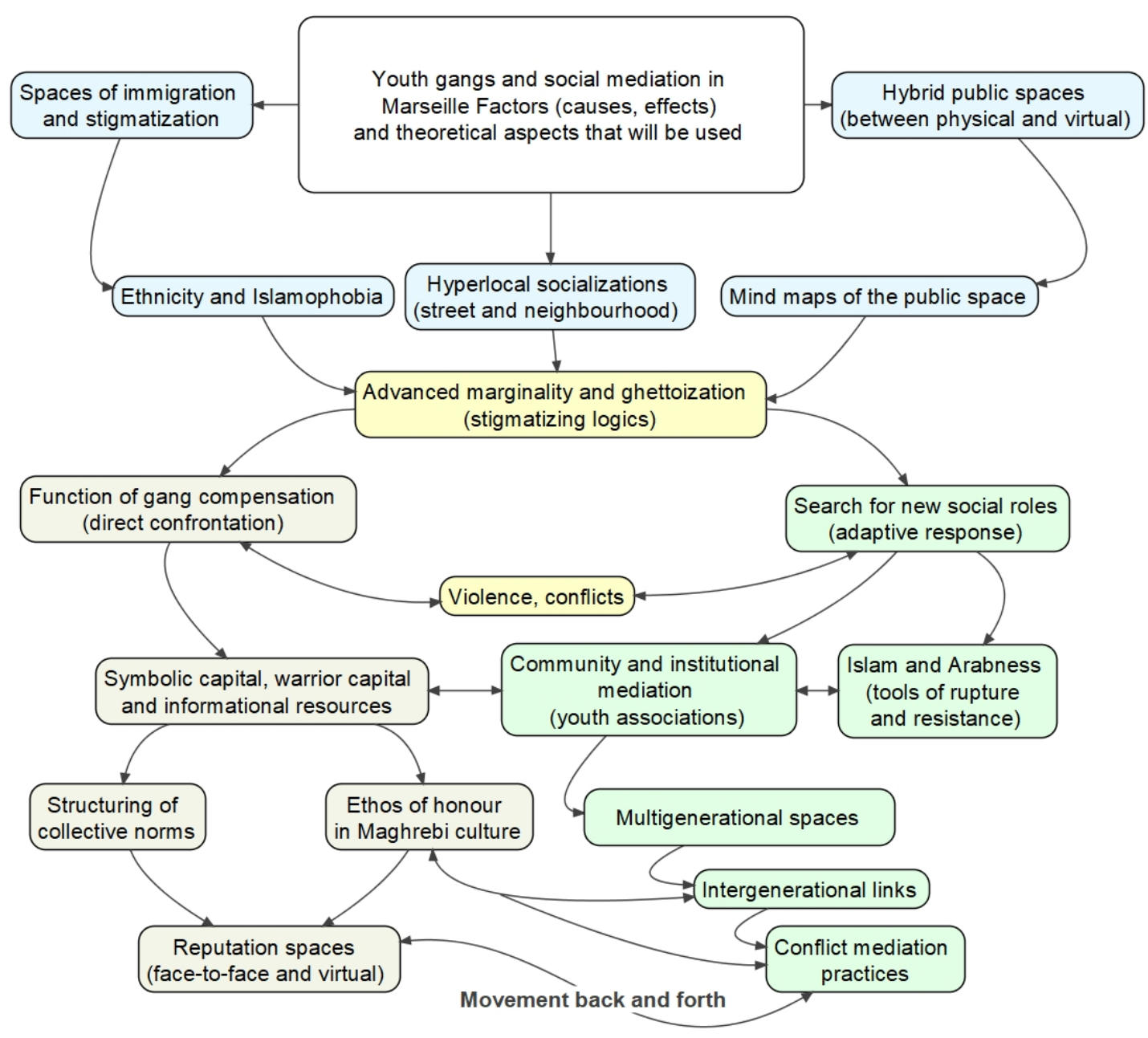

Source: Own elaboration. 


\subsection{Conclusions}

\subsubsection{Overall aim}

The generational dimension will be the common research thread in Marseille. We will place intergenerational ties in the religious, associative, family and street spheres at the centre of our observations. Our study will deal with the impact of multigenerational spaces in the mediation of conflicts in youth gangs and of these with their ecosystem (gang field). It is also intended to understand the impact of these mediation practices on the life trajectory of these young people, and whether or not they can be considered as a "set of lasting changes in the lives of individuals" (Mohammed, 2015, p. 48).

\subsubsection{Research Dimensions}

In Marseille, youth street groups can be defined by the intersection of four main dimensions:

\subsubsection{Spaces of immigration and ghettoization}

Marseille is historically a city of immigration. After the Second World War, the "thirty glorious years" meant that the local industry developed rapidly. The working class of the Mediterranean basin arrived progressively. Algeria's declaration of independence in 1962 generated a massive wave of immigrants. Single men, mainly North African, came to work in the port and the metallurgical, soap and oil factories. The local authorities then built housing for these temporary migrant workers close to the factories. Over time, their families also crossed the Mediterranean and settled in the social housing (HLM), located mainly in the north of the city. Others formed new families and decided to stay in Marseille. All of them are likely to have had the aim of leaving the hotels meublés in the centre of the city - a symbol of material and administrative precarity - and to move to the HLM of the north, which represented the culmination of their perspective of social and economic ascension) (Donzel, 2014).

This first generation of Maghreb immigrants settled permanently in Marseille. With this, the question of the legitimacy of the Arab and Muslim presence in French territory in the post-colonial era became central in the national debate. The children of these immigrants, the second generation (the beurs), rejected the acts of xenophobia and marginalization that their families suffered and still suffer. Some formed the first bandes des jeunes and committed crimes. Others sought political and cultural resistance. In 1982, the first peaceful march against Arab racism began in the Cayolle in Marseille, a neighbourhood symbolizing the ghettoization of immigrant populations in France and it went all the way to the Bastille in Paris. The third generation (the rebeus) live in the same social housing buildings as their grandparents. The trivialization of drug 
trafficking and the role of the digital social networks are new elements in a world that continues to marginalize them. The confusion between social and ethnic exclusion is added to the context of marginality in their neighbourhoods. In a "dual" city marked by socioeconomic differences between the districts of the south (autochthonous) and north (immigrants), the social universe of youth in marginalized neighbourhoods is ghettoized. In short, the "advanced marginality" (L. Wacquant, 2006) that young people in these neighbourhoods suffer today revolves around the deprivation of recognition, self-esteem and a sense of life that society imposes on them.

\subsubsection{The neighbourhood and hyperlocal identity}

The young members of street gangs share a history of immigration and socioeconomic relegation that materializes in a common living space: the neighbourhood where they live. In Marseille, these young people assume their conflictive actions - or social mediation - from and with the objective of a local identity. In the "field of reputations" (Sauvadet, 2005) the most important information for them is hyperlocalized (in the set of buildings, the basketball court, the cultural centre, the corner). The neighbourhood represents both the social prison imposed by history and the shell that allows them to survive. A place for violence, solidarity and reinvention of its social codes, the neighbourhood defines the nature of the gang, its "mind maps" of action and possibilities (Mohammed, 2016, p. 21). Marseille is a particular case in France in that young people feel attached to and identify with the city. For young people from popular neighbourhoods, the Marseillaise identity is more important than that of the French identity. Considering themselves French only seems possible for these young people if it is to the extent of the Marseillais identity. In Marseille, the divide between urban groups is not between "working classes" and "bourgeois classes" but rather between autochthonous and immigrants. This is why there is a need for young people to consolidate a Marseillais identity rather than their ethnic or family identity. Nowadays, the local identity of these young people also stems from the assertion of Maghrebness and Muslimness (Cesari, 1994, p. 77), even though they might not be Muslims.

\subsubsection{Ethnicity and assertion of Maghrebness and Muslimness}

For young Maghrebi in Marseille, ethnicity represents both a factor of stigmatization and a resource for political action of assertion. Political exercise and social integration of immigrant communities in Marseille does not bypass the concretization of a national citizen ideology, but rather by ties of local identity, such as the neighbourhood, ethnicity, or religion, creating a type of communal republicanism. The assertion of ethnicity and its cultural forms such as religion appears as a kind of aggregator element in these neighbourhoods. As a result of social ruptures (family, school, cultural, social, ethnic, residential, criminal), street gangs emerge as a "compensation network" (Mohammed, 2011, 2016) from their urban experience. This means that the criminal act is not a determining character for its creation. For these young people, ethnicity and religion become tools of rupture, resistance and affirmation against the dominant 
assimilationist ideology. Faced with the xenophobia to which they are subjected, the strategy of affirming ethnic difference plays a central role in their relationships with the rest of society. The new generations of young Maghreb street gangs thus adapt their "non-Western cultural frameworks" (Sánchez García, 2010) together with the French ones depending on the resources made available to them.

\subsubsection{Community and institutional social mediation}

In Marseille, youth associations (recognized by the local government and eligible for subsidies) have been emerging since the 1980 s as an alternative to socialization among young people from peripheral popular neighbourhoods and are very different from deviant forms of association such as criminal gangs. The law passed on October 9, 1981 recognizes the associations created by immigrants as subjects of common law, and thus made it easier for them to carry out their activities and receive institutional support. Consequently, an associative community, managed by young people and supported institutionally, developed. The main aim was to consolidate the appropriation of spaces of hyperlocalized community life such as those represented by residential buildings, the street, the basketball court, the corner, and the neighbourhood. According to several analysts, this constitutes one of the keys to the stability of the neighbourhoods in Marseille during the révoltes des banlieues in 1990 and 1991 which involved the police and young people from marginalized neighbourhoods in France's metropolises.

For the state, youth associations represent a kind of urban regulation of conflict and a way to gradually move Islam out of the mosques (due to fear of difference and community confinement which promulgates Islamophobia). For young people, the association is an alternative that compensates socially for the marginalization that they have suffered in the past. The figure of the grands frères et grandes sæurs (GRAFS) (Big brothers and sisters) in the popular neighbourhoods is a reference and a bridge to open dialogue between new generations and the other actors of the district (family, school, public bodies). Being in charge of community associations or pursuing a professional path in popular culture or sports, the GRAFS play a leading role in mediating the conflicts of the youngest in the neighbourhood. Football, one of the identity traits of these young people, becomes a form of integration and social mediation in the popular neighbourhoods of Marseille. However, informal sport (outside of sports clubs), their logical socialization, channelling teen violence and the possible effects on the output of crime gangs in Marseille have been studied very little. Social mediation of conflicts between youth street gangs is part of a continuum. Community and institutional intervention are rarely separated; on the contrary, they are frequently combined to a greater or lesser extent depending on the political and social context. 


\subsubsection{Research Hypotheses}

We propose a series of cross-sectional hypotheses on the following research dimensions:

\subsubsection{Intergenerational spaces}

[Discussion] The generation gap, accentuated by the lack of in-depth insight into the past of the gangs (because importance is only placed on the last event, the last fight or the most recent photo) (Cesari, 1993, p. 45) and the conflict they have with future (because they have a clear preference for the present and light-hearted issues) (Chottin et al., 2009, p. 48), is one of the structural elements of youth street gangs. The lack of references to the past and to the community biography leads to a generational break between the gang and the other actors in the neighbourhood. Because of this, the following hypothesis is proposed:

[Hypothesis] Multigenerational integration in the neighbourhood (i.e., recurring interactions between different age groups that mean that spaces for dialogue are created $^{62}$ ) favours conflict mediation in youth gangs (a necessary but not sufficient cause). On the contrary, the more young people from marginalized neighbourhoods (gang members or not) experience the breakdown of generational ties in their community (family, school, institutional), the more the phenomenon of delinquent youth gangs tends to increase (a necessary but not sufficient cause).

\subsubsection{Football, mediation and gender}

[Discussion] In Marseille, football creates such strong identification among young people from marginalized neighbourhoods that there are several experiences of social mediation with street youth groups through this sport. It is worth noting that there is a gender bias that can occur when targeting soccer in this way because it is generally less practised by young women. However, first of all, it must be determined whether soccer in these neighbourhoods today is only a male issue. This will enable the researchers to not only determine if there are women footballers, but also how they became involved in the sport and the type of roles they take on. In the gang field, the neighbourhood's football universe is not limited to the duration of a match. Therefore, the ways in which young women intervene, directly or indirectly, in the experiences of social mediation through football will be studied. Based on this finding the following hypothesis is proposed:

62 From D. Bohm's perspective (Bohm, 2004) "dialogue" allows individuals to become aware of the processes of "fragmentation" (separations) that govern the totality of our reality (social, political, epistemological). The objective of the dialogue is therefore to identify the paradoxical patterns of thoughts and sensations in order to change the way these occur collectively. 
[Hypothesis] The intergenerational factor is a necessary but not sufficient cause of social mediation in the marginalized neighbourhoods of Marseille. Intergenerational ties foster spaces for conflict mediation within youth gangs and also between gangs and other actors in the gang field. In sports- or culture-based community associative experiences, the participation of the grands frères et grandes sæurs (GRAFS) who are former gang members between the ages of 30 and 40 can offer new ways of mediating conflicts for the young gang members of the new generations. Football as a social mediation experience is not just about men. The intervention of women, which is increasingly on the pitch, is part of the production of the football universe in these popular neighbourhoods. There, women appear in formal (associative) and informal (street football, without adult supervision) contexts, to a greater or lesser degree depending on the forms and places where it takes place.

\subsubsection{Natural mediators living in the gang field}

[Discussion] During and after adolescence, young people experience important social, biological and psychological transformations. Apart from young people who suffer from specific disorders, we know that transgressive behaviours are confirmed during preadolescence, then reach their highest levels at around 15-17 years, where they remain until the age of twenty, after which they begin to decrease (Mohammed, 2015, p. 52). There is a certain scientific consensus affirming that criminal trajectories are only a biographical stage of individuals and that it occurs in relation to their psychobiological development, but it is not known why and how individuals move away from these (Mohammed, 2015, p. 49). Individuals veer away from crime as a result of maturation, adopting new social roles, leaving adolescence behind, etc. The vast majority of criminals retire before the age of thirty (Mohammed, 2015, p. 52). Today, the debate focuses more on the modalities, stages and inequalities of maturation towards adulthood. Although there are multiple theories about the reasons for the "desistance from crime" (Blokland \& Nieuwbeerta, 2005; Farrall et al., 2014; Glueck \& Glueck, 1940; McNeill et al., 2012; Mohammed, 2015; Van Ginneken, 2017; Ziegler et al., 2017), all converge on the multifactorial nature of the withdrawal of gangs. Fatherhood or motherhood, a new job, physical and mental wear and tear caused by social conflict, religion or a cultural or sports project are some of the most cited motivations (Mohammed, 2015, p. 11). However, it is necessary to consider how "desistance from crime" should be understood. Do young people leave the gangs that are assumed to be criminal in nature? Or do the gangs cease to carry out criminal activities? Although related, these two issues are different. Disaffiliation from the gang is a slow, progressive and conflictive process, with "much back and forth movement" between the unknown search for new social roles and the known and protective world that the gang provides (Mohammed, 2015). The ideological construction of the gangs implies the acceptance of common values and attitudes of their members; while leaving "marks the moment in which the individual seeks to regain possession of themselves" (Chottin et al., 2009, p. 49). One weakness of the social mediation for gang conflicts is the detachment that their former members may feel regarding the neighbourhood in which they grew up (Chottin 
et al., 2009, p. 50). This stance feeds individualistic development rather than neighbourhood and community development. In Marseille, the local social fabric depends largely on the associations led by young people and former gang members between the ages of 25 and 40 born in these marginalized neighbourhoods. Given this finding, the following research hypothesis is proposed:

[Hypothesis] If the trajectories of social ascension occur outside the neighbourhood, the new generations that successively renew the "street culture" will not have close references of an alternative path to crime. This represents a threat to the experiences of community mediation in these neighbourhoods. Conflict mediation in the youth street gang space occurs when older members of a "moral community"63, (Harper, 1992), who are respected and who serve as group referents, decide to act in search of mediation, while still being part of the community and living in it. This highlights the importance of the Big Brothers and Sisters (GRAFS) in mediating conflicts within youth gangs.

\subsubsection{Intergenerational subcultures of counter stigmatization}

[Discussion] The specific acts of stigmatization towards a marginalized neighbourhood and its inhabitants are an element that consolidates the intergenerational action of these communities. For example, in Clichy-sous-Bois (the epicentre of the first clashes between youth and law enforcement in 2005 during the révoltes des banlieues), the police threw tear gas inside the mosque during the sermon and prayer service. This caused uproar from the entire community, surpassing the generational differences. The "collective emotion" thus intensified the legitimacy of the riots (Mohammed, 2007, p. 9). Stigmatization therefore consolidates the social ties of the excluded group. In the context of national Islamophobia - when stigmatizations insult the community's religious values - intergenerational solidarity of the stigmatized group increases. Moreover, youth unemployment in these neighbourhoods means that the youth street groups combine urban arts with criminal economies (Feixa, 2006). Given this finding, the following study hypothesis is proposed:

[Hypothesis] Different intergenerational subcultures are created as a form of direct confrontation (violence, transgression of institutional norms) or adaptive response (social mediation, creation of cultural or sports associations) to the stigmatization and violence imposed by the dominant society. In the gang space, a direct confrontation or the adaptive response is more than a single or recurrent event. It represents a codified communication system that is used by actors within the gang field and also with wider society. The confrontations not only make the ghettoized communities visible in media discourse, but also feed into the collective identities of all the actors involved.

63 The set of cultural expectations and practices of a group of individuals united by an ingrained collective identity, not necessarily a population in a specific place. These expectations constitute a whole universe of shared cultural knowledge that allows defining whether or not an individual belongs to a community. E. Durkeim, quoted by D. Harper (1992), called this process "moral integration". 


\subsubsection{Gang ethos of honour in hybrid spaces}

[Discussion] The "warrior capital" (Sauvadet, 2005) developed by young people in street gangs allows them to obtain symbolic and material resources. The defence of honour and the attitude of non-submission are the pillars of this alternative capital. In Marseille, the logic of honour, which is popularly attributed to Islam, actually corresponds to the Maghreb and Turkish culture (D. Moore \& Cesari, 2003, p. 261). The ethos of honour implies first of all "existing in the function of others, that is, living under the gaze of the other and feeling the omnipresence of opinion. The feeling of honour and its opposite (fear and shame) encourage and direct relationships with others $^{64 "}$ (D. Moore \& Cesari, 2003, p. 261). Given this finding, the following study hypothesis is proposed:

[Hypothesis] The remote space of computerized social networks modifies and transforms the gang field. For street gangs of young North Africans, the ethos of honour and the warrior capital, their stronghold, evolve in a hybrid space (face-to-face and virtual) of which immediacy is the main feature. The Internet makes it possible for everyday interactions to be kept at a distance, impacting codes and social interactions. The online social networks of these gangs are not a simple reflection of their values and daily lives. On the contrary, they are living spaces that influence their reality, contribute to their social codes and affect their field of reputations.

\subsubsection{Theories of youth gang formation in France (synthesis)}

France has a long ethnographic tradition and multi-faceted theoretical production on youth gangs. Conceptualizations are not intended to be considered as a whole but rather they must be understood as socio-historical mosaic pieces that evidence the complexity of the phenomenon. It has been discussed above how various theoretical arguments are articulated in research of youth street groups in Marseille. In response to socio-spatial marginalization that weighs down on them, deviation or social conflict regarding their immediate environment (neighbours, institutions, other youth) (Chottin et al., 2009, p. 48; Robert \& Lascoumes, 1974) is one of the defining characteristics. The purpose of this transgressive dynamic is twofold: for identity and for conflict (Mohammed, 2016). Youth gangs are also characterized by their volatility to form and dissociate (Monod et al., 2008, p. 51). Their informal nature does not mean that their social interactions are anomic. On the contrary, the social norms of the gangs are highly codified. The violent behaviour signifies a hierarchical role for the members of the gang and also the gang itself against other actors in the neighbourhood (Sauvadet, 2005, p. 118). A paradoxical fact defines the gang field of youth street groups. These young people become more visible as their social ruptures increase, which is when their violent behaviours are more mediated.

${ }^{64}$ Own translation from Spanish for the purposes of this paper. 
Age solidarity is another factor in the formation of youth gangs in popular neighbourhoods. They are often considered homogeneous (Robert \& Lascoumes, 1974) in terms of the age of their members. However, this age division is porous. Understanding the "gangs as a continuum" (Feixa et al., 2019, p. 45), with some groups engaged in illicit activities and others involved in leisure activities, all of which are susceptible to being combined in any given moment, may combine them into one point, makes it pertinent to think that gang practices involve individuals of different ages. The gang is inscribed therefore in a social setting which is intergenerational by definition. More than homogenous, the gangs are groups that emerge at the interstice of different age groups in the neighbourhood. The (re)appropriation of public spaces, beyond the primary affectation decided by the institutionality, represents for these young people the possibility of moving from a "lived social space" to an "imagined social space" (Mauger, 1994).

These young people build a "warrior capital" that directs their socialization processes: "a form of moral discipline (of not submitting, of defending their honour, of knowing the rules of the street) to handle violence and vice [street smarts] ${ }^{65}$ " (Sauvadet, 2005, p. 118). For these young people, the deficiencies (school, materials) generate "pillars of social compensation" such as the phenomenon of gangs, which are inversely proportional to their degree of integration in school and family (Mohammed, 2011, p. 22). These compensations, closely linked to the reputation and ethos of honour in the Maghreb culture (D. Moore \& Cesari, 2003, p. 261), materialize both in hybrid socialization networks (face-to-face and virtual) and in collective identity offered by the gang. For the young Maghreb in Marseille, religion and culture (reflected in the Maghrebness and Muslimness) become tools of rupture, resistance and affirmation in the face of the "dominant assimilationist ideology" (Cesari, 1993, p. 91). Their nonWestern cultural frameworks are mixed with those of global popular culture - along with those of French national culture - "negotiating the adequacy of one framework or another according to their objectives" (Sánchez García, 2010, p. 137).

${ }^{65}$ Own translation from Spanish for the purposes of this paper 


\subsection{References}

AGAM. (2013). Insertion des jeunes métropolitains, quels enjeux? (Société N. ${ }^{\circ}$ 12; Regards de l'Agam, p. 4). agAM [Agence d'urbanisme de l'agglomération marseillaise]; ISSN: 2266-6257. https://www.ampmetropole.fr/sites/default/files/2017-09/AGAM_Regards12 _INSERTION_JEUNES_2013.pdf

AGAM. (2015). Quand la jeunesse s’invite dans les enjeux métropolitains (Société N. 32; Regards de l'Agam, p. 8). agAM [Agence d'urbanisme de l'agglomération marseillaise]; ISSN: 2266-6257. http://doc.agam.org/doc_num.php?explnum_id=3771

AGAM, \& AMP. (2017). Atlas du parc locatif social. Territoire Marseille Provence. Données au ler janvier 2015 (8e édition; p. 29). agAM [Agence d'urbanisme de l'agglomération marseillaise], AMP. http://www.agam.org/fr/etudes/habitat/observatoire-de-lhabitat.html

Allemand, S. (2013). Marseille. Une terre d'asile séculaire à l'épreuve des politiques nationales d'intégration. Hommes \& migrations. Revue française de référence sur les dynamiques migratoires, 1301, 168-173. https://doi.org/10.4000/hommesmigrations.1944

Althabe, G. (1977). Le quotidien en procès. Entretien réalisé par M. Abélès.

Althabe, G. (1985). Production de l'étranger, xénophobie et couches populaires urbaines. L'Homme et la société, 77(1), 63-73. https://doi.org/10.3406/homso.1985.2221

Althabe, G., \& Sélim, M. (1985). 4. Production de l'étranger en situation pluriethnique. Journal des anthropologues, 21(1), 26-34.

Amelin, H. (2019, agosto 19). Marseille: Les nouvelles ficelles marketing du business de la drogue. RTL (journal). https://www.rtl.fr/actu/justice-faits-divers/marseille-les-nouvelles-ficelles-marketing-dubusiness-de-la-drogue-7798196474

Audren, G., Baby-Collin, V., \& Valcin, M. (2018). L'école, une ressource pour les populations migrantes. Regards croisés de l'institution et des parents d'élèves dans le centre-ville de Marseille. Revue européenne des migrations internationales, Vol. 34(4), 93-118.

Augustin, J.-P. (1989). Les jeunes dans la ville: Institutions de socialisation et différenciation spatiale dans la communauté urbaine de Bordeaux : recherche de géographie sociale et politique [Thesis, Bordeaux 3]. En Http://www.theses.fr. http://www.theses.fr/1989BOR30054

AUPA. (2015). Le portrait social du Pays d'Aix: Un autre regard sur le territoire (p. 108). AUPA [Agence d'urbanisme Pays d'Aix - Durance]. https://www.aupa.fr/actualites/actualitesgenerales/portrait-social-du-pays-aix-un-autre-regard-sur-territoire

Bariol-Mathais, B. (2017). MÉTROSCOPE 50 indicateurs clés pour les métropoles françaises (p. 64). La Fédération des agences d'urbanisme (FNAU), l'Assemblée des communautés de France (AdCF) et France urbaine (FU), Commissariat général à l'Egalité des Territoires (CGET); ISBN: 979-1090777-07-1. https://www.apur.org/sites/default/files/documents/metroscope_juin_2017.pdf

Baubérot, J. (2012). French Secularism: Republican, Indivisible, Democratic, and Social. Cités, No 52(4), 11-20. https://doi.org/10.3917/cite.052.0011 
Becker, H. S. (2014). What about Mozart? What about murder? reasoning from cases. The University of Chicago Press.

Bernardot, M. (1999). Chronique d'une institution: La «sonacotra» (1956-1976). Sociétés Contemporaines, 33(1), 39-58. https://doi.org/10.3406/socco.1999.1750

Blaya, C., \& Gatti, U. (2010). Deviant Youth Groups in Italy and France: Prevalence and Characteristics. European Journal on Criminal Policy and Research, 16(2), 127-144. https://doi.org/10.1007/s10610-010-9124-9

Blokland, A. a. J., \& Nieuwbeerta, P. (2005). The Effects of Life Circumstances on Longitudinal Trajectories of Offending*. Criminology, 43(4), 1203-1240. https://doi.org/10.1111/j.17459125.2005.00037.x

Blöss, T. (1989). Jeunes Maghrébins des quartiers nord de Marseille, une génération charnière. Les Annales de la Recherche Urbaine, 41(1), 59-66. https://doi.org/10.3406/aru.1989.1426

Bohm, D. (2004). On dialogue (Routledge classics ed.). Routledge.

Bon, F., Cheylan, J.-P., \& Brunet, R. (1988). La France qui vote. Hachette.

Boucher, M. (1998). Rap, expression des lascars: Significations et enjeux du rap dans la société française. Union peuple et culture : L'Harmattan.

Boucher, M. (2015). « Bandes de jeunes »: De quoi parle-t-on ? Empan, $n^{\circ}$ 99(3), 17-19. https://doi.org/10.3917/empa.099.0017

Bouillon, F., Lafaye, C., Baby-Collin, V., \& Deboulet, A. (2017). Ville ordinaire, citadins précaires. Transition ou disparition programmée des quartiers tremplin? (p. 106) [Research Report]. PUCA, rapport 2017. https://hal.archives-ouvertes.fr/hal-01643207

Bourdieu, P., \& Passeron, J.-C. (1964). Les héritiers: Les étudiants et la culture. Les Éd. de Minuit.

Brinbaum, Y., \& Guégnard, C. (2011). Parcours d'insertion et sentiment de discrimination des secondes générations en Zus. 34, 13. https://halshs.archives-ouvertes.fr/halshs-00603365

Bromberger, C. (1987). L'Olympique de marseille, La Juve et le Torino: Variations ethnologiques sur l'engouement populaire pour les clubs et les matchs de football. Esprit, 125 (4), 174-195. JSTOR.

Calogirou, C. (1989). Sauver son honneur: Rapports sociaux en milieu urbain défavorisé. Harmattan.

Carle, Z., \& Olmedo, É. (2019). Marseille est trop grande pour Marseille. Vacarme, $N^{\circ}$ 89(4), 3-11. https://doi.org/doi.org/10.3917/vaca.089.0003

Castells, M. (Ed.). (2004). The network society: A cross-cultural perspective. Elgar.

Castells, M. (2008, diciembre 12). Manuel Castells. Entrevista Citilab-Cornellá [Entrevista]. http://www.stgo.es/2009/10/manuel-castells-entrevista-citilab-cornella/

Cesari, J. (1993). Les leaders associatifs issus de l'immigration maghrébine: Intermédiaires ou clientèle. Horizons Maghrébins - Le droit à la mémoire, 20(1), 80-95.

https://doi.org/10.3406/horma.1993.1170 
Cesari, J. (1994). Marseille face à ses communautés. Esprit (1940-), 202 (6), 66-77. JSTOR.

Chamboredon, J.-C. (1971). La délinquance juvénile, essai de construction d'objet. Revue française de sociologie, 12(3), 335-377. JSTOR. https://doi.org/10.2307/3320235

Chamboredon, J.-C., \& Lemaire, M. (1970). Proximité spatiale et distance sociale. Les grands ensembles et leur peuplement. Revue française de sociologie, 11(1), 3-33. https://doi.org/10.2307/3320131

Chappet, D. (2018, enero 8). Casque d'Or et les Apaches [BNF, Gallica]. Le blog Gallica. https://gallica.bnf.fr/blog/08012018/casque-dor-et-les-apaches?mode=desktop

Charrier, D., \& Jourdan, J. (2015). Le sport comme levier éducatif dans les territoires urbains en difficulté. Informations sociales, 187(1), 58-65. Cairn.info. https://doi.org/10.3917/inso.187.0058

Charvet, M. (2005). Les fortifications de Paris: De l'hygiénisme à l'urbanisme : 1880-1919. Presses universitaires de Rennes.

Chiron, L. (2018). Les usages sociaux du sport dans la prise en charge des mineurs délinquants sous protection judiciaire: L'exemple d'un établissement de placement éducatif et d'insertion. 203.

Chottin, A., Jobard, F., \& Mohammed, M. (2009). La « troisième voie ». Entretien avec Marwan Mohammed. Vacarme, 49(4), 48-50. Cairn.info. https://doi.org/10.3917/vaca.049.0048

Coing, H. (1966). Rénovation urbaine et changement social. Éditions ouvrières.

Comité interministériel des villes. (2011). Médiation sociale: Pour la reconnaissance d'un métier (Cahiers pratiques Hors-série, p. 56) [Rapport du groupe de travail Interministériel et Interpartenarial]. Secrétariat Général du Comité interministériel des villes; ISBN: 978-2-11-1281745. http://www.ville.gouv.fr/IMG/pdf/sgciv-ouvragemediationsociale.pdf

Dell'Umbria, A. (2008). Le paysage contemporain de la ville de Marseille. Aux origines de l'avantdernière destruction (1960-2005). En B. Eugène \& T. Discepolo (Eds.), Villes et résistances sociales (Éditions Agone, pp. 27-47). Agone. https://agone.org/revueagone/agone38et39/

Donzel, A. (2014). Le nouvel esprit de Marseille. L'Harmattan.

Donzel, A., \& Moreau, A. (2005). Ville et intégration: Le creuset marseillais. http://fairesavoirs.mmsh.univ-aix.fr/Pdf/FS-5-2005-073.pdf

Dorier, E., \& Dario, J. (2018). Les espaces résidentiels fermés à Marseille, la fragmentation urbaine devient-elle une norme ? Espace géographique, Tome 47(4), 323-345.

https://doi.org/10.3917/eg.474.0323

Dubet, F. (1987). La galère: Jeunes en survie. Fayard.

Dubet, F. (1995). Les figures de la ville et la banlieue. Sociologie du travail, 37(2), 127-150. https://doi.org/10.3406/sotra.1995.2201

Duclos, H., Gresy, J.-E., Dacy, S., \& Salzer, J. (2008). Évaluation de l'utilité sociale de cinq structures de médiation sociale. Rapport final (p. 115) [Rapport à Christine Boutin, ministre du Logement et de la Ville]. Culture et Promotion, ACAJ. https://www.viepublique.fr/sites/default/files/rapport/pdf/084000184.pdf 
Duneier, M. (1992). Slim's table: Race, respectability, and masculinity. University of Chicago Press.

Duprez, D., \& Hedli, M. (1992). Le mal des banlieues? Sentiment d'insécurité et de crise identitaire. L'Harmattan.

Duret, P. (1996). Anthropologie de la fraternité dans les cités. Presses Universitaires de France. https://doi.org/10.3917/puf.duret.1996.01

Durieux, S. (2016). Marseille concentre la moitié de la population des quartiers de la politique de la ville de la région (INSEE, Ed.). Insee Analyses PACA. https://www.insee.fr/fr/statistiques/2019628

Elias, N., Scotson, J. L., Wieviorka, M., \& Dauzat, P.-E. (1997). Logiques de l'exclusion: Enquête sociologique au coeur des problèmes d'une Communauté. Fayard.

Esterle-Hedibel, M. (1996). Virées, incendies et vols de voitures: Motivations aux vols et aux dégradations de voitures dans les bandes de jeunes de milieu populaire. Déviance et société, 20(2), 119-139. https://doi.org/10.3406/ds.1996.1600

Farrall, S., Hunter, B., Sharpe, G., \& Calverley, A. (2014). Criminal careers in transition: The social context of desistance from crime (First edition). Oxford University Press.

Feixa, C. (2006). De jóvenes, bandas y tribus (3a. ed. actualizada). Ariel.

Feixa, C., Sánchez García, J., Ballesté, E., Cano-Hila, A. B., Masanet, M.-J., Mecca, M., \& Oliver, M. (2019). La (Trans) Banda: Notas y cuestiones para la investigación con grupos juveniles de calle (TRANSGANG Working Papers 2.2, p. 126). Universitat Pompeu Fabra \& European Research Council. http://dx.doi.org/10.31009/transgang.2019.wp02.2

Ferrell, J., Hayward, K. J., \& Young, J. (2008). Cultural Criminology: An Invitation (1 edition). SAGE Publications Ltd.

Fize, M. (1993). Socialisation-sociabilité: Qu'en dire, qu'en faire ? En Du stade au quartier: Le rôle du sport dans l'intégration sociale des jeunes (pp. 39-43). IDEF-Syros.

Fize, M. (2008). Les bandes: De l'"entre-soi adolescent" à l'"autre-ennemi". Desclée de Brouwer.

Gallissot, R. (Ed.). (1997). Les Accords d'Evian: En conjoncture et en longue durée. Karthala ; Institut Maghreb-Europe, Université de Paris 8.

Gasparini, W. (2005). Les contradictions de l'intégration par le sport. En M. Falcoz \& M. Koebel (Eds.), Intégration par le sport: Représentations et réalités (pp. 243-260). L’Harmattan.

Gastaut, Y. (2000). L'immigration et l'opinion en France sous la Ve République. Seuil.

Gaulejac, V. de, \& Mury, G. (1977). Les Jeunes de la rue: Ce qu'ils disent de leur vie quotidienne, famille, travail, violence, sexualité, drogue. Époque privat.

Glueck, S., \& Glueck, E. (1940). Juvenile Delinquents Grown Up. Commonwealth Fund.

Goffman, E. (2006). Estigma: La identidad deteriorada. Amorrortu.

Grafmeyer, Y., \& Joseph, I. (1979). L'École de Chicago. Naissance de l'écologie urbaine. Aubier. https://halshs.archives-ouvertes.fr/halshs-00606860 
Hajjat, A., \& Mohammed, M. (2013). Islamophobie: Comment les élites françaises fabriquent le problème musulman. La Découverte.

Harper, D. (1992). Smalls N's and community case studies. En H. Becker \& C. Ragin (Eds.), What is a case? Exploring the foundations of social inquiry (Cambridge University Press, p. 254).

Harrison, P. (1985). Inside the inner city: Life under the cutting edge (Rev. ed). Penguin.

Hocquet, M. (2016). Les 111 quartiers de Marseille Croissance démographique à l'est, déclin au centreville (N. ${ }^{\circ}$ 25; Insee Flash). Insee Provence-Alpes-Côte d'Azur; ISSN: 2417-1417. https://www.insee.fr/fr/statistiques/2019743

INSEE. (2020). Dossier complet Commune de Marseille (13055). Sources: INSEE RP1967 à 1999 dénombrements; RP2006, RP2011 et RP2016 (exploitations principales et complémentaires) en géographie en vigueur au 01/01/2019; Insee-DGFiP-Cnaf-Cnav-Ccmsa, Fichier localisé social et fiscal (FiLoSoFi) en géographie au 01/01/2019; Insee, CLAP en géographie au 01/01/2019; répertoire des entreprises et des établissements (Sirene) en géographie au 01/01/2019 (p. 24) [Statistiques et études]. Institut national de la statistique et des études économiques - Ministère de l’Économie et des Finances. https://www.insee.fr/fr/statistiques/2011101?geo=COM13055\#consulter-sommaire

Jazouli, A. (1992). Les années banlieues. Editions du Seuil.

Jordi, J.-J., \& Témime, É. (1991). Migrance: Histoire des migrations à Marseille. Le choc de la décolonisation: (1945 - 1990). Edisud.

Kokoreff, M. (1991). Tags et zoulous: Une nouvelle violence urbaine. Esprit (1940-), 169 (2), 23-36. JSTOR.

Kokoreff, M. (1996). Jeunes et espaces urbains. Bilan des recherches en France, 1977-1994. Sociologie et sociétés, 28(1), 159-176. https://doi.org/10.7202/001389ar

Kokoreff, M. (2009). Ghettos et marginalité urbaine: Lectures croisées de Didier Lapeyronnie et Loïc Wacquant. Revue française de sociologie, 50(3), 553-572. JSTOR.

Lagrée, J.-C., \& Lew-Fai, P. (1985). La galère. Marginalisations juvéniles et collectivités locales. C.N.R.S. Editions; Cairn.info. https://www.cairn.info/la-galere--9782222036340.htm

Lanoux, A. (1952). Casque d'Or ou la Sauvage de Paris (Les OEuvres Libres).

Lapassade, G., \& Rousselot, P. (1999). Le rap ou La fureur de dire: Essai. L. Talmart.

Lapeyronnie, D. (1993). L'individu et les minorités: La France et la Grande-Bretagne face à leurs immigrés (1re éd). Presses universitaires de France.

Lapeyronnie, D. (2005). Racisme, espaces urbains et ghetto. En M. Boucher (Ed.), Discriminations et ethnicisation: Combattre le racisme en Europe (pp. 55-80). Editions de l'Aube.

Lapeyronnie, D. (2008). Ghetto urbain: Ségrégation, violence, pauvreté en France aujourd'hui. Robert Laffont.

Lapeyronnie, F. D. et D., \& Dubet, F. (1992). Les Quartiers d'exil. Le Seuil. https://www.cairn.info/lesquartiers-d-exil--9782020141529.htm 
Le Breton, D. (2003). Activités physiques et sportives et intégration: Aspects anthropologiques. Empan, 51(3), 58-64. Cairn.info. https://doi.org/10.3917/empa.051.0058

Le matin (journal). (1902, agosto 29). Interview à Médéric Chanut, le tatoueur des Apaches. Le matin (journal), 2.

Le Monde (journal). (1990, agosto 11). L'été zoulou. Les bandes de jeunes Noirs sont de plus en plus nombreuses en région parisienne. https:/www.lemonde.fr/archives/article/1990/08/11/1-ete-zouloules-bandes-de-jeunes-noirs-sont-de-plus-en-plus-nombreuses-en-regionparisienne_3990828_1819218.html

Lepoutre, D. (1997). Cour de banlieue: Codes, rites et langages. Odile Jacob.

Lesourd, S. (1992). Adolescents dans la cité (P. Baudry, Ed.). Erès.

Lesourd, S. (2007). La construction adolescente. ERES; Cairn.info. https://www.cairn.info/laconstruction-adolescente--9782749203966.htm

Leveau-Fernandez, M. (1992). La zone et les fortifs. En A. Fourcaut (Ed.), Banlieue rouge: 1920-1960: Années Thorez, années Gabin: Archétype du populaire, banc d'essai des modernités (Ed. Autrement, pp. 56-65). Temps des cerises.

Liauzu, C. (2002). Interrogations sur l'histoire française de la colonisation. Geneses, no 46(1), 44-59.

Liauzu, C., \& Blili, L. (2004). Colonisation: Droit d'inventaire. Armand Colin.

Libération (journal). (1979, mayo 28). Antiracisme à travers les Unes de «Libé». Libération (journal). https://www.liberation.fr/planete/2011/03/24/antiracisme-a-travers-les-unes-de-libe_724121\#s4

Liogier, R. (2012). Le mythe de l'islamisation: Essai sur une obsession collective. Seuil. EAN 9782021078848

Livet, P. (2002). Emotions et rationalité morale (1 re éd). Presses universitaires de France.

Londres, A. (1927). Marseille porte du Sud (Les éditions de France).

Louis, P., \& Prinaz, L. (1990). Skinheads, Taggers, Zulus \& co. La Table ronde.

Madelin, B. (2007). Le rôle des femmes-relais. En Seine-Saint-Denis, avec Profession banlieue. Informations sociales, $n^{\circ}$ 141(5), 120-127. https://doi.org/10.3917/inso.141.0120

Mansilla, J. C. (2015). The Access to the City in the Medellín Urban Experience. World Academy of Science, Engineering and Technology, International Science Index, Humanities and Social Sciences, 9(4), 714. ISNI: 0000000091950263.

Mansilla, J. C. (2017). Hybrid cultural resistance of the youth of popular neighbourhoods in the digital age: Case study and qualitative comparative analysis (QCA) of Medellin, Paris and São Paulo [Université Sorbonne Paris Cité (USPC) - Université Sorbonne Nouvelle - Paris 3]. https://jeannicod.ccsd.cnrs.fr/STAR/tel-01910811v1

Mansilla, J. C., \& Schwartz, G. (2017). Youth Culture and Digital Resistance: Paris, Medellín and São Paulo. En Brazilian Internet Steering Committee \& Brazilian Network Information Center, Survey on the use of information and communication technologies in brazilian cultural facilities: ICT in 
culture 2016 (Center of Studies on Information and Communication Technologies (Cetic.br ; NIC.br), Committee of Internet of Brazil (CGI.br), pp. 171-180). Regional Center for Studies on the Development of the Information Society - Cetic.br; ISBN: 978-85-5559-043-6. http://cetic.br/media/docs/publicacoes/2/TIC_CULT_2016_livro_eletronico.pdf

Marcelle Media. (2018, noviembre 23). Rue d'Aubagne, et après ? Marcelle Media. https://marcelle.media/2018/11/23/rue-daubagne-et-apres-2/

Marsactu (journal). (2017, septiembre 11). [Vivre à Bougainville] Aux Docks Libres, entre protection et fragmentation sociale. https://marsactu.fr/vivre-a-bougainville-aux-docks-libres-entre-protectionfragmentation-sociale/

Masclet, O. (1990). Les Zoulous: Une identité de mise en scène. Journal des anthropologues, 42(1), 117 123. https://doi.org/10.3406/jda.1990.1572

Mauger, G. (1994). Des jeunes et des banlieues, perceptions du quartier et visions du monde social. Critiques sociales.

Mauger, G. (2009). III. Des «blousons noirs » aux « loubards ». En La sociologie de la délinquance juvénile (Repères, pp. 58-77). La Découverte. https://www.cairn.info/la-sociologie-de-ladelinquance-juvenile--9782707149718-page-58.htm

Mauger, G., \& Fosse, C. (1977). La vie buissonnière: Marginalité petite-bourgeoise et marginalité populaire. La Découverte.

Mayer, N., Michelat, G., \& Tiberj, V. (2013). Montée de l'intolérance et polarisation anti-islam. En La Lutte contre le racisme, l'antisémitisme et la xénophobie. Année 2012 (pp. 28-47). La Documentation française. http://spire.sciencespo.fr/hdl:/2441/7o52iohb7k6srk09mi4s0gorh

Maza, G., \& Sánchez, R. (2012). Deporte e Inmigración: Una Reflexión Crítica. Anduli - Revista Andauza de Ciencias Sociales, 11. https://doi.org/10.12795/anduli

McNeill, F., Raynor, P., Trotter, C., Maruna, S., \& LeBel, T. P. (2012). The desistance paradigm in correctional practice: From programs to lives. En Offender Supervision: New Directions in Theory, Research and Practice (pp. 65-87). Willan. https://doi.org/10.4324/9780203832974

Merklen, D. (2006). Paroles de pierre, images de feu. Sur les évènements de novembre 2005. Mouvements, 43(1), 131-137. Cairn.info. https://doi.org/10.3917/mouv.043.0131

Mernissi, F. (2016). Reflexiones sobre la violencia de los jóvenes: El caso Charmil. Icaria : IEMed.

Mesure, S., \& Savidan, P. (Eds.). (2006). Dictionnaire des sciences humaines (1. éd). PUF.

Mignolo, W. D., Carballo, F. J., \& Herrera Robles, L. A. (2015). Habitar la frontera: Sentir y pensar la descolonialidad:(antología, 1999-2014). CIDOB.

Milliot, V. (1997). Les fleurs sauvages de la ville et de l'art: Analyse anthropologique de l'émergence et de la sédimentation du mouvement hip hop lyonnais [Thesis, Lyon 2]. En Http://www.theses.fr. http://www.theses.fr/1997LYO20080

Mirza, H. S. (2013). Embodying the Veil: Muslim Women and Gendered Islamophobia in 'New Times'. En Z. Gross, L. Davies, \& A.-K. Diab (Eds.), Gender, Religion and Education in a Chaotic 
Postmodern World (pp. 303-316). Springer Netherlands. https://doi.org/10.1007/978-94-007-5270$2 \_20$

Mohammed, M. (2007). Les voies de la colère: « violences urbaines » ou révolte d'ordre «politique »? L'exemple des Hautes-Noues a Villiers-sur-marne. Socio-logos. Revue de l'association française de sociologie, 2. http://journals.openedition.org.inshs.bib.cnrs.fr/socio-logos/352

Mohammed, M. (2011). La formation des bandes: Entre la famille, l'école et la rue (1re éd). Presses universitaires de France.

Mohammed, M. (2015). Sortir de la délinquance. Idées économiques et sociales, $N^{\circ} 181(3), 48-52$. https://doi.org/doi:10.3917/idee.181.0048

Mohammed, M. (2016). La dynamique des bandes de jeunes: Compensation et réputation. Sens-Dessous, $N^{\circ}$ 18(2), 17-23. https://doi.org/doi:10.3917/sdes.018.0017

Mohammed, M., \& Mucchielli, L. (2007). Les bandes de jeunes. Des « blousons noirs » à nos jours. La Découverte; Cairn.info. https://www.cairn.info/les-bandes-de-jeunes--9782707153456.htm

Moignard, B. (2007). Bandes d'adolescents de la France au Brésil: Comparer l'incomparable ? En Les bandes de jeunes (pp. 351-377). La Découverte; Cairn.info. https://www.cairn.info/les-bandes-dejeunes--9782707153456-p-351.htm

Monod, J., Kokoreff, M., Padis, M.-O., \& Marchandier, I. (2008). Des Barjots aux bandes des cités. Esprit, Février(2), 39-54. https://doi.org/doi.org/10.3917/espri.0802.0039

Moore, D., \& Cesari, J. (2003). Les jeunes, l'islam et les pratiques culturelles. De l'indignité culturelle à la relégation institutionnelle (p. 269). Persée http://www.persee.fr. https://www.persee.fr/doc/debaj_1275-2193_2003_ant_13_1_1156

Moore, J. (1992). Les problèmes de l'inner city en Grande-Bretagne: La version anglaise des citésguettos. Les Annales de la Recherche Urbaine, 54(1), 39-43. https://doi.org/10.3406/aru.1992.1654

Morin, E. (1963, julio 6). 1963, Edgar Morin baptise la génération « yé-yé » dans "Le Monde 》 (journal Le Monde). https://www.lemonde.fr/archives/article/1963/07/06/i-une-nouvelle-classe-dage_2207794_1819218.html

Moumen, A. (2010, mayo 1). Violences et migration politique. Quitter l'Algérie en 1962 [Fragments sur les Temps Présents]. https://tempspresents.com/2010/05/01/abderahmen-moumen-violences-etmigration-politique-quitter-1\%E2\%80\%99algerie-en-1962/

Mucchielli, L., Bibard, D., Borrelli, C., Mattina, C., \& Sahraoui, K. (2013). Trafics et trafiquants de drogues à Marseille. ORDCS (Observatoire régional de la délinquance et des contextes sociaux). Maison Méditerranéenne des Sciences de 1'Homme. http://ordcs.mmsh.univaix.fr/publications/Documents/Rapport_recherche_ORDCS_N1.pdf

Oullier, O., \& Kelso, J. A. S. (2006). Neuroeconomics and the metastable brain. Trends in Cognitive Sciences, 10(8), 353-354. https://doi.org/10.1016/j.tics.2006.06.009

Perrot, M. (2007). Dans le Paris de la Belle Époque, les « Apaches », premières bandes de jeunes. $L a$ lettre de l'enfance et de l'adolescence, $n^{\circ}$ 67(1), 71-78. https://doi.org/10.3917/lett.067.0071

Petonnet, C. (1979). On est tous dans le brouillard. Ethnologie des banlieues. Editions Galilee. 
Pigenet, M., \& Tartakowsky, D. (2003). Les marchés en France aux XIXe et XXe siècles: Récurrence et métamorphose d'une démonstration collective. Le Mouvement Social, no 202(1), 69-94.

Pouget, B. D. (1976). Adolescents de banlieue, recherche éthologique sur les groupes spontanés de jeunes dans la banlieue de Lyon. https://data.bnf.fr/en/tempwork/b9fe77bd7977a0943fd3412fc1d1bea0/

Queirolo Palmas, L. (2017). Cómo se construye un enemigo público: Las bandas latinas: una etnografía del Estado (1a. edición). Traficantes de Sueños. https://www.traficantes.net/sites/default/files/pdfs/TS-UTIL18_web_0.pdf

Rey, A. (Ed.). (1998). Dictionnaire historique de la langue française. Le Robert.

Robert, P., \& Lascoumes, P. (1974). Les bandes d'adolescents: Une théorie de la ségrégation (2e édition). Éditions ouvrières. https://catalogue.bnf.fr/ark:/12148/cb35371648x

Roulleau-Berger, L. (1991). La ville intervalle: Jeunes entre centre et banlieue (p. 211). Editions Méridiens-Klincksieck. https://halshs.archives-ouvertes.fr/halshs-00497887

Roulleau-Berger, L. (1996). Cultures de friches à Marseille. Les Annales de la Recherche Urbaine, 70(1), 16-25. https://doi.org/10.3406/aru.1996.1924

Saffari, S., Akhbari, R., Abdolmaleki, K., \& Hamdon, E. (Eds.). (2017). Unsettling colonial modernity in Islamic contexts. Cambridge Scholars Publishing.

Samson, M., Peraldi, M., \& Duport, C. (2015). Sociologie de Marseille. La Découverte.

Sánchez García, J. (2010). Jóvenes de otros mundos: ¿Tribus urbanas? ¿Culturas juveniles? Aportaciones desde contextos no occidentales. Cuadernos de antropología social, 31, 121-143.

https://doi.org/10.34096/cas.i31.2731

Sauvadet, T. (2005). Causes et conséquences de la recherche de «capital guerrier» chez les jeunes de la cité. Déviance et Société, Vol. 29(2), 113-126. https://doi.org/10.3917/ds.292.0113

Sauvadet, T. (2006). Le sentiment d'insécurité du «dealer de cité ». Sociétés et jeunesses en difficulté, 1. https://hal-upec-upem.archives-ouvertes.fr/hal-01330853

Sauvadet, T. (2010). Marginalité juvénile et lois du silence: L'entre-soi des jeunes de rue des cités HLM (pp. 279-290). Presses universitaires de Rennes. https://hal-upec-upem.archives-ouvertes.fr/hal01330890

Schwartz, O. (1998). La Notion de « classes populaires » [Habilitation à diriger des recherches (HDR)]. Université de Versailles- Saint-Quentin-en- Yvelines.

Small, M. L. (2008). Four Reasons to Abandon the Idea of “The Ghetto". City \& Community, 7(4), 389398. https://doi.org/10.1111/j.1540-6040.2008.00271_8.x

Soto, H., \& Therme, P. (1999). Les figures de l'exploit. Pratique et supportérisme chez les jeunes des quartiers sensibles marseillais. Agora débats/jeunesses, 16(1), 53-60. https://doi.org/10.3406/agora.1999.1148

Spire, A. (2003). Semblables et pourtant différents. La citoyenneté paradoxale des « Français musulmans d'Algérie » en métropole. Genèses, 53(4), 48-68. Cairn.info. https://doi.org/10.3917/gen.053.0048 
Thin, D., \& Millet, M. (2012). Ruptures scolaires: L'école à l'épreuve de la question sociale. Presses Universitaires de France. https://doi.org/10.3917/puf.mille.2012.02

Tonneau, F. (1998, agosto 31). Marseille fête ses héros. Ils étaient plus de 100000 hier sur la Canebière et le Vieux-Port. leparisien.fr. http://www.leparisien.fr/sports/marseille-fete-ses-heros-31-08-19982000222497.php

Topalov, C. (2003). Écrire l'histoire des sociologues de Chicago. Genèses, 51(2), 147-159. Cairn.info. https://doi.org/10.3917/gen.051.0147

Touzard, H. (s. f.). La médiation et la résolution des conflits. PUF.

Van Ginneken, E. F. J. C. (2017). Constrained Agency: The Role of Self-Control in the Process of Desistance. En E. L. Hart \& E. F. J. C. van Ginneken (Eds.), New Perspectives on Desistance: Theoretical and Empirical Developments (pp. 241-265). Palgrave Macmillan UK. https://doi.org/10.1057/978-1-349-95185-7_11

Vieillard-Baron, H. (1990). Le ghetto un lieu commun impropre et banal: Approches conceptuelles et représentations. Les Annales de la Recherche Urbaine, 49(1), 12-22. https://doi.org/10.3406/aru.1990.1558

Viet, V. (1998). La France immigrée: Construction d'une politique, 1914-1997. Fayard.

Vulbeau, A. (1992). Du tag au tag. Desclée de Brouwer.

Wacquant, L. (2005). Les deux visages du ghetto: Construire un concept sociologique. Actes de la recherche en sciences sociales, 160(5), 4. https://doi.org/10.3917/arss.160.0004

Wacquant, L. (2006). Réponse à la recension de Parias urbains. Hérodote, 123(4), 227-228. Cairn.info. https://doi.org/10.3917/her.123.0227

Wacquant, L. (2007). Parias urbains: Ghetto, banlieues, État. La Découverte.

Wacquant, L. J. D. (1992). Pour en finir avec le mythe des «cités-ghettos»: Les différences entre la France et les Etats-Unis. Les Annales de la Recherche Urbaine, 54(1), 21-30. https://doi.org/10.3406/aru.1992.1652

Willis, P. (1978). L'école des ouvriers. Actes de la Recherche en Sciences Sociales, 24(1), 50-61. https://doi.org/10.3406/arss.1978.2615

Wilson, W. J. (2006). The truly disadvantaged: The inner city, the underclass, and public policy (Paperback ed., [Nachdr.]). Univ. of Chicago Press.

Ziegler, J. A., Kuhl, D. C., Swisher, R. R., \& Chavez, J. M. (2017). Parenthood Residency Status and Criminal Desistance across Neighborhood Contexts. Deviant behavior, 38(1), 17-33. https://doi.org/10.1080/01639625.2016.1189758

Zreik, K. (Ed.). (2012). Villes hybrides et enjeux de l'aménagement des urbanités numériques: Actes du colloque HyperUrbain 3. Europia productions. 


\title{
5 (Trans)gangs in Milan: Re-socializing migration experiences in the richest Italian city
}

\author{
Paolo Grassi
}

\subsection{Introduction}

Referring specifically to the (Trans)gang project objectives d) and e) ${ }^{66}$, the local research in Milan aims to investigate conflict mediation or conflict resolution experiences across "street groups" (or "gangs-in-process", to use such category), in order to develop innovative comparative analysis on gangs and plan novel social actions against juvenile violence. In doing so, the local research team will focus its analysis on three main directions of analysis (mapping the gang phenomenon in Milan nowadays; reconstructing the gang dynamics in Milan over the last fifteen years; studying the perception of the phenomenon within the local communities and within the wider city of Milan - see Grassi, 2019) that will help to answer three research questions: what are the street groups of the city? Are or were there local experiences related to conflict mediation or conflict resolution inside and outside these street groups? What is the "added value" of studying gangs in Milan through ethnography?

This Background paper will set up the basis to answer these three questions, presenting five main sections and a conclusion. After this introduction, the second section (State of Art: Researching (Trans)Gangs in Milan) will review the main works on Milanese gangs since 2005. At that time, groups of young Latin Americans started to meet on street corners, in public parks and at some discotheques of the city. They gave themselves names and rules. They created their own rituals. In parallel, a team of social researchers started to work with them. This team was formed mainly by qualitative sociologists employed in an independent research agency called Codici. They published several articles (Bugli 2009, 2010; Bugli \& Conte 2010; Conte \& Bugli 2008; Conte 2007; Conte, Meola, \& Milanesi 2008), often collaborating with a group of sociologists of the University of Genova coordinated by Prof. Luca Queirolo Palmas (Cannarella, Lagomarsino \& Queirolo Palmas 2007; Queirolo Palmas 2009, 2010, 2017; Queirolo Palmas \& Torre 2005). Their analysis developed according to the evolution of the phenomenon. However, the project stopped around 2010. In the last few years, newspapers and some televisions have started to talk about gangs, especially after two "critical" events that involved at least one local clika -local designation- of Mara Salvatrucha occurred: the brutal assault of a train inspector in 2015 and the homicide of an Albanese adolescent in 2016. For the first time gang violence was directed outside

66 "d) To explore experiences in which gangs have acted as agents of mediation, as well as barriers that block these attempts; e) To deduce more effective ways of intervention to prevent the hegemony of the criminal gang pattern that still appears so dominant in the neoliberal era", Feixa Pàmpols, (Trans)gang Project: 5-6. 
the Milanese street groups and the Latin American communities. A wave of moral panic immediately grew. Since 2016, also two research groups of the Catholic University of Milan - Transcrime and ITSTIME - have started to study the gang phenomenon from a more criminological perspective. Nevertheless, apart from a couple of articles they have not published any work so far (Lombardi 2016).

The third section (Empowerment, Conflict and Mediation) will describe in depth the main mediation process between street groups and institutions in Milan. It was carried out by Codici and Comunità Nuova from 2005 to 2008, a non-governmental organization managed by a catholic priest. Through this project, a group of Latin Kings formed a formal association, called "Movimiento Real Juvenil". Today no organization is working on street education projects or mediation processes with these adolescents and young men (who - in the meanwhile - seemed to "disappear" from the public spaces of Milan). The municipality is not funding street education projects anymore. Only churches, religious groups, and some social workers have sporadic contact with some of these young men (and women).

The fourth section ((Trans)Gangs in Milan) will introduce the city of Milan and some of its quantitative indicators. Milan has changed a lot in the last few years, becoming a metropolitan city in competition with other European capitals. Milan is notably growing, but social polarization has also increased. Then, the section will describe "gang spaces" of Milan at the physical, social and virtual levels. It will be shown how these are extremely fluctuating and how any photography of the local situation can be only provisional, temporary and transitory. In this respect, also the ethnic composition of the Milanese street groups has varied a lot in the last few years. The section will eventually analyse the transnational connections and the "ideo-scapes" that link these groups, also referring to Italian media that often have described them in a superficial and stigmatized way.

The conclusion will retrace the main contents of the previous sections and will develop one main interpretation: the phase of repression and the complementary reduction of the municipal educative services have left a political vacuum in reference to the changing socialization dynamics of the young migrants within the public space of Milan. Moreover, it will deepen the research questions in the light of the analysis presented before.

Along the definition proposed by the (Trans)gang Concept paper (see Feixa et al., 2019), the Milanese street groups will be considered along a continuum, in one whose extremes are the delinquent groups (the gangs themselves) and in another the groups linked to free time (the youth cultures). For this reason, this Background paper will use both the terms "gang" and "street group", where "gang" will be more associated to a shared point of view used by media, institutions, but also the youngsters themselves, while "street group" will be more associated to an academic construction aimed not to 
develop criminalizing and stigmatizing interpretations of this complex social phenomenon.

\subsection{State of the Art: Researching (trans)gangs in Milan}

If - according to the (Trans)gang project - the existence of a gang implies at least the presence of five indicators: a) a name; b) an external label; c) an internal conscience; d) ordinary activities; and e) continuity over time ((Feixa et al., 2019), see also Klein 1971 and Thrasher 1927/2013), in regards to the Milanese context we have to focus our analysis mainly on Latin American gangs (see Cruz, 2008). In fact, we do not have any evidence about Arab groups fitting these five indicators, even if, along the continuum of gang elaborated by the (Trans)gang project, certainly it is possible to identify street groups or criminal groups mainly formed by young Arab migrants (see Colombo, $1998)^{67}$.

Thus, referring to Latin American gangs it is quite easy to find a starting point. In fact, at the beginning of 2000s, a new social phenomenon appeared in some Italian cities (firstly in Genoa and Milan): small groups of young Latin Americans - especially, but not only, from Ecuador, Peru, Salvador, and the Dominican Republic - started to meet on street corners, in public parks, and at some discotheques, with some Italian adolescents and young men and women joining them. A new moral panic developed: also in Italy street gangs have appeared (Cohen, 1972). These groups were something different from the Italian baby gangs associated to mafia or camorra, or from other past Italian experiences, such as those described by Pier Paolo Pasolini in his famous novel "Ragazzi di vita" (1955), or the subcultural groups that developed - especially in Milan - since the beginning of the Eighties (Caioli et al., 1986). Even if banditry is one of the more universal social phenomenon of their history, as Eric Hobsbawn famously wrote (1971), these "new" Italian street groups had some peculiarities: they were a contemporary phenomenon, the result of recent migration dynamics connected to transnational practices and globalized imaginaries (see section 4).

In parallel, a group of Italian researchers - especially some qualitative sociologists started to work on this topic, trying to understand what was going on. In 2005 the first book on Latin American gangs in Italy appeared. It was edited by Luca Queirolo Palmas and Andrea Torre, and it described what had happened in Genoa since the end of the Nineties, when Latin Americans became the biggest community of migrants living in the capital of the Liguria region. This increase brought much more boys and girls into the public spaces of the city. The comfortable image of the Latin American "maid" many Latin American women got jobs as housekeepers or caretakers in Italy during those years - was quickly substituted by the "spectre" of gangs. Using ethnography and participatory methodologies the authors tried to depict a first "thick" description of this social phenomenon (Queirolo Palmas \& Torre, 2005).

\footnotetext{
${ }^{67}$ In this book Asher Colombo analyses the illegal economy of thirty five Algerian migrants living in the area of the central station and Porta Venezia.
} 
Two years after, Luca Queirolo Palmas together with other two Genovese sociologists published a second seminal research on Latin American street groups in Italy (Cannarella, Lagomarsino \& Queirolo Palmas, 2007). Also referring to critical criminology (see Brotherton, 2015; Hagedorn, 2006; Vigil, 2002) and labelling theory (Becker, 1963), this book describes a long process of action-research implemented in Genoa (but also in Guayaquil, Barcelona, Madrid, New York, and Milan) with groups of Latin Kings and Netas. This is, together with a Milanese experience, probably the most important experience of mediation between gangs and Italian institutions (while it is possible to underline other forms of mediation within the groups and among them see section 3 ).

During those years the gang phenomenon also began to appear in Milan, leading a group of researchers to start working on the same issue, using a participatory perspective. The group was related to an independent research agency called Codici. The man in chief of that group was Massimo Conte. Valentina Bugli, member of Codici and then a Ph.D. candidate at the University of Milano Bicocca with a thesis on Latin American gangs - was one of the main collaborators. Together with the non-profit organization Comunità Nuova, they started to work in the streets of Milan, trying to reproduce a new mediation process between those groups and the Milanese institutions, alongside the experience of the group of Genoa.

In one of the first available essays, Massimo Conte explained the genesis of the Milanese street groups. According to the author, this phenomenon was the result of a process of interaction between two groups of young Latin Americans (especially Peruvians and Ecuadorians at the beginning): those coming to Italy through family rejoining procedures and those in a more marginal condition, escaping from street life in their home countries and looking for a better life. Street groups became a way to negotiate their frustrations, to signify a new identity against their marginalization (Conte, 2007). Conte also explained how things changed after 2006, when a first phase of repression started:

In June 2006, Milanese newspapers reported titles like "Baby gangs of Latinos, super raids in Milan", or "Gangs: raids against Latinos". The news concerned the arrests of some youngster members of the Latin Kings and Comando, two juvenile groups that since 2004 have been in conflict in the streets of Milan. [...] The police operation had a big media impact, also because it followed a similar operation executed in Genova a month before among Lating Kings and Netas. Arrests seriously affected our action and mediation process carried out in Milan and in Genova (Conte, 2007: 1) ${ }^{68}$.

One year after, Luca Queirolo Palmas, together with Massimo Cannarella and Francesca Lagomarsino, edited another book on the development of this social phenomenon in Italy. Deconstructing the stereotyped image of those youngsters that media and institutions had reproduced, in the title the authors used the word "street organization" instead of gang for the first time (see Barrios \& Brotherton, 2004). Here the authors

${ }^{68}$ All translations from Spanish and Italian into English are my own. 
developed an interesting comparative perspective. The book presented the results of the action-research projects implemented in Genoa and Milan, but it also made some references to other experiences, such as a popular gym in Perugia where a group of Latin Kings used to meet (Cannarella, Lagomarsino \& Queirolo Palmas, 2008).

In this book, two chapters are dedicated to Milan. In the first one, Massimo Conte and Valentina Bugli described how a group of Latin King became a formal association through a mediation process managed by their organization (see section 3). Analysing the social practices of those pandilleros [gang members], Conte e Bugli referred to some classical interpretations on gang dynamics, but they also underlined some Milanese specificities. As well as all the other gangs, the Latin Kings of Milan negotiated trough their practices a new provisory identity in search of freedom and social emancipation. That identity was constructed in contraposition to other groups, at a symbolical level and also through violent conflicts. However, the relation between those pandilleros and their urban territory was something new, a result of migration dynamics. Conte and Bugli indicated that it was not about a sense of belonging to the city of Milan, but it was about "precariousness" and "crossing" a specific time and space (Conte \& Bugli, 2008). In the second one, Valentina Bugli, Luca Meola and Matteo Milanesi explained how a "Latin American Milan" was inscribed in the urban space, through specific practices and imaginaries (Conte, Meola \& Milanesi, 2008; see section 4).

In 2009, Valentina Bugli wrote another article developing some of the issues described above. Gangs in Milan were seen as an experience of "defensive re-socialization" carried out by young migrants, not as a criminal phenomenon at all. They did not control territory, drug trafficking or prostitution. As explained by Massimo Conte two years before, also in Bugli's opinion gangs in Milan connected young Latin Americans just arrived in Italy with those who had already experienced social exclusion in their home countries. Gangs offered to them accessible and understandable codes. Milan was the set to display them (Bugli, 2009).

Luca Queirolo Palmas edited two other books on gangs in Italy in 2009 and in 2010 (Queirolo Palmas, 2009, 2010). In the last one, Bugli and Conte wrote a chapter where they developed their analysis on Milanese gangs. Contesting the category of "street organization" they preferred to use the word "street group", in order to not cancel the internal contradictions and idiosyncrasies of the boys and girls they met and not to overestimate their social consciousness (Bugli \& Conte, 2010).

In 2010, Valentina Bugli finished her Ph.D. thesis, where basically she retraced her research with Codici during the previous years. There, Bugli deepened three directions of analysis: the first one was related to motivations of Latin American boys and girls and their experiences as gang members, the second one was related to the "real" and symbolic geographies inscribed in the urban space by those youngsters, and the third one was about conflicts and deviance. More precisely, Bugli analysed the identity of 
some groups of migrant adolescents and the social context in which their experience was structured. She focused her attention on several elements such as: houses, schools, networks of friendships. She underlined the impossibility of these boys and girls of being autonomous, due to the difficulties to get documents or good jobs. She explored the heterogeneity of those street groups, their composition, interactions and conflicts. She analysed their socialization towards violence, often characterized by "macho" traits (Bugli, 2010).

After that, gangs in Milan seemed to disappear from the Italian academy. Codici continued to work on this topic thanks to another project for one year ("Latinos" project, see section 3), Luca Queirolo Palmas investigated similar topics in Spain (Queirolo Palmas, 2017) ${ }^{69}$. The first police operations in Milan dated back to $2005^{70}$, but repression grew more intense between 2012 and 2015, when four police operations followed one after the other (see section 5). Latin American gangs of Milan experienced an escalation of violence. Other new groups added to the old ones (Latin Kings, Comando and Netas), and the Central American Mara Salvatrucha (MS13) and Pandilla 18 also appeared ${ }^{71}$.

While social researchers stopped (at least publicly) investigating this social phenomenon, gangs of Milan evolved. For the very first time, gang violence was directed outside of the groups and the Latin American communities. A new and stronger wave of moral panic affected Latin American communities - especially the Salvadorian one - as a whole. Two events marked this step. On the $11^{\text {th }}$ of June, 2015, a supposed clika of Mara Salvatrucha attacked Carlo di Napoli, a ticket inspector of Trenord, at Milano Villa Pizzone train station. One of the boys pulled out a machete -and severely injured the inspector, who almost lost his arm in the attack (Galli \& Giuzzi, 2015). One year later, on the $3^{\text {rd }}$ of July, 2016, Albert Dreni, an Albanian of eighteen years old, got in the middle of a fight between two street groups on Tram number 15 in front of the Lime Light, a discotheque that was frequented by Latin American boys and girls, especially on Sunday afternoons. A 21 year- old member of a local clika of Mara Salvatrucha stabbed him and Albert Dreni died eleven days after (Berni, 2016).

\footnotetext{
${ }^{69}$ Using Bourdieu's sociology, in this book the author analyses how Latin American street groups in Barcelona are produced and reproduced by media, institutions, and social actors. More specifically, the book is an attempt to apply Pierre Bourdieu's theories to the study of youth gangs, in dialogue with North American critical criminology and British cultural studies. The book analyses the gang "field" as one of those fields where different social actors and different institutions are entangled. The author describes how the gangs he studies want to "distinguish" themselves from the rest of the society, to basically achieve symbolic benefits like respect, not material ones.

${ }^{70}$ As explained above, in some papers the researchers of Codici described them, always criticizing the criminalization of the Milanese street groups.

${ }^{71}$ Already in 2010 Massimo Conte declared that clikas of Mara Salvatrucha and Barrio 18 were reported by the police of Milan. During a meeting we had for my Ph.D. research, he told me that, in his opinion, these clikas were connected to former pandilleros migrated from Central America with an higher criminal profile that reproduced the same dynamics they experienced in their home countries.
} 
In those years, academics wrote very few articles on Milanese gangs, but the media started to talk more and more about them ${ }^{72}$. Sensationalistic titles were published in several newspapers. Massimo Conte and other social workers who were in contact with the imprisoned men gave some interviews. On the $22^{\text {nd }}$ of April, 2016, Roberto Valencia published a long article on Elfaro.net entitled "Mareros en Milan" (Valencia, 2016a). On the $24^{\text {th }}$ of April the article was translated in Internazionale, one of the most famous Italian weekly magazines. Valencia focused his attention on Mara Salvatrucha and Barrio 18, starting his narration from 2006. He mapped some of the "hot spots" frequented by the two gangs, following Tiger, a member of Barrio 18 escaped from El Salvador: the central station, Carbonari square, Trotter park. He also mixed this narration with several interviews: Massimo Conte again; another ex-marero called Cholo; Deidamia Morán, elderly leader of the Catholic community "Monsignor Romero", one of the reference points for the Salvadorians of Milan; Paolo Lisi and Marco Campari, two policemen members of a special gang unit of the flying squad of the city; Vanessa Hasbún, representative of the Salvadorian consulate of Milan.

Valencia indicated a precise starting point of the war between these two gangs: $13^{\text {th }}$ July of 2008, when Necio and Pirata, members of Mara Salvatrucha, attacked Ricardo, a member of Barrio 18, with a bunch of other boys. During the fight, Ricardo lost an eye. Valencia affirmed that in that period there were other Latin American gangs in Milan, both local (Comandos, Trébol and Latin Forever) and transnational (Latin Kings, Netas, Bloods e Trinitarios), but since 2008 only Mara Salvatrucha and Barrio 18 have particularly concerned Italian police for their level of organization and their presence within the city of Milan (Valencia, 2016b).

Mara Salvatrucha and Barrio 18 started to interest also Italian academy, again, but at a more criminological level. In 2016 Tommaso Comunale started a Ph.D. in criminology at the Catholic University of Milan, within the Transcrime research group ${ }^{73}$. His research interests are criminal organizations, terrorism, crime mapping and gangs. His $\mathrm{Ph} . \mathrm{D}$. thesis is analysing the main police operations concerning Milanese maras and Latin American gangs. Another research group of the same university started to study the gang phenomenon within the city, too. The group is called ITSTIME: Italian Team for Security, Terroristic Issues \& Managing Emergencies ${ }^{74}$. The group has developed several researches, always focusing on security issues from different perspectives. On

\footnotetext{
72 In 2015 I published a book on Guatemala City and gangs (Grassi 2015a). Because of the news events quoted above an online journal asked me a brief article to compare my research with the Italian context (Grassi 2015b).

${ }^{73}$ Transcrime is the Joint research center of the Università Cattolica del Sacro Cuore, the Alma Mater Studiorum Università di Bologna and the Università degli Studi di Perugia. Transcrime employs an integrated approach and performs applied research to: Analysis of criminal phenomena; Evaluation of crime prevention policies; Analysis and identification of criminogenic opportunities in legislation; Development of risk assessment models and crime (www.transcrime.it, see Savona \& Riccardi 2018).

${ }^{74}$ ITSTIME - Italian Team for Security, Terroristic Issues \& Managing Emergencies, is a research center of Department of Sociology of the Catholic University of Sacred Heart, Milan. ITSTIME addresses both theoretically and empirically the new challenges in the new hybrid war domain. It is mainly focused on: Security, Terrorism as a long term threat, Emergencies management (www.itstime.it).
} 
the $15^{\text {th }}$ of November 2016, the director, Marco Lombardi, shared a post on the website of his research group entitled: "Violence in Milan: the Latin American gangs" (Lombardi, 2016). This group continues to map the phenomenon nowadays, especially working on social networks.

Also in 2016, an academic article written by the Honorary Judge Moyersoen analysed the reconstruction of the first criminal sentence of the "Giudice dell'udienza preliminare" (Preliminary hearing judge) of the juvenile court of Milan in 2010 (Moyersoen, 2016; see section 5).

After five police operations, Latin American gangs in Milan seemed weaker and more fragmented than some years ago. Thus, their apogee can be dated back to 2015 and 2016. Among others, Massimo Conte confirmed this in an interview carried out on the $19^{\text {th }}$ of February, 2019. According to the researcher, it is possible to meet "residual" subjects on the street nowadays, i.e. adolescents or youngsters with more problematic social profiles, or former gang members ${ }^{75}$. There are certainly other groups with a higher criminal profile, but they are hardly traceable and observable. Moreover, for some of my interlocutors, socialization dynamics of the Milanese youngsters generally changed (see section 4).

A policeman who wanted to remain anonymous, member of the flying squad of Milan, confirmed this during an interview on the $29^{\text {th }}$ of April, $2019^{76}$ :

So we're talking about teenagers or youngsters coming from Latin American countries who were not gang members in their home countries, right?

Someone was already a member there. Others have started here $[\ldots]$.

How many people are we talking about? I imagine a few dozen people.

About thirty.

Latin Kings, MS13, Barrio 18: all together?

Well, the Latin Kings is a somewhat out-dated phenomenon. We are following those [gangs] that are more active, even if the "active" adjective is not the proper one, because they probably continue to meet, but fundamentally that phenomenon of recrudescence that occurred some years ago does not exist today. We are talking about twenty, thirty people between MS13 and Barrio18. They are constantly monitored ${ }^{77}$.

Also Donna De Cesare ${ }^{78}$, an American journalist, photographer and professor at the University of Texas at Austin, who started a fieldwork on Salvadorian community and

\footnotetext{
${ }^{75}$ This is probably related to the phase of police repression described above.

${ }^{76}$ The lack of research on Latin American gangs in Milan required some preliminary interviews with stakeholders and local actors in order to understand their recent developments. Some of these results are presented here.

${ }_{77}^{7 n}$ Interview, $29^{\text {th }}$ of April, 2019.

${ }^{78}$ Donna De Cesare, is an Associate Professor of Journalism at the University of Texas at Austin, a consultant to the Dart Center for Journalism and Trauma at Columbia University and a Master Teacher with the Gabriel Garcia Marquez Foundation for Latin American Journalism.
} 
gangs in Milan in 2018, elaborated a similar position (see De Cesare, 2018). I interviewed her on the $27^{\text {th }}$ of April, 2019. She declared: "I tried to figure out how big is this phenomenon. There is a phenomenon... but how many gang members there are actually? I think it is probably very, very small, maybe 30,40 at the most"79.

However, two recent events showed that somehow gangs still exist in Milan. The first one (March 2019) is linked to Mara Salvatrucha, the second one (June 2019) to Barrio 18 (see section 4).

The distance between the width of the phenomenon and the wave of moral panic that this has produced needs more reflections that could be developed through the research project. Certainly, as already pointed out by Stanley Cohen regarding English youth subcultures, the social reaction to Latin American gangs firstly showed the anxieties of the Milanese residents - and Italian citizens more in general - about migrations and (foreign) youth (Cohen, 1972).

\subsection{Empowerment, Conflict and Mediation}

Referring to conflicts among gangs, we know that urban space is the traditional set for street fights (Thrasher, 1927/2013; Whyte, 1943). In this sense, violence must be understood as a means of expression, a form of "communication" or interaction within the cities. However, violence can also regulate relations among groups through norms, symbols, and rituals. It is connected to the construction of gender and intergenerational relations based on hegemonic masculinity and respect (Cannarella, Lagomarsino \& Queirolo Palmas, 2007).

As stated by the Concept paper of the (Trans)gang project, "the classic definition of mediation says it is an alternative [to violence] system of conflict resolution" (Feixa et al., 2019, p. 46). Mediation processes can be developed at several levels, controlling violence, or transforming it into something else. At least two of them are particularly relevant for this research: community level and intercultural level (Ortega, 1995).

Taking account this definition, we could state that a single formal mediation process between street groups and institutions can be observed in Milan, that one carried out by Codici together with Comunità Nuova, from 2005 to 2008. Codici is an independent organization that promotes research and educational activities. It is based in Milan and it is formed by a team of social workers, researchers and urban planners ${ }^{80}$. Comunità Nuova is a non-profit organization that works with young people in the Lombardy region. The president is Don Gino Rigoldi, a catholic priest who has been working at Beccaria since the Seventies ${ }^{81}$.

\footnotetext{
${ }^{79}$ Interview, 27th of April ,2019.

${ }^{80}$ www.codiciricerche.it

${ }^{81}$ www.comunitanuova.it
} 
The project was called "Calle" and was funded by Vodafone Foundation for the educative component and the Ministery of Social Solidarity for the research component (Bugli, 2010). The "Calle" project essentially was an action-research project based on street education. The project brought a group of social workers and researchers in contact with informal groups of adolescents and pre-adolescents in the streets and the parks of Milan. The project ended in 2008, when the municipality of Milan decided to close all the street education activities. On the $15^{\text {th }}$ of March, 2019, Don Gino Rigoldi explained to me:

With Comunità Nuova we did a job with groups of young migrants: Latin Kings and two or three other groups, but this ended five or six years ago. There was a group of us - sometimes I joined them too - who went around the streets [...] We had to send one of my collaborators to New York, where he met one of the Latin King leaders. He basically gave us "a pass" to work with these guys here. We spent up to seven months just to get a contact. Then they finally opened up to us, they realized we weren't policemen. Of course you could see violence, bad habits, not just crimes, but certainly violent relationships between them and with other groups. This work went on for a few years, then it stopped because at some point the municipality that had commissioned this stuff started to pay nothing. For a year, maybe two, we went ahead with our expenses, then I had to stop ${ }^{82}$.

Through the "Calle" project a group of Latin Kings founded a formal association, the "Movimiento Real Juvenil". A ceremony was performed during a public event in front of the then counsellor of Ecuador, Narcisa Soria Valencia, the vice-counsellor Monica Lasso, a member of the Participation Department of the Province of Milan, and some journalists (Affari Italiani, 2008).

Through this formalization process at least a Milanese street group certainly acted as a "bridge" between institutions, cultures and generations, operating at a community and intercultural level. In this respect, Don Gino Rigoldi said to me, almost sermonising:

In this sense, could gangs have had a positive role of mediation, between them and the Italian society, or the institutions?

I believe that loneliness is the absolute evil, while groups are "relatively" good. I say relatively because if you go to steal, it doesn't work [...] Loneliness is the absolute evil. The groups, well it depends. These groups have positive and negative aptitudes, certainly they have aptitudes. I believe that working with these groups is possible ${ }^{83}$.

However, today the association "Movimiento Real Juvenil" does not exist anymore. Codici continued to partially work with street groups thanks to another project for one year. The project was called "Latinos" 84 . It implemented actions for social integration of

\footnotetext{
${ }^{82}$ Interview, $15^{\text {th }}$ of March, 2019.

${ }^{83}$ Interview, $15^{\text {th }}$ of March, 2019.

${ }^{84}$ The project was funded by the Ministry of the Interior and the European Union (Integration fund). It was an action-research project aimed to promote social integration of Latin American children and young adults living in Milan. The project was carried out using a "peer research" methodology.
} 
young Latin Americans together again with Comunità Nuova, and then the NGO Soleterre and the association Suoni Sonori ${ }^{85}$.

After the police operations, street groups seemed to disappear from the public spaces of Milan. On the other hand, some Milanese gangs probably acquired a more criminal status. In the meanwhile, Mara Salvatrucha and Barrio 18 emerged.

My interlocutors change their position about mediation chances when they talk about these "new groups". On the $30^{\text {th }}$ of March, 2019, a social worker who had worked with some imprisoned gang members of Mara Salvatrucha during their rehabilitation process, declared:

That group [the gang] had a containment function, yes, even if I understand that it is an almost provocative concept. The boys who came out of it - I have in mind two or three of them, especially one - have succeeded in doing it. It is a very long process: reconstructing the negative dimensions but also the meanings of that.

But could a process of formalization be possible with these groups nowadays? A process just like that of Codici, moving from the idea of transforming those groups into formal, institutionalized associations. Is it feasible nowadays?

I don' know. It's just a feeling. I think it was possible before, maybe you can imagine something, you can think about it ... When you get there [at that "breaking point" of violence] I think you have already crossed a border, beyond the possibility of integration. Perhaps the work that had been done a few years ago had managed to intercept an earlier phase of this phenomenon ${ }^{86}$.

Anyway, today no organization is working on street education projects or mediation processes with these adolescents and young men. Only churches, religious groups, and some social workers have contacts with some of these guys, but more on individual basis. An Evangelical priest confirmed this during an interview on the $5^{\text {th }}$ of April, 2019:

Did you approach the issue of gangs, here in Milan?

Yes, we even had someone that was part of those pandillas.

When did it happen?

These pandillas - which are gangs that organized themselves to do bad things - I invited them with other pastors, we talked [...] Because there were families, mothers, parents: we prayed together [...]. Some of them came from pandillas, some of them came here to the church [...]. So we tried to help them, they finished their sentence and they came here to the church, regularly ${ }^{87}$.

On the $30^{\text {th }}$ of June, 2019 I had another interview with a former member of a Milanese clika of Mara Salvatrucha. The boy, who prefers to remain anonymous, explained to me that he tried to contact the Salvadorian consulate to organize meetings or some kind of activity to "help" other young migrants, but without success. In Milan, at least

\footnotetext{
${ }^{85}$ www.soleterre.org; https://suonisonori232.org

${ }^{86}$ Interview, 30 ${ }^{\text {th }}$ of March, 2019.

${ }^{87}$ Interview, $5^{\text {th }}$ of April, 2019.
} 
institutionally, Latin American street groups seem to have become exclusively a security affair.

\section{4 (Trans)gangs in Milan}

This section will firstly introduce the city of Milan and some indicators. Then, it will describe its "gang spaces" at physical, social and virtual levels, focusing in particular on some media discourse that feed the mythological imaginary connected to Latin American gangs.

Milan is the economic capital of the seventh most powerful country in the world. It has $1,300,000$ residents and it produces about $10 \%$ of the national GDP. The unemployment rate is at $6.2 \%$ (against a national average of around $10 \%$ ). The per capita income is the highest in the country ( $€ 30,156$ in 2014). In 2018 in the metropolitan area of Milan there were around 460,000 foreigners (14\% of the population) ${ }^{88}$. Most of them came from Egypt (12.2\%), the Romania (10.9\%), and Philippines (10.6\%). Chinese residents occupied the fourth place $(8,4 \%)$, before the Peruvians $(6.7 \%)$ and Ecuadorians $(5.3 \%$, National Institute of Statistics - ISTAT 2018, elaborated by Tuttitalia.it) ${ }^{89}$. Foreign boys and girls between 10 and 24 years old were around 71,400 (10-14: 5.3\%; 15-19: 4.6\%; 20-24: 5.6\% - Ibidem). In 2016, 6.545 children were born in Milan from foreign parents (around 24\% of the newborns, Ministero del Lavoro e delle Politiche Sociali, 2017).

The 2015 Universal Exposition guaranteed investments for billions of Euros (Camera di Commercio Metropolitana 2017). Giuseppe Sala, the manager of the public company in charge of its administration, today is the mayor of the city. Through the Expo, Milan invested in regenerating vast urban areas. New squares, skyscrapers and infrastructures appeared, resulting in major changes to the skyline of the city. Milan became a metropolitan city able to compete with other major European capitals (Bolocan Goldstein, 2009). The rhetoric of the "Milanese Renaissance" was supported by local and national politicians and media, sometimes hiding the problems that the most marginal neighborhoods have to face (Zajczyk et al., 2005). In fact, polarization has increased in the last few years: "Milan grows, rises, runs, [...] but well-being is not spread [...] on all the citizens. It pushes up the urban elite, but it leaves the poor behind" (Comune di Milano \& Assolombarda, 2018, p. 15, in Italian in the original version). The Lombard capital is therefore a "double city", a set of two urbanities with differential speeds (see Lévy, 2008).

88 On 31st of December 2018, within the only Municipality of Milan there were 275,818 foreign residents, 41,732 of them coming from the Philippines (15,1\%), 40,080 from Egypt (14,5\%), 31,214 from China (11,3\%), 18,430 from Peru (6,7\%), 17,279 from Sri Lanka (6,3\%), 15,351 from Romania (5,6\%), 12,300 from Ecuador (4,5\%), 9.525 from Bangladesh (3,5\%), 8,819 from Ukraine (3,2\%), 8,220 from Morocco (3,0\% - database of the Municipality of Milan). Italy is the European country with most Salvadorian migrants. On the 1st of January, 2017, there were 13,492 Salvadorians in Italy, 10,840 of them in Lombardy and 7,687 of them in Milan (Soleterre 2019).

${ }^{89}$ In 2008 there were around 300.000 foreign residents; in 2010 they were 350.000 (ISTAT 2008 and 2010, elaborated by Tuttitalia.it). 
However, Milan is not characterized by high levels of spatial and social segregation (see Pacchi \& Ranci, 2017), even if a "periphery" issue has been growing in last few years ${ }^{90}$. Also violence rates in Milan are extremely low (see Balducci, 2017). Nevertheless, security anxieties continue to worry Italian citizens, as the last national election campaigns demonstrated ${ }^{91}$. The crisis related to the management of asylum seekers and the terrorism alert that can be observed at an European level contributed in mounting fear. As I will describe below, the "specter" of the Milanese gang grew within this framework, especially since 2015.

Understanding gang space in Milan means interpreting it as an extremely dynamic matter. Any photography of the Milanese situation can be only provisional, temporary and transitory. The policeman I interviewed on the $29^{\text {th }}$ of April, 2019 explained to me why:

What about the control of the urban territory? A few years ago gangs occupied some parks and some squares or discos? And nowadays? Have they ever controlled neighborhoods?

\begin{abstract}
No, no neighborhoods. Moreover, these squares, discos and parks can also change over time. They [gang members] use to mark them with graffiti. They write MS13 or Barrio18 with spray. We have noted both MS and 18 tags in the same parks. This means that for a certain period that area was "property" of a band and then of another one. Because then they change, they move around.
\end{abstract}

\title{
Is it very fluid?
}

Yes, it's very fluid. Look at the discos: they are frequented mainly by Latin Americans, but maybe that disco is more frequented by Barrio18 rather than by MS13, and so on. In short, they are variable, we don't talk about entire neighborhoods or areas dominated by specific groups. Especially nowadays, because numbers are very small ${ }^{92}$.

In an article of 2008, Valentina Bugli, Luca Meola and Matteo Milanesi perfectly explained how in this sense a "Latin American Milan" has been inscribed in the urban space through specific practices and imaginaries. Even if Latin American boys and girls are not socially segregated in Milan, they are considered as a "potential danger" by dominant groups because they are young and migrants. Thus, "reinventing" the city means resisting to this exclusion process. Drawing tags or graffiti, using public spaces, meeting at the discos or in some private houses in the morning indicates their strategy to signify their marginalization (Conte, Meola \& Milanesi, 2008). Gang space in Milan is not about control of neighbourhoods; it is about inscribing and re-inscribing the city, signifying it, through fluctuating modalities. Thus, in Milan gangs implement a peculiar

\footnotetext{
${ }^{90}$ It is worth mentioning that, for example, in 2017 the Municipality launched a "Periphery plan" [Piano periferie] (then nominated "Neighbourhoods plan" [Piano quartieri]).

${ }^{91}$ Following the elections of March 5, 2018, a new government chaired by Giuseppe Conte was formed. The government was a coalition of Lega Nord - a conservative party whose motto was "Italians first" and Cinque Stelle movement - a "populist" party founded in 2009 by the comedian Beppe Grillo. The former Minister of the Interior, Matteo Salvini, declared the fight against irregular immigration. The approval of a new security decree (Gazzetta Ufficiale 4/10/2018), which came into force on 27 November 2018, marked the climax of this escalation. On September 5, 2019 a new government was formed. The security decree will be probably modified.

${ }^{92}$ Interview, $29^{\text {th }}$ of April, 2019.
} 
action of "territorialization", i.e. a socialization process of urban space, a form of symbolical mediation within the city of Milan. Along this process, also violence could be a tactic to contrast homologation, even if it is a dysfunctional one. In other words, gangs in Milan could be considered agents of mediation between unstable identities especially of young migrants - and a peculiar social context (see Raffestin, 1984).

On the $8^{\text {th }}$ of February, 2016 Repubblica, one of the main Italian newspapers, tried to depict a photography of the Milanese gang space, also publishing an interactive map:

Corso XXII Marzo for Ñeta, Trotter park for Barrio 18, Brenta park for Latin forever, Viale ${ }^{93}$ Monza and Northern park for the Latin Kings, Portello for MS13: these are some the headquarters of the Latinos in Milan. It is difficult to map all the gangs, especially the small ones that are less stable. Many pandillas appeared and disappeared, new ones appeared. Others, more rooted, enlarge their domain on other zones. Others have lost territory after some arrests (Zanella \& De Carolis, 2016).

Two months later, on April 2016, in the article translated by Internazionale quoted above, Roberto Valencia confirmed some of these places related to Barrio 18: the central station, Carbonari square, Trotter park (Valencia, 2016b). These descriptions underline how - at least three years ago - the Milanese "gang space" was extremely variegated.

It is worth mentioning that the ethnic composition of these groups seem to be very changeable, too. MS13 and Barrio 18 were initially formed by Salvadorians, Neta by Puerto Ricans, Trinitarios by Dominicans, Latin Kings by Ecuadorians. However, this division is not so stable. Peruvians and Colombians, as well as Filipinos, Srilankians, Africans, and some Italians joined the two maras and the Latin Kings. Other gangs were formed in Italy (for example, Latin forever and Trébol, but also Bloods, despite it being a North American gang). In general, following Massimo Conte, it is possible to state that street groups in Milan are the result of a process of interaction between two groups of young Latin Americans: those coming to Italy through family re-joining procedures and those in a more marginal condition, escaping from street life in their home countries and looking for a better life (Conte, 2007; see also Colombo, 2010).

In a couple of years this photography has changed a lot. During a long interview on the $18^{\text {th }}$ of January, 2019, a researcher of the ITSTIME group (Catholic University of Milan) who had been monitoring Latin American gangs in Milan since 2015, listed a series of places that, in his opinion, I had to check in order to find some more information, with some of them being: Via Padova and Crescenzago for Comando, Trinitarios and Latin Kings; Lambrate and Brenta park for Barrio 18; Famagosta, Lodi, Maciachini and Affori for MS13. I spent days visiting all the places mentioned, but I did not find any stable "street group" there. Referring to the discotheques, the conclusion was the same. Some of them were closed by police (the Lime club, or the Space 25 , for example) and some re-opened after a period of time.

93 "Corso", "Viale" and "Via" means "street". 
All my interlocutors explained to me that nowadays, after a phase of strong repression (see section 5), it is very difficult to find gangs in the public space of Milan. However, the policeman told me that there are still some places that can be considered "hotspots":

Even now. In Viale Ungheria for example, there are about fifty people [on Sunday afternoons]. However, if I go there, as a "normal" person walking with my family, nothing happens. They are there on their own. There is a problem when a member of the opposing gang passes by: that could be a provocation with consequent quarrel or fight that can end up badly or not [...] But a person who lives there and wants to have a walk in that park can do it quietly, without problems. So there are not offlimits areas, like - I don't know - the Spanish neighbourhoods in Naples ${ }^{94}$.

The position of the policeman is far from some sensationalistic representations: usually gangs are not a problem for "normal" people; they are "on their own". During a recent interview, a former member of a Milanese clika of Mara Salvatrucha confirmed that, in his opinion, members of Barrio 18 still meet in the North East of Milan ${ }^{95}$.

It is worth considering also that, for some of my interlocutors, socialization dynamics of the Milanese youngsters have deeply changed. For example, a manager of a social cooperative that has implemented several street education projects over the last 15 years ${ }^{96}$, during an interview on the $9^{\text {th }}$ of July 2019 explained to me that the public space of the city does not provide stable meeting points for groups of adolescents and young boys and girls nowadays: "They use Whatsup, they don't hang out around", she stated $^{97}$. Also for this reason street education seems not to be anymore the appropriate tool to approach the Milanese youngsters.

In parallel, public space of Milan was targeted by specific policies aimed to regulate it in a repressive way. In addition to the well-studied urban policies connected to gentrification processes that affect minorities and homeless population (see Smith, 1996), there are many punitive policies registered in Italy in the last years. In 2017, a security decree sponsored by Interior Minister Marco Minniti considered homelessness a threat to "urban decorum" (Pisianello, 2017). Several municipalities had already launched anti-beggar ordinances starting in 2008. Examples of "hostile architecture" also began proliferating in Milan (blockers, barriers, benches designed to prevent people from lying down, etc.). Therefore, the possibility of using public space by young migrants intersects with economic factors, the social control of institutions, and the accessibility of services and resources.

Despite this very fluctuating and changing dynamics, at least two recent events showed that gangs still exist in Milan. The first one dates back to March 2019; Ernesto Odir Barrientos Tula, a Salvadorian citizen of 34 years old, was stabbed to death in an abandoned farmhouse in San Giuliano Milanese, in the outskirts of the city. Three

\footnotetext{
${ }^{94}$ Interview, $29^{\text {th }}$ of April, 2019.

${ }^{95}$ Interview, 30th of June, 2019.

96 Social Cooperative Tuttinsieme: www.cooptuttinsieme.it

${ }^{97}$ Interview, 9th of July, 2019.
} 
compatriots were arrested some days after. Police talked about an internal fight among members of Mara Salvatrucha (Il Giorno 2019). The second one dates back to June 2019, when a Peruvian citizen was killed by two members of Barrio 18 due to an attempted robbery (Carra, 2019). It seems that no researcher, or association have any contact with the members of these groups nowadays.

If we talk of "gang space" we have also to analyse the transnational connections and the "ideo-scapes" that link these groups (Appadurai, 1996; Glick Shiller, Basch \& SzantonBlanc, 1992). The global scale of gangs is well known. On the one hand, similar social conditions (poverty, inequality, socio-spatial segregation) have facilitated the birth of these groups, especially within urban contexts; on the other, globalization has supported the spread of common imaginaries. However, underlining the global dimension of the phenomenon does not mean declaring the existence of international criminal organizations, as it has been claimed on several occasions by the governments of various states (see Rodgers, 2012; Hazen and Rodgers 2014).

From this point of view, the case of Central American maras is emblematic: they were born in the United States within communities of Latin American migrants in the Sixties, then they proliferated in Central America from the end of the 1980s, and they were partially reproduced also in Europe (especially Spain and Italy) in the last few years, with completely different kinds of practices and structures:

The most commonly referenced groups - the Mara Dieciocho and the Mara Salvatrucha (also known as M-18 and MS-13) - supposedly operate territorially throughout the isthmus and in large swathes of the United States and Canada. Law enforcement studies have repeatedly alleged the existence of links between maras in the United States and El Salvador. The Federal Bureau of Investigation created a special task force focusing on maras in December 2004 and established an office in San Salvador in February 2005 specifically to monitor the phenomenon as a transnational security threat. By contrast, most academic studies of the mara phenomenon have generally emphasized that these are local-level social forms, and although local maras do explicitly identify with either the Mara Dieciocho or the Mara Salvatrucha, neither über-mara is a federal structure, much less a transnational one, with a federated nature more imagined and symbolic of a particular historical origin than demonstrative of any real unity, be it of leadership or action (Hazen \& Rodgers, 2014, p. 3).

Also Italian maras have maintained relations among countries, but sporadically and on individual basis. I asked the policemen if he supposed the Milanese gang members had relations with their home countries:

Yes, there could be in the sense that communication is always possible. For example, when we investigated, we saw that there were constant contacts between South America and Italy, and therefore even advice on how the gangs were organizing and operating. In short, there were contacts. Even for "indoctrinating", doing or not doing a thing, punishing or not punishing, and so on. Some advice, some directives could also come from South America. However, basically they were here, on the territory of Milan. Here they organized what to do. Informing other members in the home countries was considered an "opportunity" for them [...]. However, at this moment we can say that, since we do 
not have a direct activity, we do not know what actually is going on. But as it was then, probably it is done even now ${ }^{98}$.

If we talk about transnational connections, it is worth mentioning that some Latin American citizens of Milan (especially from El Salvador) escaped from their home countries also due to gang violence. For example, I interviewed José (fictional name) in January 2016. He explained to me that he lived in a marginal neighbourhood of San Salvador, managing a small shop. A local clika of Mara Salvatrucha started to extort him, so he had to leave the country with his family. He came to Milan with a tourist visa, but there he was exploited by an Italian employer. Finally, he reported him and he succeeded in entering into a program for victims of trafficking, getting regular documents, an apartment, and then a new job.

The globalization of networks, the reduction of state control in the neoliberal era, the increases in inequality and social insecurity, are just some of the elements that can be found, in different degrees, in several contexts, including Milan (Harvey 2005). However, the effects of economic globalization are accompanied by a myriad of connections and flows concerning cultural exchanges (Hannerz 1992). The experience of the Milanese gangs is the result of structural dynamics conjugated at the local level, a phenomenon that in parallel feeds on the trafficking of transnational symbols (cf. Hagedorn 2008).

Ideo-scapes basically travel on media and social networks. There is a conspicuous amount of films, books, articles, researches, and TV-shows that describe, interpret, and signify Latin American gangs, in a never-ending process that contributes in their mythmaking (Fontes 2018, see Leccardi 2016, Queirolo Palmas 2016) ${ }^{99}$. In this regard, it is worth mentioning the experience of Daniel (fictional name), a youngster living in a neighborhood of social housing of Milan where I have been carrying out an ethnographic research since 2017. Daniel had some relation with a interethnic local gang, without being an active member. Daniel and his friends sometimes called their neighborhood "barrio", in Spanish, evoking a precise territorial inscription, a supralocal "periphery" that connected the "rough quarters" of Milan with those of New York, or San Salvador, or Quito, or Lima. Daniel also loved rap music. He wrote songs and he used to play with local crews, sometimes participating in hip-hop contests organized by a local group of activists that fight for the right to the city together with other Milanese movements (see Harvey 2012). His rhymes mixed languages (Italian, English, and Spanish), also drawing on the myth of the Central American maras, whose history and supposed proliferation were well known to him (see Grassi 2018).

\footnotetext{
${ }^{98}$ Interview, $29^{\text {th }}$ of April, 2019.

${ }^{99}$ Specifically focusing on the extreme case of Central American gangs Anthony Fontes wrote that: "In twenty-first-century Central America, maras have become erstwhile emissaries of extreme peacetime violence. They have come to distil in spectacular fashion the fear, rage, and trauma swirling around outof-control crime. Young mareros $[\ldots]$ are drawn in by and work hard to e-create the phantasmagoric figure the maras cut in social imaginaries, linking the acts of violence gang perform to the ways gang members (and others) collectively and individually make sense of this violence" (Fontes 2018: 35).
} 
For their part, Milanese gang members use social networks like everybody does. Facebook and Instagram are the most important ones (at the beginning of 2000s Hi5 was another social network very famous among Latin American boys and girls - see Bugli 2010). In the past, before the phase of repression (2012-2015), it was possible to find also some Facebook groups (for example a street group based in Crescenzago, a neighborhood at the north east of Milan had its own page, but it has been inactive since 2016). Boys and girls create their networks, sharing information, constructing common imaginaries among countries, cities, and neighborhoods. Through bricolages they compose their style, taking the elements they need from dominant and subcultural fields (see Hall \& Jefferson 1975, Hebdige 1979).

Referring to the Italian media, newspapers and televisions focused their attention on street groups especially since the episodes of the $11^{\text {th }}$ of June, 2015 (the attack against the train inspector) and the $3^{\text {rd }}$ of July, 2016 (the homicide of the young Albanese) described above. This was not the first time, but these two events marked a turning point. In fact, for the very first time gang violence was directed outside the groups. A wave of moral panic developed, especially against maras, the new transnational gangs ready - from Central America - to "conquest" Milan (see Cohen 1972). Moral panic allows the production of public enemies, i.e. scapegoats that can be easily forgotten when the phase of repression ends (see also Queirolo Palmas 2017). Italian newspapers described the phenomenon inadequately, often making mistakes about its origins, causes, and practices. Photos of tattooed pandilleros filled the web, forgetting that even in Central America tattoos are not so common among the mareros nowadays, due to the repressive policies implemented by the local governments over the last fifteen years (see Demoscopía S.A. 2007).

To give an idea of the level of media attention captured by maras, it is worth mentioning that even Roberto Saviano, a famous Italian journalist and writer expert of Camorra, the Mafia of Naples, wrote at least an article on one of the most important national newspapers entitled "Droga e machete, quel codice rosso sangue delle gang latine" [Drugs and machete, that bloody red code of the Latin gangs" (Saviano 2015)]. Also Sky television broadcasted a documentary three years later entitled "Barrio Milano. Viaggio al centro delle gang" [Barrio Milano. Journey to the centre of the gangs] $]^{100}$.

100 "Barrio Milano - Ascesa e crollo delle gang latino americane", written by Lirio Abbate, and directed by Gabriele Gravagna. Among the others, also Massimo Conte, policemen, social workers, and former pandilleros gave interviews for this documentary. 


\subsection{Conclusions}

In contrast with other contemporary cities well studied by social researchers (Caldeira 2000, Davis, 2006, Graham \& Marvin 2001, Wacquant, 2008), Milan is not a strongly segregated conurbation (Pacchi \& Ranci 2017), where isolated urban spaces are controlled by criminal youth groups that resist to their own marginalization in a dysfunctional way. Nevertheless, in Milan some young boys and girls started to use urban space, marking it, signifying it, connecting their own practices also to transnational imaginaries and street groups or gangs. Through urban space they began to exercise a form of autonomy and power, struggling basically among themselves to conquer it, at least at a symbolical level.

Latin American gangs in Milan have a quite short history that dates back to the beginning of 2000s. Since then, the geography of the phenomenon has changed a lot. Formed by youngsters coming from several countries, some of these street groups evolved, while others disappeared. Today, the gangs of Milan seem more hidden than in recent past. While according to some interlocutors it is still possible to indicate some urban "hotspots", in general the "Latin American Milan" looks very different.

Gangs in Milan are a dynamic and fluctuating phenomenon that interest a small number of boys and girls. Their practices are the result of structural forces combined with local dynamics. Their imaginary feeds on the trafficking of transnational symbols, i.e. ideoscapes and mediascapes that cross cities and countries. At least two waves of moral panic invested these Latin American street groups since their birth. The first one was in 2006; the second and stronger one was in 2015, after an attack perpetrated by a clika of Mara Salvatrucha against a train inspector.

The first police operation against the Milanese street groups dates back to 2005 ("Street fighter" operation). However, only in 2012 a phase of strong repression started. Since then, four police operations have nearly put an end to all the Latin American street groups. Around two hundred people were investigated and judges considered them criminal associations in some cases. In parallel, the municipal educative services changed their focus, abandoning street education projects. Latin American street groups seem to have become exclusively a security affair.

Today at least two active groups - Mara Salvatrucha and Barrio 18 - are still present in the city, or, better said, are still in the public eye - even if trough less sensationalistic tones - mainly because of two recent violent events (the homicides of two young Latin American citizens in March and in June 2019). Mara Salvatrucha and Barrio 18 were originally formed by Salvadorian citizens, but then some youngsters from other nationalities joined them.

Since the beginning of 2000s a group of Milanese sociologists members of Codici, an 
independent social research agency, have started to study this phenomenon. Their publications helped to interpret it, especially understanding its differences from the Latin American context and contrasting the stigmatized image developed by institutions and local media. In a comparative perspective the experience of Codici is similar to that one developed in Genova by a group of sociologists coordinated by Luca Queirolo Palmas. Both groups implemented important mediation processes that have lead to two street groups becoming formal associations that were recognized by local institutions. Unfortunately, these processes stopped around 2010 and they were not replaced by something else.

Taking into account this Background paper, it is possible to reformulate and deepen the three questions presented in the introduction. First, in order to develop this contrast case study, it is essential to ask what is the current situation of street groups in Milan. What are the main street groups of the city? How are they organized? What are their practices? Which is the current role of girls within them? What is their imaginaries? How are they described by the residents of the city, by the media and by the local institutions and how do they describe themselves? Second, if any mediation process among streets groups and their communities seems to have disappeared, are or were there formal or informal experiences, policies, or practices related to conflict mediation or conflict resolution inside and outside these street groups a part from the ones described above? If yes, how could they be compared to other practices collected by the local researchers of the project and, therefore, how could they inform the wider (Trans)gang theoretical framework? Third, if street groups disappeared from the public space of Milan, how could we study them ethnographically? Which analytical data and significant insights could we collect thanks to this peculiar methodology?

Referring to the three cluster of questions we could suppose that the principal target of this investigation should be the local clikas of Mara Salvatrucha and Barrio 18. However, according to the complexity of these kind of target groups, it is necessary to open up the field towards other possible interlocutors. Moreover, it is important not to abandon an intersectional approach focusing on gender and age dimensions, in order to interpret this phenomenon in a complex and multifaceted way (Crenshaw 1989; Winker \& Degele 2011).

For this reason, as indicated in the Research plan of Milan, both male and female social actors will be chosen among three groups of potential interlocutors: the first one will be formed by social workers, researchers, and journalists (i.e. social actors who worked with, studied, or wrote about gangs in Milan); the second one will be formed by the Latin American local communities; the last one will be formed by gang members or exgang members themselves. In relation to this last group, the research team will also consider females who had contacts with gang members or ex-gang members without being totally involved in these street groups. Moreover, according to the objectives of the (Trans)gang project, Arab youngsters could possibly be considered, departing from the networks that will be developed through the research. 
Whether they are called gangs or street groups, it is clear that socialization dynamics of some young migrants within the public space of Milan has changed over the last few years. However, as my interlocutors have supposed and the media confirmed, they have not totally disappeared. Gang numbers in Milan seem very small. The discrepancy between the width of the phenomenon and its sensationalistic representations constitutes an important element of reflection on how moral panic waves work. Certainly, the social reaction to Latin American gangs firstly showed the anxieties of the Milanese residents - and Italian citizens more in general - about migrations and (foreign) youth (see Cohen 1972).

Thus, we need to refine our methods to see and interpret them. We need to adopt flexible and modular research tools (see Aull Davies 1999, Büscher, Urry \& Witchger 2010; Marcus 1995). It is not about denying the territorialization processes of the Milanese street groups. It is about understanding their original and innovative characteristics. We should think about different forms of territorialization, probably more difficult and challenging to investigate. 


\subsection{References}

Affari Italiani (2008). Stop alla guerra tra bande. A Milano fondato il Movimiento Real Juvenil: si occuperà di reintegrare adolescenti latinoamericani con un passato difficile. Affari italiani, 24 giugno 2008, www.affaritaliani.it.

Antigone (2015). Seconda casa di reclusione Milano - Bollate. http://www.antigone.it/osservatorio_detenzione/lombardia/11-seconda-casa-di-reclusione-milanobollate.

Antigone (2017). Ragazzi dentro. Rapporto 2017. http:/www.ragazzidentro.it/it/rapporto-2017/istitutipenali-per-minorenni/.

Antigone (2018). Casa Circondariale di Milano San Vittore. http://www.antigone.it/osservatorio_detenzione/lombardia/98-casa-circondariale-di-milano-sanvittore.

Appadurai, A. (1996). Modernity at Large. Cultural Dimensions of Globalization. Minneapolis, London: University of Minnesota Press.

Aull Davies, C. (1999). Reflexive ethnography. London and New York: Routledge.

Balducci, G. (2017), Milano, gli omicidi ai minimi storici, ma crescono le rapine per strada. In Corriere della Sera, $30^{\text {th }}$ of December.

Becker, H. S. (1963). Outsiders. Studies in the Sociology of Deviance. New York: The Free Press.

Berni (2016). Rissa in via Castelbarco, morto il 18enne accoltellato domenica. Corriere della Sera, $15^{\text {th }}$ of July.

Bolocan Goldstein, M. (2009). Geografie milanesi. Rimini: Maggioli Editore.

Brotherton, D. C. (2015). Youth street gangs: A critical appraisal. London: Routledge.

Brotherton, D. C., \& Barrios, L. (2004). The Almighty Latin King and Queen Nation. Street Politics and the Transformation of a New York City Gang. New York: Columbia University Press.

Bugli, V. (2009). Diventare latinos e latinas a Milano. In L. M. Visconti, E. M. Napolitano (Eds.), Cross generation marketing (pp. 303-325). Milano: Egea.

Bugli, V. (2010). Percorsi Banditi. Diventare latinos e latinas a Milano. Università degli Studi di Milano-Bicocca, Dipartimento di Sociologia. Tesi di dottorato URBEUR - Studi Europei Urbani e Locali, XXII Ciclo.

Bugli, V., Conte, M. (2010). Giovani latinos e gruppi di strada nella metropoli Milanese. In L. Queirolo Palmas (Eds.). Atlantico latino. Gang giovanili e culture transnazionali (pp. 85-102). Roma: Carocci.

Büscher, M., Urry, J., \& Witchger, K. (Eds.) (2010). Mobile Methods. London: Routledge. 
Caldeira, T., (2000). City of walls: crimes, segregation and citizenship in Sao Paulo. Berkeley: University of California Press.

Caioli, L., Calabrò, A. R., Fraboni, M., Leccardi, C., Tabboni, S., Venturi R. (1986). Bande: un modo di dire. Rockabillies, Mods, Punks. Milano: Unicopli.

Camera di Commercio Metropolitana (2017). Milano, l'Europa. Città metropolitane a confronto. Milano: Camera di Commercio Metropolitana (Milano, Monza-Brianza, Lodi).

Cannarella, M., Lagomarsino, F., \& Queirolo Palmas, L. (Eds.) (2007). Hermanitos. Vita e politica della strada tra i giovani latinos in Italia. Verona: Ombre corte.

Cannarella, M., Lagomarsino, F., \& Queirolo Palmas, L. (Eds.) (2008). Messi al bando. Una ricercaazione tra i giovani migranti e le loro organizzazioni della strada. Roma: Carta.

Carra, I. (2019). Milano, cadavere nel Lambro: due uomini fermati per omicidio. In Repubblica, $14^{\text {th }}$ of June.

Cohen, S. (1972). Folk, devils and moral panics. The creation of the mods and rockers. London: McGibbon \& Kee.

Colombo, A. (1998). Etnografia di un'economia clandestina. Immigrati algerini a Milano. Bologna: Il Mulino.

Colombo, E. (2010). Figli di migranti in Italia. Identificazioni, relazioni, pratiche. Milano: UTET.

Comune di Milano \& Assolombarda, (2018). Osservatorio Milano 2018. Milano: Comune di Milano e Assolombarda.

Conte, M. (2007). Latinos metropolitani. In Contest, 2(4), 22-28.

Conte, M. \& Bugli, V. (2008). Latin Kings a Milano. Dagli scontri alla costituzione in associazione. In C. Cannarella, F. Lagomarsino \& L. Queirolo Palmas (Eds.). Messi al bando. Una ricerca-azione tra $i$ giovani migranti e le loro organizzazioni della strada (pp. 40-63). Roma: Carta.

Conte, M. Meola, L. \& Milanesi, M. (2008). Milano. Giovani latinoamericani alla prova della metropolis. In C. Cannarella, F. Lagomarsino \& L. Queirolo Palmas (Eds.). Messi al bando. Una ricercaazione tra i giovani migranti e le loro organizzazioni della strada (pp. 102-121). Roma: Carta.

Crenshaw, K. (1989). Demarginalizing the Intersection of Race and Sex: A Black Feminist Critique of Antidiscrimination Doctrine, Feminist Theory and Antiracist Politics. In University of Chicago Legal Forum, Iss. 1, Article 8.

Cruz, J. M. (2008). Central American Maras: From Youth Street Gangs to Transnational Prison Gangs. London: Atlantic.

Davis, M., (2006). The planet of slums. London: Verso.

De Cesare, D. (2018). The Specter Of Ms-13. Understanding Fears And Perceptions Of Belonging Among Diaspora Salvadorans. In T.note 61, May.

Demoscopía S.A. (2007). Maras y pandillas. Comunidad y policía en Centroamérica. Guatemala: ASDI, BCIE, Guatemala. 
Feixa Pàmpols, C. (2018). TRANSGANG. Transnational Gangs as Agents of Mediation: Experiences of Conflict Resolution in Street Youth Organizations in Southern Europe, North Africa and the Americas, Universitat Pompeu Fabra, Barcelona.

Fontes, A. W. (2018). Mortal Doubt. Transnational Gangs and Social Order in Guatemala City. Oakland: Univerity of California Press.

Galli, A. \& Giuzzi, C. (2015). Milano, capotreno ferito col machete, Intervento di 8 ore per salvare l'arto. Due fermati, membri di gang latinos. In Corriere della Sera, $11^{\text {th }}$ of June.

Gazzetta Ufficiale della Repubblica Italiana, 4/10/2018, DECRETO-LEGGE 4 ottobre 2018, n. 113 Disposizioni urgenti in materia di protezione internazionale e immigrazione, sicurezza pubblica, nonché misure per la funzionalità del Ministero dell'interno e l'organizzazione e il funzionamento dell'Agenzia nazionale per l'amministrazione e la destinazione dei beni sequestrati e confiscati alla criminalità organizzata. http://www.gazzettaufficiale.it/eli/id/2018/10/04/18G00140/sg.

Glick Shiller, N., Basch L., \& Szanton-Blanc C. (Eds.) (1992). Towards a transnationalism perspective in migration. New York: New York Academy of Science.

Graham, S. \& Marvin, S., (2001). Splintering urbanism: networked infrastructures, technological mobilities and the urban condition. London: Routledge.

Grassi, P. (2015a). Il limbo urbano. Conflitti territoriali, violenza e gang a Città del Guatemala. Verona: Ombre corte

Grassi, P. (2015b). Droga e machete? La Mara Salvatrucha e la sua (supposta) proliferazione in Italia. In Il Lavoro Culturale, $31^{\text {st }}$ of August.

Grassi, P. (2018). Deux périphéries, trois jeunes, un imaginaire partagé. Note comparative sur la violence et l'adolescence entre un barrio de Guatemala-ville et un quartier d'habitat populaire de Milan. In Cultures \& Conflits, n. 110, 77-97.

Grassi, P. (2019). (Trans)gangs in Milan. Research Plan. Barcelona: Universitat Pompeu Fabra (UPF), (Trans)gang project.

Hagedorn, J. M. (2008). A World of Gangs: Armed Young Men and Gangsta Culture, Minneapolis: University of Minnesota Press.

Hagedorn, J. M. (Eds.) (2007). Gangs in the Global City: Alternatives to Traditional Criminology. Chicago: University of Illinois.

Hall, S. \& Jefferson, T. (Eds.) (1975). Resistance Through Rituals. Youth subcultures in post-war Britain. London and New York: Routledge.

Hannerz, U. (1992). Cultural Complexity: Studies in the Social Organization of Meaning. New York: Columbia University Press.

Harvey, D. (2005). A Brief History of Neoliberalism. New York: Oxford University Press.

Harvey, D. (2012). Rebel Cities. From the Right to the City to the Urban Revolution. London and New York: Verso. 
Hazen J. M. \& Rodgers, D. (Eds.) (2014). Global Gangs. Street Violence across the World. Minneapolis: University of Minnesota Press.

Hebdige, D. (1979). Subculture. The Meaning of style. London: Methuen \& Co.

Hobsbawn, E. (1971). I Banditi: il banditismo Sociale nell'età moderna. Torino: Einaudi.

Il Giorno (2019). San Giuliano Milanese, accoltellato e sepolto in un campo: vendetta dei latinos. In $\mathrm{Il}$ Giorno, $15^{\text {th }}$ of March.

Klein, M. W. (1971). Street gangs and street workers. Englewood Cliffs: Prentice Hall.

Leccardi, C. (2016). Young Transnationalists (and Cosmopolitans). Forward, in C. Feixa, C. Leccardi and P. Nilan, Leiden (Eds.) Youth, Space and Time. Agoras and Chronotopes in the Global City. Boston: Brill, pp. 19-24.

Lévy J., (Eds.) (2008). The City: Critical Essays in Human Geography: London: Routledge.

Lombardi, M. (2016). Violenze a Milano: le gang dei Latinos. 15th of November. http://www.itstime.it/w/violenze-a-milano-le-gang-dei-latinos/.

Marcus, G. F. (1995). Ethnography in/of the World System: The Emergence of Multi-Site Ethnography. In Annual Review of Anthropology, 24, 95-117.

Ministero della Giustizia (2019). Schede trasparenza istituti penitenziari, $24^{\text {th }}$ of May. https://www.giustizia.it/giustizia/it/mg_2_3_2.page.

Ministero del Lavoro e delle Politiche Sociali (2017). La presenza dei migranti nella città metropolitan di Milano. Ministero del Lavoro e delle Politiche Sociali.

Moyersoen, J. (2016). Le bande di giovani latino-americani: dalle origini del fenomeno agli interventi della giustizia minorile a Milano. In Minorigiustizia n. 3, 130-140.

Ortega Pinto, H. D. (1995). Guía para el Análisis y Mediación en la Resolución de Conflictos. Como Ayudar a Transformar Conflictos en Relaciones de Cooperación. Guatemala: IRIPAZ Publicaciones.

Pasolini, P. P. (1955). Ragazzi di vita. Milano: Garzanti.

Pisanello, C. (2017). In nome del decoro. Dispositivi estetici e politiche securitarie. Verona: Ombre Corte.

Queirolo Palmas, L. (2016). Gangs in the Latin Atlantic: La Raza Latina, Transnationalism and Generations. In C. Feixa, C. Leccardi and P. Nilan, Leiden (Eds.) Youth, Space and Time. Agoras and Chronotopes in the Global City. Boston: Brill, pp. 85-114.

Queirolo Palmas, L. (2017). Cómo se construye un enemigo público: las «bandas latinas» Una etnografía del Estado. Madrid. Traficantes de suenos.

Queirolo Palmas, L. (Eds.) (2009) . Dentro le gang. Giovani, migranti e nuovi spazi pubblici. Verona: Ombre corte. 
Queirolo Palmas, L. (Eds.) (2010) . Atlantico latino. Gang giovanili e culture transnazionali. Roma: Carocci, Roma.

Queirolo Palmas, L. \& Torre, A. (Eds.) (2005). Il fantasma delle bande. Genova e i latinos. Genova: Fratelli Frilli.

Pacchi, C. \& Ranci C. (2017). White flight a Milano. La segregazione sociale ed etnica nelle scuole dell'obbligo. Milano: Franco Angeli.

Raffestin, C. (1984). Territorializzazione, deterritorializzazione, riterritorializzazione e informazione. In A. Turco Angelo (Eds). Regione e regionalizzazione: colloquio internazionale. Verona. Milano : Franco Ageli, pp. 69-82.

Rodgers, D. (2012). Gangs of Central America. In South America, Central America, and the Caribbean Regional Survey 2013, 30-35, 30-35.

Saviano, R. (2015). Droga e machete, quel codice rosso sangue delle gang latine. In Repubblica, 14th of June.

Savona, E. U. \& Riccardi, M. (Eds) (2018). Mapping the risk of Serious and Organised Crime infiltration in European Businesses - Final report of the MORE Project. Milano: Transcrime - Università Cattolica del Sacro Cuore.

Smith, N. R. (1996). The new urban frontier: Gentrification and the revanchist City. London, New York: Routledge.

Soleterre (2019). Cooperazione tra Italia ed El Salvador in tema di migrazione e inclusione socioeconomica. Da El Salvador all'Italia (e ritorno): analisi di un fenomeno migratorio (a cura di GMIES e ISMU). Milano: Soleterre.

Tagliafierro, F. (2015). I detenuti per tipologia di reato. Periodo di riferimento: anni 2015-2016 e confronti con anni precedenti. In Rassegna penitenziaria e criminologica, 3, 5-24.

The Trans Gang research team 2019. The (Trans)gang: Some Notes and Queries on Youth Street Groups Research, Working Paper in (Trans)gang Studies, Number: 2.

Thrasher, F. M. (1927/2013). The Gang. A study of 1313 gangs in Chicago. Chicago: Chicago University Press.

Valencia, R. (2016a). Mareros en Milán. In El Faro, 22 ${ }^{\text {nd }}$ of April.

Valencia, R. (2016b). Milano è la capitale europea delle gang salvadoregne. In Internazionale, $24^{\text {th }}$ of April.

Vigil, J. D. (2002). A Rainbow of Gangs: Street Cultures in the Mega-City. Los Angeles: University of Los Angeles Press.

Wacquant, L. (2008), Urban Outcast: a comparative sociology of advanced marginality. Cambridge: Polity Press.

Whyte, W. F. (1943). Street Corner Society. The Social Structure of an Italian Slum. Chicago: Chicago University Press. 
Winker, G. \& Degele, N. (2011). Intersectionality as Multi-Level Analysis: Dealing with Social Inequalities. In European Journal of Women Studies, 18, 1, 51-66.

Zajczyk F., Borlini B., Memo F., Mugnano S. (2005). Milano. Quartieri Periferici. Milano: Mondadori.

Zanella, C. \& De Carolis, N. (2016). Latinos a Milano tra odio, sangue e appartenenza: viaggio nel mondo delle pandillas. In Repubblica, $8^{\text {th }}$ of February. 


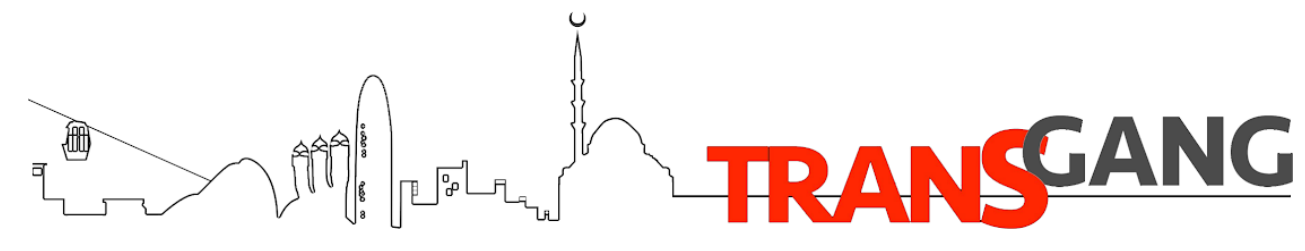

(C) TRANSGANG \& UPF

www.upf.edu/web/transgang

transgang@upf.edu

This project has received funding from the European Research Council (ERC) under the European Union's HORIZON 2020 research and innovation programme under grant agreement No 742705

$\mathbf{u} p f$.

Universitat

Pompeu Fabra

Barcelona

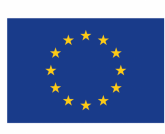

ër 